\title{
Sustainable Coal Tar Pitch Carbon Fiber Manufacturing
}

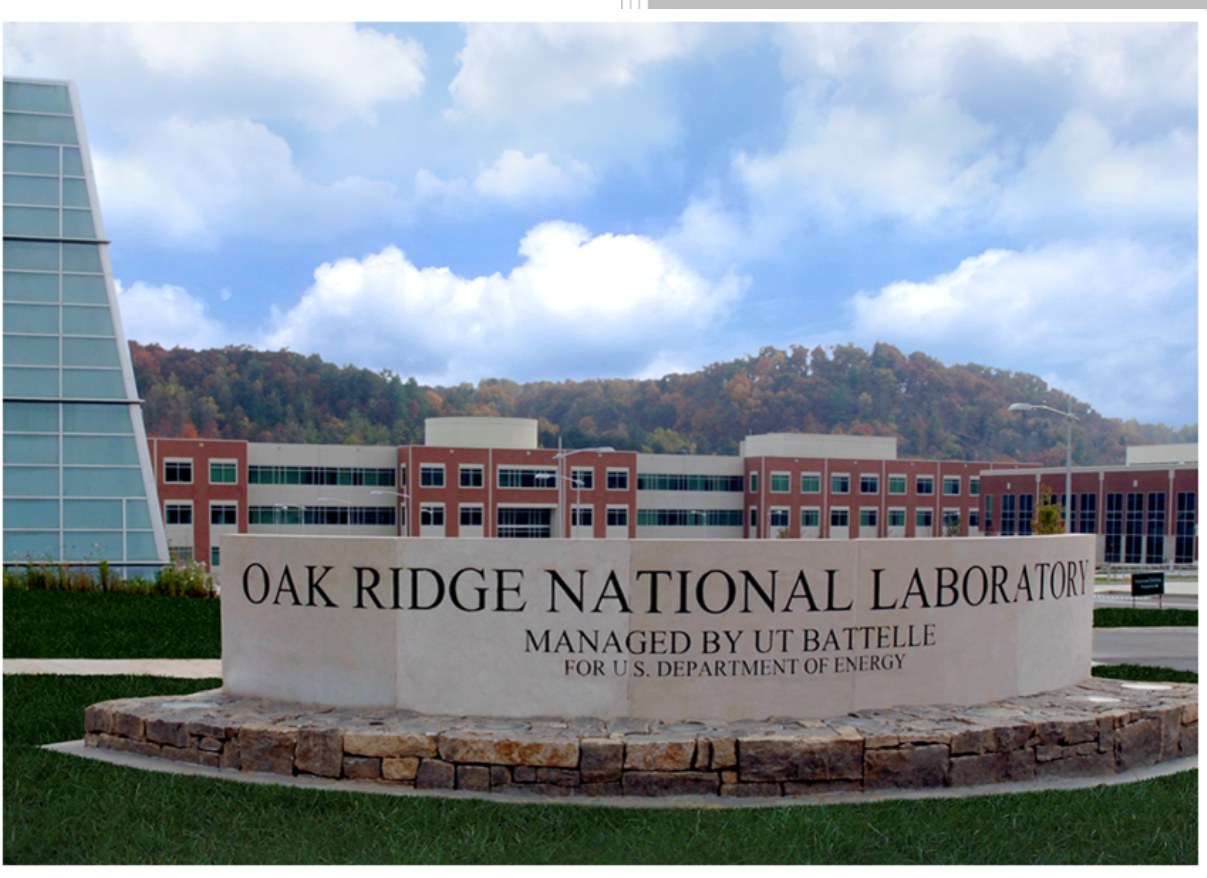

Sujit Das

Prashant Nagapurkar

April 2021

Approved for public release

Distribution is unlimited 


\section{DOCUMENT AVAILABILITY}

Reports produced after January 1, 1996, are generally available free via US Department of Energy (DOE) SciTech Connect.

Website www.osti.gov

Reports produced before January 1, 1996, may be purchased by members of the public from the following source:

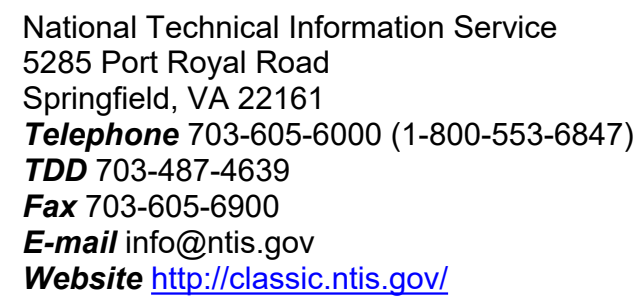

Reports are available to DOE employees, DOE contractors, Energy Technology Data Exchange representatives, and International Nuclear Information System representatives from the following source:

Office of Scientific and Technical Information

PO Box 62

Oak Ridge, TN 37831

Telephone 865-576-8401

Fax 865-576-5728

E-mail reports@osti.gov

Website http://www.osti.gov/contact.html

This report was prepared as an account of work sponsored by the U.S. Department of Agency Fossil Energy Office of the United States Government. Neither the United States Government nor any agency thereof, nor any of their employees, makes any warranty, express or implied, or assumes any legal liability or responsibility for the accuracy, completeness, or usefulness of any information, apparatus, product, or process disclosed, or represents that its use would not infringe privately owned rights. Reference herein to any specific commercial product, process, or service by trade name, trademark, manufacturer, or otherwise, does not necessarily constitute or imply its endorsement, recommendation, or favoring by the United States Government or any agency thereof. The views and opinions of authors expressed herein do not necessarily state or reflect those of the United States Government or any agency thereof. 
Manufacturing Science Division

\title{
SUSTAINABLE COAL TAR PITCH \\ CARBON FIBER MANUFACTRING
}

\author{
Sujit Das \\ Prashant Nagapurkar
}

April 2021

\author{
Prepared by \\ OAK RIDGE NATIONAL LABORATORY \\ Oak Ridge, TN 37831-6283 \\ managed by \\ UT-BATTELLE, LLC \\ for the \\ US DEPARTMENT OF ENERGY, Fossil Energy Office \\ under contract DE-AC05-00OR22725
}





\section{CONTENTS}

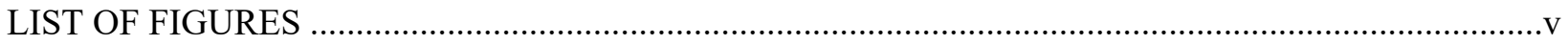

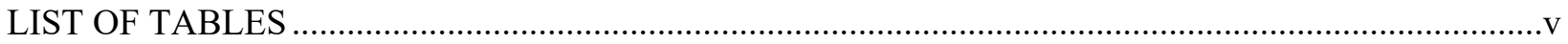

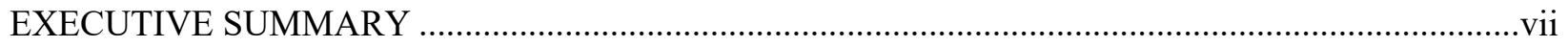

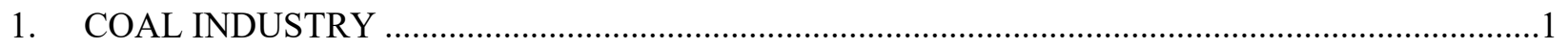

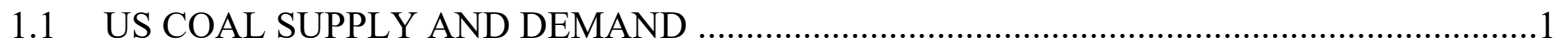

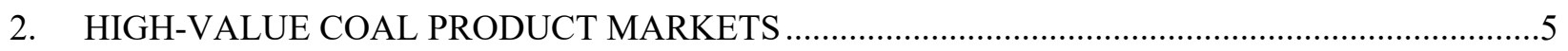

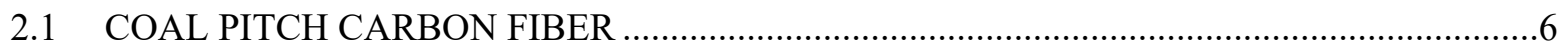

2.2 PITCH CARBON FIBER MANUFACTURING ENERGY ….........................................

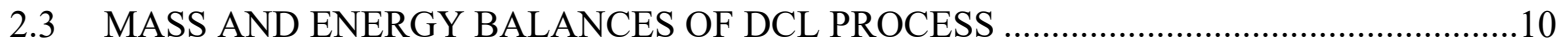

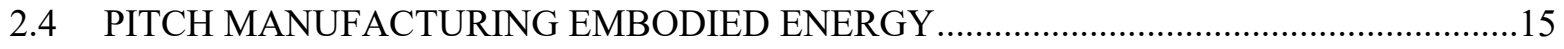

2.5 CONVENTIONAL METALLURGICAL COKE MANUFACTURING PROCESS ...............15

2.6 EMBODIED ENERGY OF RC COAL PITCH TAR MANUFACTURING ….....................17

2.7 COMPARISON OF PITCH EMBODIED ENERGY MANUFACTURING ........................18

2.8 PITCH CARBON FIBER EMBODIED MANUFACTURING ENERGY ............................20

2.9 PITCH CARBON FIBER MANUFACTURING EMISSIONS …........................................22

2.10 PAH CONTENT AND EMISSIONS IN COAL PITCH MANUFACTURING .....................23

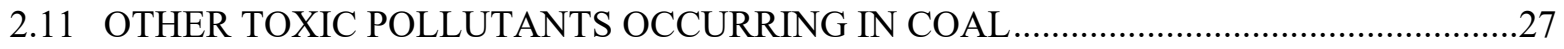

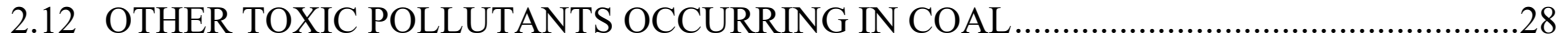

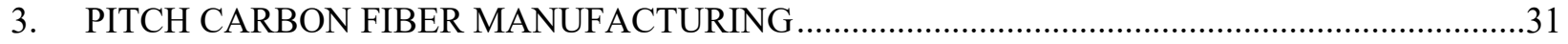

3.1 MESOPHASE COAL PITCH PRECURSOR MANUFACTURING COST .............................32

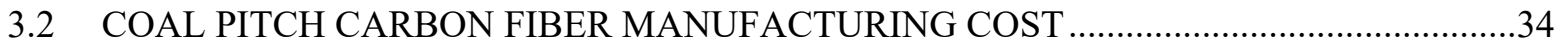

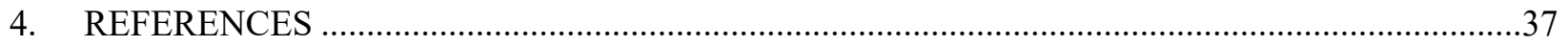





\section{LIST OF FIGURES}

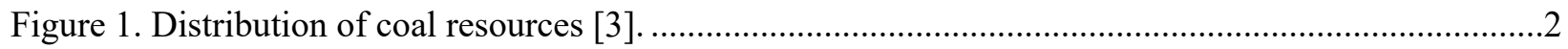

Figure 2. Estimated 2019 US recoverable coal reserves and current production. .....................................3

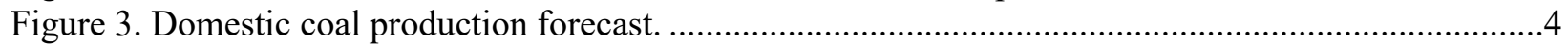

Figure 4. Process flow diagram of pitch from coal manufacturing. .....................................................10

Figure 5. Mass and energy balances of the RC DCL process [33] .......................................................11

Figure 6. Mass energy balance of Shenhua, China DCL plant. ............................................................12

Figure 7. Mass-energy balances of NETL-DOE DCL process [35] .......................................................13

Figure 8. Energy demand (MJ) of different DCL processes per unit mass of input coal $(\mathrm{kg})$....................13

Figure 9. Pitch carbon fiber manufacturing embodied energy calculation methodology..........................15

Figure 10. Comparison of net input embodied energy per $1 \mathrm{~kg}$ of pitch via two different processes (without allocation of embodied energy between products)......................................................19

Figure 11. Comparison of unit pitch embodied energy and input material and energy distribution

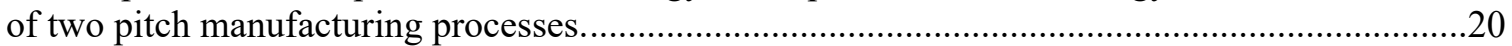

Figure 12. Comparative conventional and coal pitch carbon embodied energy ( $\mathrm{MJ} / \mathrm{kg}$ of carbon

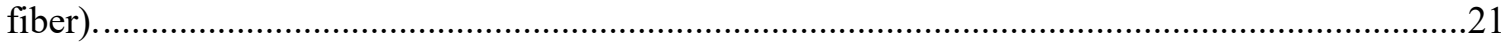

Figure 13. Simplified process flow diagram of DCL facility in West Virginia, USA..............................22

Figure 14. Section-wise breakdown of emissions by RC DCL manufacturing process by major

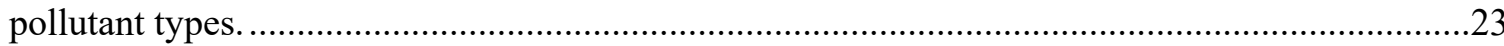

Figure 15 Concentration of EPA-PAHs in three coal tar pitch samples [58] .........................................26

Figure 16. Major, minor, and trace constituent elements of coal [61] ................................................28

Figure 17. Comparative environmental emissions impacts of conventional PAN vs. coal pitch

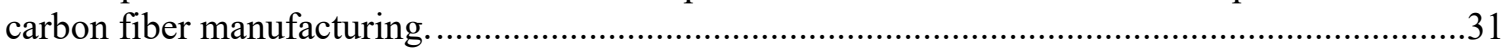

Figure 18. A schematic process flow mesophase coal tar pitch precursor manufacturing. ........................32

Figure 19. Total coal tar pitch fiber precursor cost distribution by major cost categories. ..........................34

Figure 20. Total coal tar pitch fiber precursor cost distribution by major processing steps.......................34

Figure 21. Major sequential processing steps of pitch carbon fiber manufacturing. ...................................35

Figure 22. Total coal tar pitch carbon fiber cost distribution by major cost categories and processing steps. .36

\section{LIST OF TABLES}

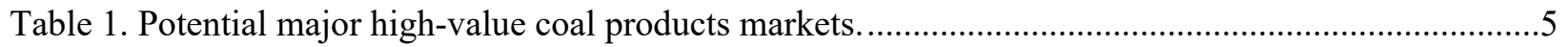

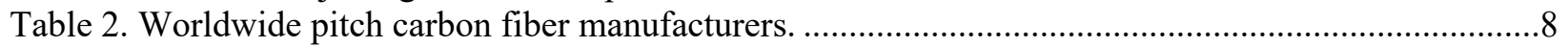

Table 3. Potential 2019 US supply value-chain of pitch carbon fiber manufacturing................................9

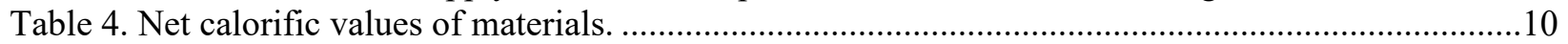

Table 5. Mass and energy efficiency of direct coal conversion of valuable commercial products. .............14

Table 6. Embodied energy of coal pitch manufacturing by coking process............................................16

Table 7. Mass and embodied energy breakdown of traditional coke manufacturing output........................16

Table 8. Coal pitch tar input embodied energy distribution of the RC catalytic hydrogenation

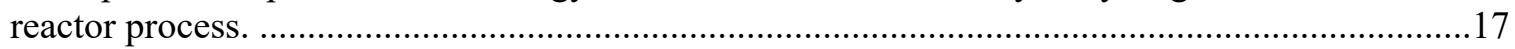

Table 9. Embodied energy distribution of the RC catalytic hydrogenation reactor products......................18

Table 10. BOM at three major stages of cradle-to-gate coal pitch fiber manufacturing. ..........................20

Table 11. Total PAH and EPA-PAH concentrations in different US raw coal types [48] .......................24

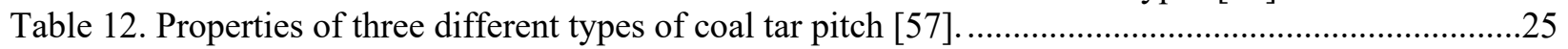

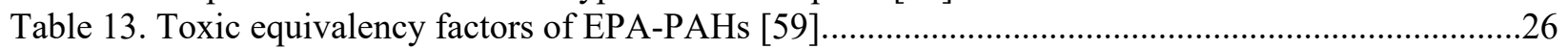


Table 14. Standards and regulations for PAH exposure. [60].

Table 15. Major polluatant emissions of isotropic coal pitch manufacturing .........................................29

Table 16. Major PAH polluatant emissions of isotropic coal pitch manufacturing...................................30

Table 17. Parameter assumptions to estimate carbon fiber manufacturing cost........................................33

Table 18. Baseline major input parameters of 3,750 tonnes/year 50,000 tow pitch carbon fiber manufacturing. 


\section{EXECUTIVE SUMMARY}

Coal is a versatile resource that has historically propelled the Industrial Revolution, transportation, and energy generation, and continues to meet needs for power. The United States possesses the largest worldwide coal reserves (with a 2019 total production-to-recoverable-reserves ratio of 0.05) that are of high quality and are cost-effective to recover (i.e., $\$ 0.03 / \mathrm{kg}-\$ 0.10 / \mathrm{kg}$ ). However, the demand of coal for power generation has declined because of a shift to natural gas (because of lower natural gas prices) and to renewable energy sources. This decline has affected the economic viability US coal industry. Historically, domestic demand for coal was driven mostly by the electric power sector, which accounts for about $93 \%$ of the total demand, followed by industrial uses (primarily for cement and chemicals at a minimal level) and steel production (coke). The complex, dense carbon chemical structure of coal, abundant domestic supply, and stable, low price gives it great potential for use in a wide range of valueadded non-fuel coal products (e.g., nanomaterials at $\$ 20,000 / \mathrm{kg}-\$ 100,000 / \mathrm{kg}$ and commercial-grade carbon fiber at $\$ 22 / \mathrm{kg}-\$ 33 / \mathrm{kg}$ ), as well as in upgraded coal fuels.

High-value coal products based on three major coal conversion manufacturing routes of carbonization, gasification, and liquefaction - such as fuels, chemicals, carbon fiber, graphite electrodes, electrodes for aluminum smelters, and specialty carbon products - have so far been limited to the by-products of coal tar pitch obtained during the production of metallurgical coke used in making steel. Among high-value coal products, pitch carbon fiber is being considered as one of the potential high-value coal products whose global demand is projected to reach $\sim 120,000$ MT ( $\sim \$ 4.5$ billion) by 2022 for the near-term large automotive and wind energy markets. [1] For any new high-value coal products industry such as pitch carbon fiber, this report focuses on the preliminary techno-economic analysis of its sustainable manufacturing in terms of energy, emissions, and economic/cost detrimental to its competitiveness against the conventional petroleum-based polyacrylonitrile (PAN) carbon fiber today.

The supply of coal tar pitch is an issue being raised by the existing small high-value coal products industry. It is closely tied to integrated steel production, which is projected to decline with a shift toward electric arc furnaces that use more steel scrap as the input raw material, besides there are active substitution plans for coal by the hydrogen use in part by $\mathrm{CO}_{2}$ emissions in Europe. Alternative direct coal liquefaction (DCL) technologies such as the low-severity DCL process under development by Ramaco Carbon (RC) for the potential large amount of supply of initial isotropic pitch for the high-value coal product market. The RC DCL has been considered here for the specific coal-derived pitch carbon fiber sustainable manufacturing energy analysis.

For the embodied energy estimation of the initial coal isotropic pitch for the final carbon fiber manufacturing, three alternative DCL processes of isotropic coal pitch manufacturing were considered from the following organizations: RC, Shenhua China, [2] and National Energy Technology LaboratoryUS Department of Energy (NETL-DOE). [3] In all the processes, the mass conversion efficiency of coal to valuable products were between $50 \%$ and $66 \%$ while the energy efficiency values varied between $67 \%$ and $87 \%$, computed based on the net heating value varying owing to differences in each process mass and energy demand. From the mass conversion standpoint, the highest conversion efficiency at $66 \%$ (moisture-ash free coal basis) was observed for the NETL-DOE process owing to it use of advanced reactor conversion based on the ebullition bed that maintains catalyst activity and increases yield relative to other DCL processes. However, from an energy standpoint, the RC process possessed the highest efficiency based on the preliminary available data; its on-site energy demand was half of that reported for other two DCL processes (Shenhua and NETL-DOE extraction process). More actual operating conditions data with the development of the RC process would be useful to identify the attractiveness of this energy-efficient DCL technology compared to the other past DCL technologies. 
The embodied energy estimates of coal tar pitch via two different processes - the RC process and the conventional coke manufacturing process - were found to be 56 and $38 \mathrm{MJ} / \mathrm{kg}$, respectively, compared with $94 \mathrm{MJ} / \mathrm{kg}$ for the conventional PAN precursor. A larger amount of on-site energy use besides the low amount of desired pitch output (i.e., 26\% mass conversion efficiency) resulted in a higher energy content of RC pitch. The cradle-to-gate (from raw coal extraction to final carbon fiber manufacturing) embodied energy estimates were made for the pitch carbon fiber vs. the conventional PAN carbon using the life cycle analysis SimaPro software, starting with the raw isotropic pitch followed by its sequential conversion into mesophase coal pitch precursor and finally the multi-step automated final carbon conversion. The total embodied energy of pitch carbon fiber manufacturing was 2.4 to 2.5 times lower than the conventional PAN carbon fiber energy of $1,188 \mathrm{MJ} / \mathrm{kg}$. A significantly higher final carbon fiber conversion yield of $74 \%$ of coal pitch fiber compared with $45 \%$ for the PAN fiber facilitates in the lower embodied energy of the former fiber case, in spite of a significantly higher energy content of initial PAN precursor. A significantly higher pitch carbon fiber conversion yield than $45 \%$ conventional PAN fiber yield will be one of the major drivers for twice the less energy efficient conventional DCL processes and the RC process under development for the initial raw precursor material manufacturing (i.e., PAN vs. coal tar) to the competitiveness of the final energy-efficient coal pitch carbon fiber manufacturing pathway.

The emissions analysis of coal pitch vs. the conventional PAN carbon fiber was also considered, the former based on a plantwide emissions analysis of RC process using air permit applications filed by Domestic Synthetic Fuels I and Copper Creek Chemical Facility in 2020. Pollutant emissions of 17 species were estimated based on per unit mass of isotropic coal pitch manufacturing, and of all the pollutants, particulate matter ( $\left.\mathrm{PM}_{\text {Total }}\right)$ was observed to be the largest quantity of emissions. Furthermore, the coal tar distillation unit emitted nearly $80 \%$ of the total gaseous pollutants followed by sections of hydrogen $\left(\mathrm{H}_{2}\right)$ section $(8 \%)$, utilities $(5 \%)$, H-coal $(4 \%)$ and coal handling $(3 \%)$.

One of the major concerns of coal processing has been the polyaromatic hydrocarbon (PAH) emissions, of which 12 pollutants (known as US Environmental Protection Agency [EPA]-PAHs) are currently regulated and have also been considered in the emissions impact analysis of coal pitch carbon fiber. The PAH concentration in coal has been reported to vary by its rank and location source. Additionally, the total concentration of intermediate molecular weight EPA-PAHs (fluoranthene, pyrene, and benzo[a]anthracene) were reported to be typically higher than low- and high-molecular weight EPAPAHs in all three pitch types considered in the analysis. Nine environmental impact categories considered under the TRACI2.1 life cycle analysis impact method were considered in the comparative coal pitch carbon fiber emissions analysis, and all of them were found to be lower, and mostly less than $50 \%$ of the conventional PAN fiber because of higher manufacturing yield of the coal pitch fiber conversion process as impacts were more than $80 \%$ under two impact categories i.e., ozone and fossil depletion. Nine environmental impact categories considered under the TRACI2.1 impact assessment method does include 7 out of 12 EPA-PAH chemicals besides toxicity impacts of missing five chemicals were found to be negligible with respect to the baseline toxicity of Benzo(a)pyrene chemical. Not only the PAH controlled equipment use is limited today due to a lack of EPA regulation enforcement, but difficulties in the conversion of actual LCA mass emissions per unit of manufactured mass output to total EPA-PAH limit in terms of $\mathrm{mg} / \mathrm{m}^{3}$ fail to assess accurately its overall environmental impacts. Additional environmental impact analysis of coal pitch carbon fiber manufacturing is needed to consider the on-site manufacturing process emissions including remainder PAH emissions after being condensed, captured, and processed for the comparative environmental viability of new fiber manufacturing technologies.

Coal pitch fiber manufacturing cost was estimated at the level of two major process steps: conversion of isotropic pitch to melt spinning of mesophase pitch precursor followed by its final carbon fiber manufacturing in a multi-step batch belt ovens using the preliminary industry processing data. The estimated total mesophase pitch precursor cost of $\$ 4.52 / \mathrm{kg}$ was found to be higher based on the assumed significantly lower yield of $50 \%$ than the earlier projected cost of $\$ 3.30 / \mathrm{kg}$ for the residual oil-based 
ACP20 mesophase pitch developed by Advanced Carbon Products. The baseline 50,000 tow significantly higher than the commercially available tow pitch carbon fiber sizes, its cost for an annual production volume of 3,750 tonnes/year is estimated to be $\$ 10.29 / \mathrm{kg}$ resulting from not only a lower precursor cost but a significantly higher carbon fiber conversion yield than for the commodity-grade PAN carbon fiber at $\$ 18 / \mathrm{kg}-\$ 22 / \mathrm{kg}$. Fiber precursor cost contributes to more than $50 \%$ of total fiber cost; hence, a $74 \%$ fiber conversion yield for the coal pitch fiber compared with $45 \%$ for the conventional PAN fiber provides a significantly lower carbon fiber cost in the former case. For this potential product, an adequate supply of low-cost coal tar pitch in addition to the supply needed for competing applications is critical. The use of pitch carbon fiber will be limited initially to specialty market applications requiring low compressive strength, for which this type of carbon fiber is best suited. 


\section{COAL INDUSTRY}

The United States has the largest estimated global coal reserves in the world. (Russia, Australia, China, and India - in declining order - are the other countries with substantial recoverable coal reserves.) As of 2016, of the total estimated global recoverable coal reserves of 1 trillion MT [4], the United States has about 22\%, or 220 billion tonnes [4]. Most of the coal produced in the United States has been used for electricity generation. However, during the past decade, cheaper natural gas and clean energy alternatives, as well as flat electricity demand, have resulted in a domestic decline in demand for coal. The declining demand has resulted in plunging coal production, which is causing financial hardships for the coal industry and a loss of jobs in coal mining areas. The number of people employed in coal mining in the United States has decreased from its highest level of 90,000 in 2012 to $\sim 50,000$ today.

A recent economic analysis of the Appalachian coal industry ecosystem examined the ripple economic impacts of diminishing coal extraction through the industry supply chain, which extends to a wide number of economic sectors, occupations, and county and multi-county regions of the Appalachia [5]. The job losses are due not only to the decline in coal-fired power generation but also to the shifting structure and spatial locations of power generation, which create additional impacts on the economic base, tax base, and employment prospects. Additionally, the regional rail transportation infrastructure faces a risk of declining traffic that may translate into higher transportation costs and diminished opportunities for economic development tied to the movement of bulk commodities, mining supplies, and products. Coal consumption in these traditional areas, such as electricity generation, is projected to remain low; therefore, new high-value products that can be derived from the country's vast coal reserves must be identified. Economics and environmental sustainability are two important aspects that need to be kept in mind while new coal conversion technologies for a high-value coal products industry are being considered.

\subsection{US COAL SUPPLY AND DEMAND}

In 2019, 706 million tonnes of coal were produced in the United States, which is about $5 \%$ of the total recoverable reserves of 14.2 billion tonnes at producing mines [4]. Error! Reference source not found. shows the distribution of US coal reserves along with the types of coal available in different regions [6]. Generally, US coal reserves and production can be attributed to six major coal-producing regions: ${ }^{1}$ the Appalachia, Interior, Gulf, Dakota, Wyoming, and Rocky Mountains are major US coal-producing regions, of which Wyoming accounted for about 39\% of the country's 2019 total coal production; other prominent coal-producing states are West Virginia (13\%), Pennsylvania (7\%), Illinois (6.5\%), and Kentucky (5\%) [7].

\footnotetext{
${ }^{1}$ Appalachia: Pennsylvania, Maryland, Ohio, Northern West Virginia, Southern West Virginia, Virginia, Eastern Kentucky, Northern Tennessee, Alabama, Southern Tennessee; Interior: Illinois, Indiana, Mississippi, Western Kentucky, Iowa, Missouri, Kansas, Oklahoma, Arkansas, Texas (bituminous); Gulf (lignite only): Texas, Louisiana, Arkansas; Dakota: North Dakota, Montana (lignite), Montana (bituminous and subbituminous); Wyoming: Wyoming portion of Powder River Basin, Wyoming other than Powder River Basin; Rocky Mountain: Colorado, Utah.
} 


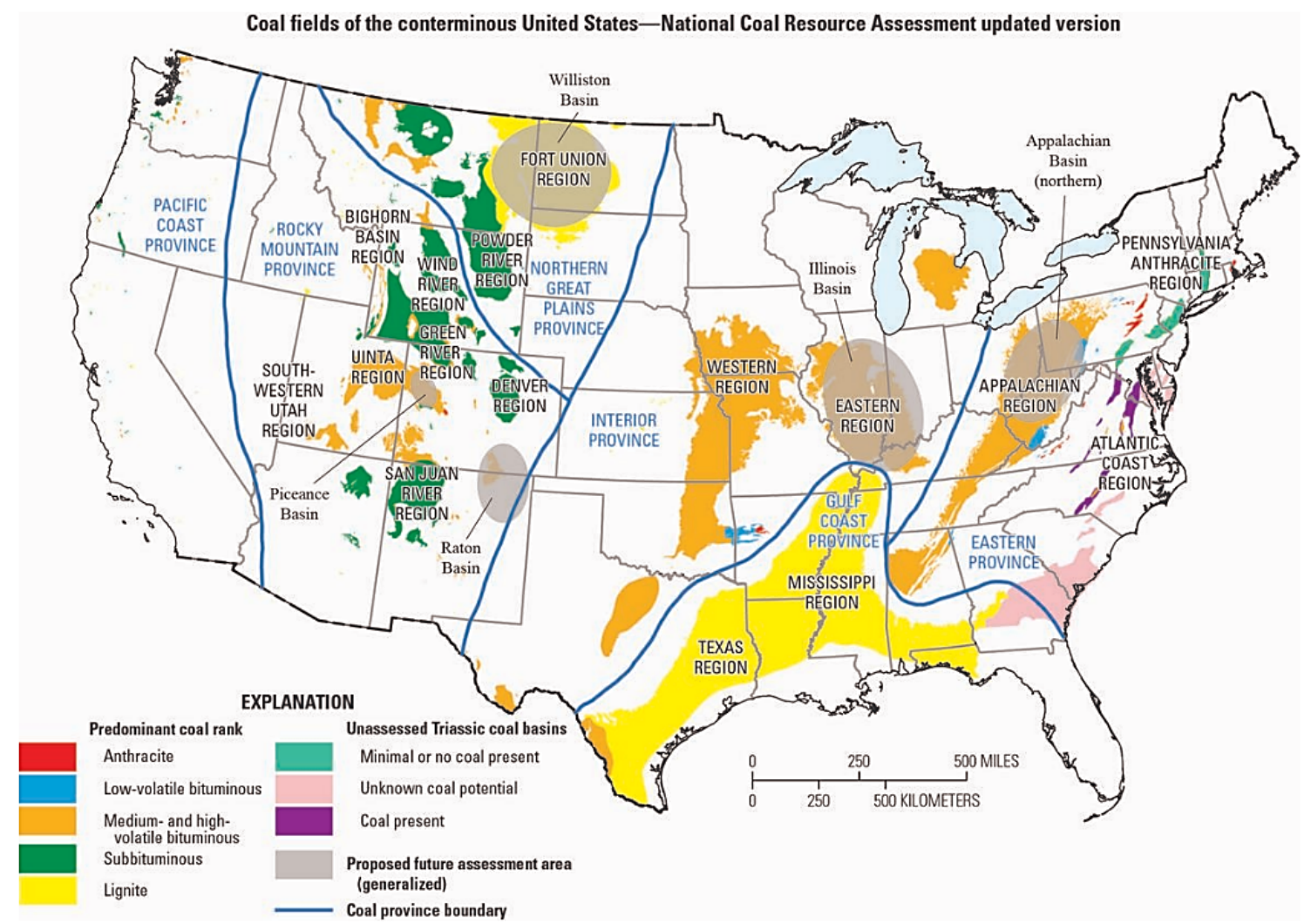

Figure 1. Distribution of coal resources [6].

Coal is a relatively inexpensive resource compared with petroleum at a price range of $\$ 0.03 / \mathrm{kg}$ to $\$ 0.10 / \mathrm{kg}$, depending on its rank, grade, mining method, and geographic region. The thinner and deeper deposits of the Appalachia are difficult to mine and therefore cost more than coal mined from the western Powder River Basin. The Powder River Basin, covering Wyoming and Montana, is one of the largest repositories of coal in the United States. The coal there lies in thick seams near the surface, which makes it easy to mine using large machinery; it is the most affordable US coal, costing as low as $\$ 15 /$ ton [8] in the United States. The ease of mining, coupled with its low ash and low sulfur content, makes Wyoming coal attractive for high-value applications with such initial raw coal type requirement. Ramaco Carbon (RC) is setting up a first-of-a-kind world's only vertically integrated carbon resource-based research, development, and production facility in Sheridan, Wyoming to develop products from the locally available inexpensive coal. Transportation costs, as well as mining costs, can be significant and result in a higher final delivered coal price; therefore, mine mouth projects are economically preferable.

The total estimated 2019 US demonstrated reserve base of 430 billion tonnes compared with 13 billion tonnes of recoverable reserves [9] and, at the current production level of 642 million tonnes [7], is expected to last for around 670 years or considerably less ( 20 years) in the latter case. The low total U.S. production to reserves ratio of 0.04 means that opportunities for increasing coal production are available if new demands for coal-based products/services emerge in future. Arkansas (Interior Region), Mississippi (Interior Region), Alaska, Arizona (Wyoming Region), and North Dakota (Dakota Region) are the states with the lowest production to reserve ratios (Figure 2). 


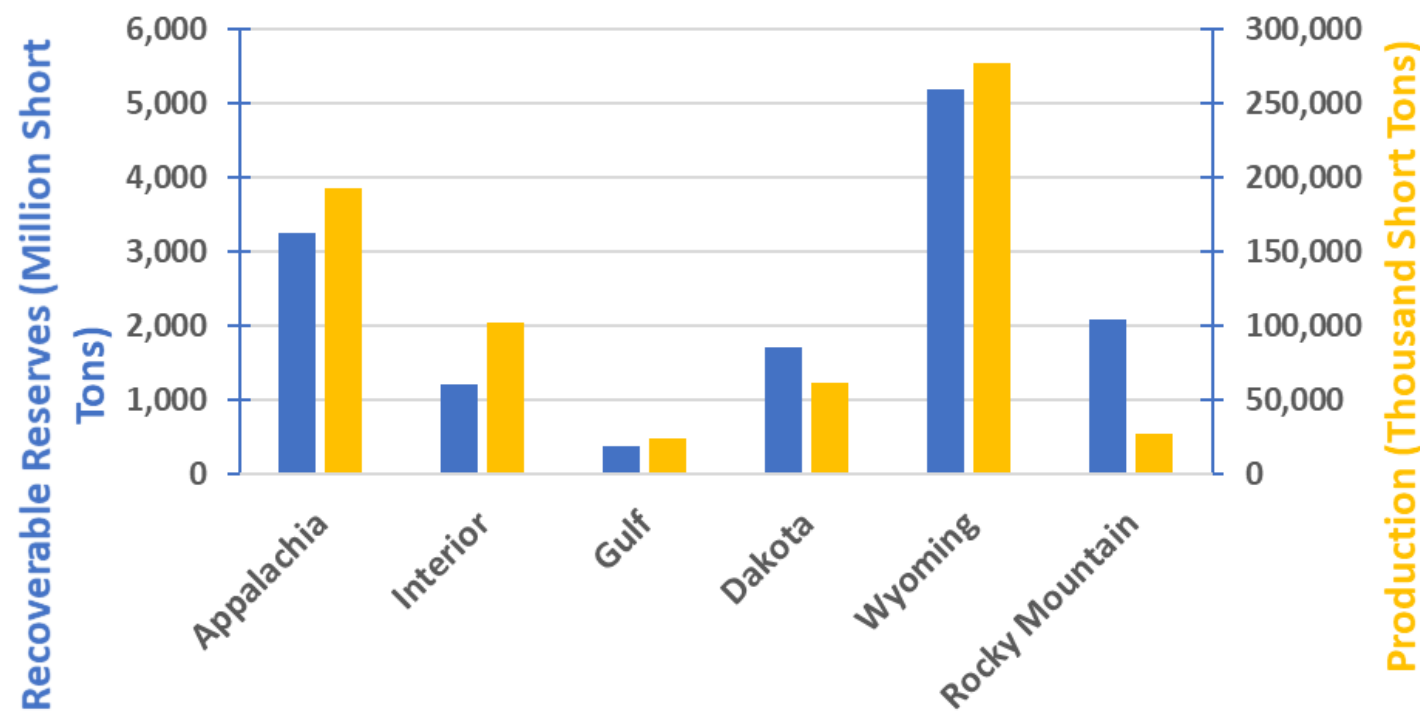

Region

\section{Recoverable Coal Reserves $\quad$ Production}

Figure 2. Estimated 2019 US recoverable coal reserves and current production.

Despite the large reserves, coal production has declined over the years. A 37\% drop in coal production was observed from 2006 to 2016 [10], which coincided with the drop in the cost of natural gas and its replacement of coal in electricity generation with the decline of the cost of utility-scale solar and wind. Although production in 2017 saw an increase of 6.5\% over 2016, the increase was mostly driven by an increase in exports due to a recovery in Asian coal demand. The Annual Energy Outlook 2018 of the US Energy Information Administration forecasts that domestic coal production will continue to be flat in the future as shown in Figure 3. Among the different regions, coal production in Wyoming is expected to be high in the future, which makes a strong case for greater development of the coal industry in that state. Coal production from the Appalachia is expected to decline but this supply deficiency may be filled in by increased production from Kentucky and from Illinois in the Eastern Interior region. 


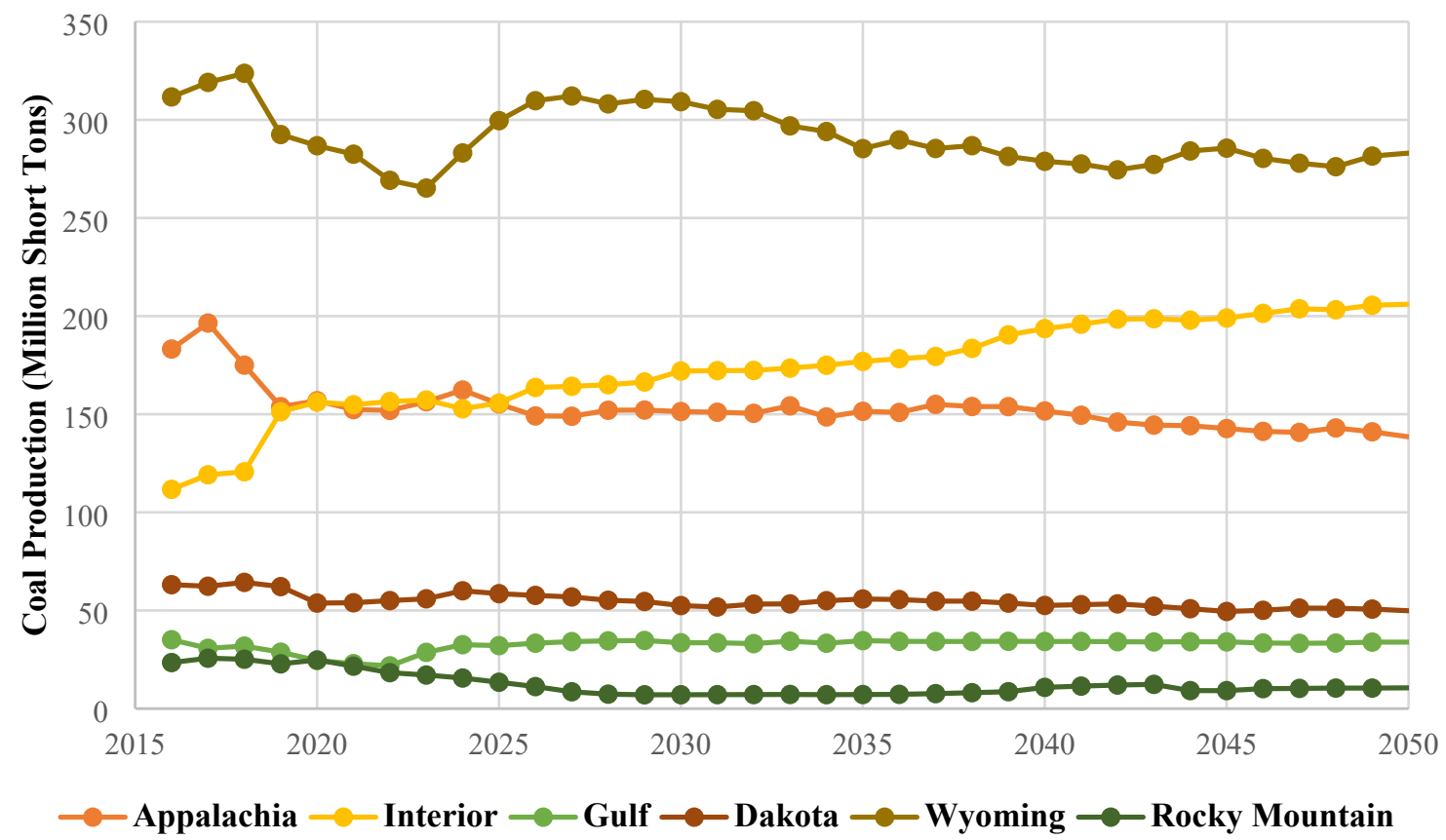

Figure 3. Domestic coal production forecast. [11]

Most of the coal produced in the United States is consumed domestically; only a small portion, $\sim 7 \%$, is exported. Domestic demand for coal is driven mostly by the electric power sector, which accounts for about $93 \%$ of the total demand, followed by industrial use and steel production (the coke industry). Domestic consumption of coal declined from by 14.8\% [12] from the 2018 level to 533 million tonnes in 2019 and continues to decline. Most of this decline can be attributed to a decrease in consumption by the electric power sector, which decreased by 34\% over that decade, from 931 million tonnes in 2006 to 615 million tonnes in 2016 [13]. According to the Annual Energy Outlook 2018, coal consumption is expected to remain flat in the future as a result of its replacement by natural gas and renewable energy sources for power generation. Demand from other industrial sectors and coke production is also expected to remain flat. Some relief for coal producers in 2017 came from a rebound in the global demand for coal, reflecting an uptick in demand in China and India.

The International Energy Agency projection in 2018 indicates coal demand to flatten at around 5,400 million tonnes of coal; falling consumption in China $(-15 \%)$, the European Union $(-65 \%)$, and the United States $(-30 \%)$ is balanced by rising demand in India (+120\%) and Southeast Asia $(+120 \%)$ [14]. The prospects for the United States as an exporter of coal to the countries expecting a high demand depend heavily on competition from other major global suppliers (such as Australia) that are geographically closer to those markets. It will also depend on the interplay of alternative resources such as renewables and natural gas to fuel the energy needs of these nations. Although the flow of new coal projects starting operation will slow sharply post-2020, coal remains a viable resource in the global power mix because the average age of a coal-fired plant in Asia is less than 15 years, compared with 40 years in advanced economies.

The US coal industry is highly concentrated, with a handful of producers operating primarily in four states-Wyoming, West Virginia, Kentucky, and Illinois. Three top producers, Arch Coal, Peabody Energy, and Alpha Natural Resources (ANR), have filed for bankruptcy since 2015 [15], demonstrating the financial troubles faced by the coal industry. In the wake of flat domestic demand and uncertain global demand, revival of the US coal industry calls for diversifying the use of coal toward making high-value 
products. Doing so will ensure that this abundant and inexpensive natural resource is optimally used and will help create new employment opportunities in coal states. Lower volatility in coal prices compared with crude oil and natural gas prices and flat price projections by the US Energy Information Administration make coal a reliable feedstock for carbon-based high-value products.

\section{HIGH-VALUE COAL PRODUCT MARKETS}

The combustion of coal for power and heat generation is predicted to gradually decrease as nations seek to lower $\mathrm{CO}_{2}$ emissions. A declining demand trend in coal for power generation is providing opportunities for using coal for non-energy purposes. Non-energy uses of coal are growing in all sectors, and cumulatively, the total requirement for coal feedstocks for those purposes exceeds 100 Mtonnes/year. [16] Today, the coal-to-chemicals industry is the fourth-largest consumer of coal after the power, steel, and cement sectors. Other commercial uses for coal include the synthesis of activated carbon, carbon fiber, composite materials, carbon electrodes, and asphalt cement binders and modifiers for the pavement and roofing industries. [17] There are three main processes for coal conversion to alternative valuable products: carbonization, gasification, and liquefaction. Coal carbonization has been the traditional source of coal chemicals, tars, or liquids as by-products from coke ovens. Coke production has steadily decreased in the past decades because of a downturn in the steel industry and a shift in that industry away from blast furnaces to electric arc furnaces and the coal replacement by hydrogen playing a major role in the this industry in future. Major uses of coal today include alumina refining, paper manufacturing, and chemical and pharmaceutical production. Domestically available inexpensive coal in the price range of $\$ 0.03 / \mathrm{kg}$ to $\$ 0.10 / \mathrm{kg}$ is a potentially valuable alternative resource for high-value products such as nanomaterials at $\$ 20,000 / \mathrm{kg}$ to $\$ 100,000 / \mathrm{kg}$ and commercial-grade carbon fiber at $\$ 22 / \mathrm{kg}$ to $\$ 33 / \mathrm{kg}$.

The market share for products currently made from conventional resources, such as petroleum, that could potentially be made instead from coal (Table 1) will depend on the cost-benefit trade-offs between the two competing resources (i.e., conventional resources vs. coal). The total market size for chemicals that could be produced via coal gasification and liquefaction is fairly large compared with other potential nonchemical coal products based primarily on coal carbonization. The global methanol market size based on natural gas and coal is projected to reach $\$ 75$ billion by 2024 [18], at a compound annual growth rate of $12.4 \%$ [19]. The increasing use of methanol as a fuel in the automotive industry, increasing olefin production from (methanol to olefins/methanol to propylne (MTO/MTP) plants in China, increasing petrochemical demand globally, continuous expansion, and various joint ventures and agreements undertaken by different companies are the key factors for the growth of the global market. The current market for global syngas chemical products - consisting mainly of methyl tertiary-butyl ether, formaldehyde and resins, acetyls, and methanol — is larger than the methanol market but is projected to reach a similar level of $\$ 75$ billion by 2024 because of an anticipated compound annual growth rate of $9.1 \%$, according to one estimate [20]. On the contrary, the coal gasification market is projected to be significantly smaller, reaching $\sim \$ 1$ billion by 2024 . Of four major coal gasification markets - chemicals, liquid fuels, power, and gaseous fuels - chemicals dominate the total market.

Table 1. Potential major high-value coal products markets.

\begin{tabular}{|l|c|c|}
\hline \multirow{2}{*}{ High-value coal product } & \multicolumn{2}{c|}{ Market size (\$B) } \\
\cline { 2 - 3 } & $\mathbf{2 0 1 8}$ & $\mathbf{2 0 2 4}$ \\
\hline Methanol (global) [19] & $\$ 37$ & $\$ 75$ \\
\hline Syngas chemicals (global) [20] & $\$ 51$ & $\$ 75$ \\
\hline Coal gasification (global) [18] & $\$ 0.69$ & $\$ 0.96$ \\
\hline Naphthalene (global) [21] & $\$ 1.6$ & $\$ 1.9$ \\
\hline Rare earth metals (global) [22] & $\$ 11$ & $\$ 20$ \\
\hline
\end{tabular}




\begin{tabular}{|l|c|c|}
\hline Carbon fiber (global) [23] & $\$ 3$ & $\$ 6$ \\
\hline Activated carbon (USA) [23] & $\$ 1.0$ & $\$ 2.2$ \\
\hline Nanomaterials (global) [24] & $\$ 26$ & $\$ 80$ \\
\hline Graphene (USA) [25] & $\$ 0.01$ & $\$ 0.06$ \\
\hline Graphite (global) [26] & $\$ 15$ & $\$ 21$ \\
\hline Building thermal insulation (global) [27] & $\$ 28$ & $\$ 35$ \\
\hline
\end{tabular}

These chemicals are mostly manufactured from petroleum, and so a stable domestic and less expensive resource such as coal could potentially be a viable resource for this large market. One of the major hurdles to the coal-to-chemicals market has been cost. The recent declining price trend of petroleum and the availability of an abundant, less expensive alternative domestic resource such as natural gas poses additional challenges for coal as a viable alternative resource for the chemicals market.

Nanomaterials, such as nanotubes, fullerenes, graphene, and quantum dots, are a few of the major potential high-value coal by-products of coal carbonization, for which the global market is projected to increase more than threefold in less than a decade, from an estimated total \$26 billion market today [24]. The factors that drive the demand for nanomaterials in various end-user industries, such as paints and coatings, energy, and electronics and consumer goods, are growing investments in research and development, the increasing popularity of nanomaterials in various industries, and the excellent physiochemical properties of nanomaterials. Graphene, one of the three major markets for different types of carbon-based nanomaterials, has a relatively insignificant market share of less than $\$ 1$ billion compared with the overall estimated market size. Other potential major markets for high-value coal products from coal carbonization include graphite and building thermal insulation. As with other coal carbonizationbased high-value products, the availability of coal pitch at a reasonable quality and cost will dictate the extent of market penetration.

\subsection{COAL PITCH CARBON FIBER}

Carbon fiber is being considered as one of the key reinforcement materials in polymer composites, with anticipated growth in several lightweighting applications such as automobiles and aerospace because of its excellent weight and performance benefits. The main technical benefit of using carbon fiber for most applications is the material's high strength-to-weight performance, which leads to lightweight, more efficient structures. It is estimated that every $10 \%$ of vehicle mass savings results in a $6 \%-8 \%$ improvement in fuel economy, [28] In most applications, the main technical benefits of carbon fiber derive from the high strength-to-weight performance of the material, leading to lightweight structures. Carbon fiber reinforced polymer (CFRP) composites also enable the extension of the blade length in wind turbines. Longer blades result in more wind energy captured per turbine and allow the development of mid- and lower-wind speed resources that might be impractical given the limitations of conventional glass fiber-reinforced polymers. Other potential CFRP applications include pressure vessels, oil and gas industry uses, and civil infrastructure, in addition to the current uses in sports equipment.

The market for carbon fiber continues to grow at 10\% to $12 \%$ per year [1]. In 2019, global demand for carbon fiber totaled $\sim 100,000$ tonnes ( $\sim \$ 3$ billion) and was projected to reach $\sim 120,000$ tonnes $(\sim \$ 4.5$ billion) by 2022. The growth in 2019 was led by incremental volume gains in carbon fiber use in aerospace programs, wind turbine blades, and a variety of industrial applications. Worldwide, CFRP accounts for $1 \%-2 \%$ of the market for fiber-reinforced composites. In 2019, global demand for CFRP was estimated at 141,500 tonnes or \$18 billion compared with 125,500 tonnes in the previous year [29]. That corresponds to a growth of $10.1 \%$ - a slightly lower rate than in recent years and projected to reach 197,000 tonnes by 2023. Continued growth at this rate is expected for the foreseeable future. Aerospace 
and wind blade applications each made up about one-fifth of the market, while automotive and sporting goods accounted for approximately one-sixth each. The remaining $25 \%$ to $30 \%$ of the market comprised a variety of applications, including compounding for injection-molded plastics, pressure vessels, construction and infrastructure reinforcement, tooling, marine, and oil and gas [1].

All segments are growing as additional applications and programs come into production. It is predicted that wind energy would have a similar share as the automotive industry. To date, the most automotive composites applications in order of volume are under-the-hood components and drive shafts, exteriors, and interiors. The market for CFRP in automotive applications continues to grow and is expected to reach $\sim 23,000$ MT by 2025 from 19,000 MT in 2019 [30]. The initial CFRP automotive application occurred in premium vehicles such as BMW i3/i8 earlier during the last decade, and its latest introduction in 2019 Audi A8/R8 vehicles. For carbon fiber to gain a greater share of the overall composites market, volume is key. High-volume applications and broader adoption of CFRP composites require lower costs - both the costs of carbon fiber materials and the manufacturing costs of making CFRP parts.

Pitch-based carbon fiber is another type of fiber produced by the carbonization of an oil/coal pitch precursor. It has extensive favorable properties ranging from low elastic modulus to ultrahigh elastic modulus. The substitution of coal tar pitch for conventional petroleum-based polyacrylonitrile (PAN) is considered to be a more economical route than the conventional carbon fiber manufacturing. An advantage of the production of pitch-based fibers over PAN-based fibers is that the former does not require constant tension on the fibers at all processing stages. Pitch is an isotropic viscoelastic material, but it can be made anisotropic through the use of heat treatments. However, the most important factor in carbon fiber production is mesophase pitch because it allows melt spinning of anisotropic mesophase pitch without filament breakage. Mesophase pitch is made by polymerizing isotropic pitch to a higher molecular weight. Pitch-based carbon fibers have been found to be more sheet-like in their crystal structure, as opposed to PAN-based carbon fibers, which are more granular.

Pitch carbon fibers with ultrahigh elastic modulus are extensively used in high-stiffness components; various non-crash-sensitive automotive applications requiring high thermal conductivity and electric conductivity (e.g., liners, covers, load floor, and fascias), and high-end applications in the aviation, aerospace, and motor sport sectors. High-quality pitch fiber is deployed in spacecraft materials and can exhibit exceptional thermal conductivity properties. Compared with PAN-based carbon fibers such as Grafil and Pyrofil, the major pitch-based carbon fiber available today, DIALEAD, has a tensile modulus that is several orders of magnitude higher - in the range of 400 to 1,000 $\mathrm{GPa}$. A wider range of tensile modulus is observed for pitch fiber, which is attributed to variable feedstock and preparation conditions. However, it has a lower tensile strength than PAN because of the presence of flaws in the carbon filaments that may be caused by insoluble components in the tar pitch. The low compressive strength of pitch-based carbon fiber is a major reason for its current limited, low-volume specialty market applications.

The global pitch carbon fiber market today is relatively small with the PAN-based carbon fiber dominance, and it is expected to have a compound annual growth rate of $6.4 \%$ to reach $\sim \$ 104$ million by the end of 2023 [31]. The rising demand for carbon fibers in the aerospace and defense industry is ensuring the stable revenue source to the growth of the global pitch-based carbon fiber market. Additionally, the growth in the wind energy sector is another major factor expected to fuel the growth of the market. Furthermore, the increasing demand for carbon fibers in the automotive industry is projected to offer growth opportunities for the players operating in the market during the forecast period. However, the current high cost of pitch-based carbon fibers has increased the preference for low-cost PAN-based and fiberglass substitutes, which is projected to be the major restraining factor to the growth of the global pitch-based carbon fiber market during the forecast period. Asia-Pacific, with the largest market share by China, accounted for the largest market share of $36.2 \%$ in 2018, with a compound annual growth rate of 
higher than $7.0 \%$ during the forecast period because of rapid industrial growth and growing aerospace and power generation industries, including renewable energy in the region. [31] North America was the second-largest regional market in 2018, with a compound annual growth rate of higher than $6.0 \%$ during the forecast period owing to the growth of aerospace and defense industries along with the increasing application of pitch-based carbon fiber in sports and construction industries.

Pitch fiber is dominated by small tows (less than 24,000), which hold a $\sim 70 \%$ share (in terms of tonnage) of its total market today. Table 2 shows three major pitch carbon fiber manufacturers, including the raw material resource used, available fiber forms, and market applications for each manufacturer. DIALEAD, manufactured by Mitsubishi Chemical Corporation, is the most commonly used pitch-based carbon fiber. It is characterized by high vibration damping, high thermal conductivity rates, and excellent tension modulus. Mitsubishi Chemical Corporation has the largest pitch carbon fiber production capacity in the world (1,000 tonnes/year) currently, with a $71 \%$ share of total worldwide capacity [32]. Besides being the largest manufacturer today, it is the producer with the least costly available pitch carbon fiber, in the range of $\$ 88 / \mathrm{kg}-\$ 110 / \mathrm{kg}$. Its pitch carbon fiber is $100 \%$ coal-based and is predominantly a large fiber tow (12,000-16,000 - equivalent to 24,000-30,000 tow PAN carbon fiber). Mitsubishi Plastics (Tokyo) and Mitsubishi Rayon (business companies whose common holding company is Mitsubishi Chemical Holdings Corporation) have plans to integrate the pitch-based carbon fiber business of Mitsubishi Plastics and the PAN-based carbon fiber business of Mitsubishi Rayon to enhance the carbon fiber and composite materials business. Lightweight, high-performance CFRP drive shafts using Mitsubishi chemical pitch for the BMW M3/M4 model have shown 50\% mass savings compared with the earlier steel version. [32]

Table 2. Worldwide pitch carbon fiber manufacturers.

\begin{tabular}{|l|l|l|}
\hline \multicolumn{1}{|c|}{$\begin{array}{c}\text { Pitch fiber supplier } \\
\text { (resource/fiber tow size) }\end{array}$} & \multicolumn{1}{|c|}{ Fiber form (brand name) } & \multicolumn{1}{c|}{ Applications } \\
\hline $\begin{array}{l}\text { Mitsubishi Chemical Corporation, } \\
\text { Japan (coal/large tow) }\end{array}$ & $\begin{array}{l}\text { DIALEAD_large tow (fiber } \\
\text { [continuous, chopped, and } \\
\text { milled], fabric, and prepreg) }\end{array}$ & $\begin{array}{l}\text { Automotive, aerospace, industrial } \\
\text { machines, and civil infrastructure }\end{array}$ \\
\hline $\begin{array}{l}\text { Nippon Graphite Fiber } \\
\text { Corporation, Japan } \\
\text { (coal and petroleum/small tow) }\end{array}$ & $\begin{array}{l}\text { GRANOC_-small tow (fiber, } \\
\text { fabric, and prepreg) }\end{array}$ & $\begin{array}{l}\text { Aerospace, satellite, sports and } \\
\text { recreation, industrial, civil } \\
\text { engineering, and thermal } \\
\text { management }\end{array}$ \\
\hline $\begin{array}{l}\text { Cytec Solvay, USA } \\
\text { (petroleum/small tow) }\end{array}$ & $\begin{array}{l}\text { THORNEL and ThermalGraph- } \\
\text { small tow (fiber [continuous, } \\
\text { discontinuous, and milled] and } \\
\text { prepreg) }\end{array}$ & $\begin{array}{l}\text { Aerospace (e.g., carbon-carbon } \\
\text { composite brakes) }\end{array}$ \\
\hline
\end{tabular}

The other two major manufacturers are Cytec Solvay in South Carolina, USA, and Nippon Graphite Fiber Corporation, with shares of $16 \%$ and $13 \%$, respectively, of the total worldwide pitch carbon fiber production capacity. Cytec Solvay is the smallest pitch fiber producer, and its products are completely petroleum-based because the company is a spin-off from American Cyanamid Company, a major manufacturer of industrial chemicals and specialty chemicals. Fibers produced by both of these small manufacturers are small tows and are limited in production volume. The fiber is highly expensive, as high as $\$ 440 / \mathrm{kg}$. Most applications of Cytec Solvay fiber are in aerospace carbon-carbon composite applications such as brakes.

Table 3 shows the estimated potential US supply value-chain of pitch carbon fiber manufacturing if all available US coal tar pitch from coke production were available for carbon fiber. About $10 \%$ of the total US 2019 coal production of 642 million tonnes was metallurgical coal. [33] Of the total 64 million tonnes of metallurgical coal production, 13 million tonnes of metallurgical coke was produced, resulting in final 
coal pitch production of 0.35 million tonnes in 2019. Because of several blast furnace restarts, the demand of metallurgical coke declined further with the falling steed from the COVID-19 pandemic [34].

Assuming production yields of $50 \%$ and $76 \%$ (based on $80 \%$ chemical yield) for conversion of coal pitch to mesophase pitch, followed by final pitch carbon fiber production, respectively, the total values of pitch precursor and fiber are estimated to be $\$ 0.9$ billion and $\$ 2.2$ billion, respectively. The total 2019 pitch carbon fiber market value of $\$ 2.2$ billion is conservative. It is based on meeting the long-term US Department of Energy carbon fiber cost target of $\$ 11 / \mathrm{kg}$ and converting all the 0.35 million tonnes of coal tar pitch from coke production in 2019 into pitch carbon fiber. The total 2019 pitch carbon fiber market value could be 8 to 10 times the estimated conservative market value based on the current large-tow pitch carbon fiber market price of $\$ 88 / \mathrm{kg}-\$ 110 / \mathrm{kg}$.

Table 3. Potential 2019 US supply value-chain of pitch carbon fiber manufacturing.

\begin{tabular}{|c|c|c|c|c|c|c|c|}
\hline $\begin{array}{c}\text { Market } \\
\text { Parameter }\end{array}$ & Coal & $\begin{array}{c}\text { Anthracite/ } \\
\text { metallurgical } \\
\text { coal }\end{array}$ & Coke & Coal tar & Coal tar pitch & $\begin{array}{c}\text { Mesophase } \\
\text { pitch carbon } \\
\text { fiber precursor }\end{array}$ & $\begin{array}{c}\text { Pitch } \\
\text { carbon } \\
\text { fiber }\end{array}$ \\
\hline $\begin{array}{c}2019 \\
\text { production } \\
\text { (million MT) }\end{array}$ & $642[33]$ & $64[33]$ & $13[33]$ & 0.7 & 0.35 & 0.18 & 0.13 \\
\hline $\begin{array}{c}2019 \text { product } \\
\text { price }(\$ / \mathrm{kg})\end{array}$ & $\$ 0.03$ & $\$ 0.11[35]$ & $\$ 0.16[36]$ & $\$ 0.40[37]$ & $\$ 0.70$ & $\$ 3.30$ & $\$ 11.00$ \\
\hline $\begin{array}{c}2019 \text { value } \\
(\$ B)\end{array}$ & $\$ 19$ & $\$ 7$ & $\$ 2.1$ & $\$ 0.28$ & $\$ 0.25$ & $\$ 0.6$ & $\$ 1.5$ \\
\hline
\end{tabular}

\subsection{PITCH CARBON FIBER MANUFACTURING ENERGY}

Direct coal liquefaction (DCL) is an alternative route for the initial raw coal tar manufacturing for coal to products by synthesizing liquid hydrocarbon distillate products from a coal's aromatic structure. DCL process increases the $\mathrm{H} / \mathrm{C}$ ratio from approximately 0.8 to 2 through the addition of $\mathrm{H}_{2}$ to coal [38]. This coal liquefaction process can be divided into two categories, namely hydro-liquefaction through catalysts and solvent extraction. The former process necessitates the addition of $\mathrm{H}_{2}$ to coal under high temperature $\left(450{ }^{\circ} \mathrm{C}\right)$ and pressure $(200 \mathrm{bar})$ conditions in the presence of a catalyst whereas the latter process adds $\mathrm{H}_{2}$ through $\mathrm{H}_{2}$-rich donor solvents like anthracene, tetralin etc. to coal under mild temperature and pressure conditions in the absence of a catalyst. In both processes, the chemical bonds within coal's structure get ruptured into molecular fragments and $\mathrm{H}_{2}$ stabilizes these fragments of free radicals to generate hydrocarbon liquids and other commercially valuable products such as gasoline, diesel, naphtha, and pitch.

In this work, energy and environmental emissions analyses of coal to hydrocarbon products were performed with a focus on pitch tar hydrocarbon product using the hydro-liquefaction technology. Figure 4 depicts the process flow diagram for producing pitch from coal. In the first step, raw coal is pulverized and introduced to the slurry mixing tank with a proprietary solvent and solvent-to-coal ratio. This slurry is then heated to $450^{\circ} \mathrm{C}$ and pumped to 190 bar prior to introducing it into the reactor. Coal gets decomposed in the reactor because of high temperature and gets solubilized into liquid form. Hydrogen is then added to dissolved coal in the reactor to increase the $\mathrm{H} / \mathrm{C}$ ratio, thereby yielding isotropic pitch as one of the final end-products. 


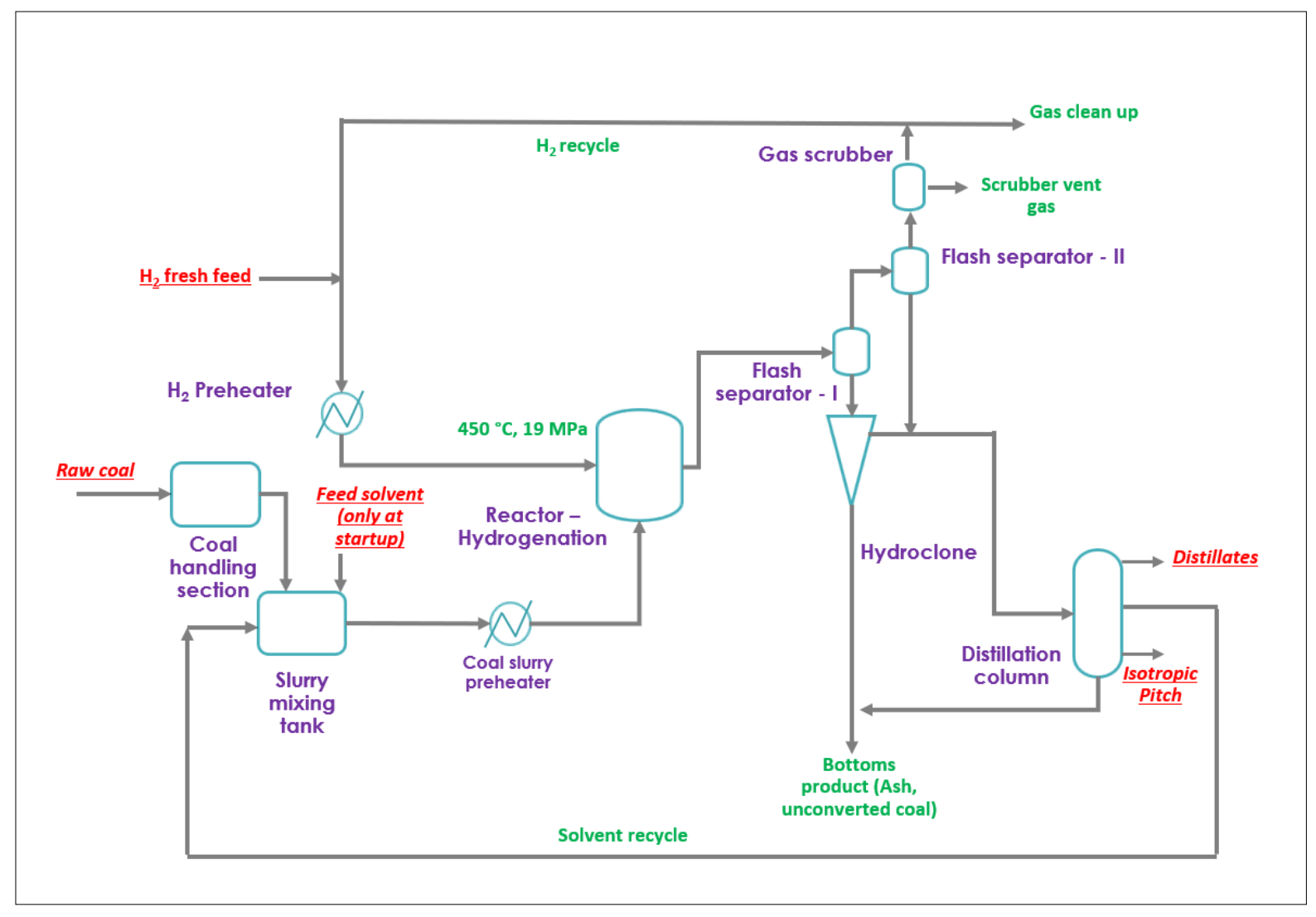

Figure 4. Process flow diagram of synthesizing isotropic pitch from coal (Ramaco Carbon process).

\subsection{MASS AND ENERGY BALANCES OF DCL PROCESS}

In this section, mass and energy balances of the RC DCL processes were conducted and compared with the past work by RC, Shenhua, and the National Energy Technology Laboratory-US Department of Energy (NETL-DOE) [39] [2] [3]. Using the material balance for the DCL unit from the industry literature (RC) and the net calorific values of value input and output materials [40] as shown in Error! Reference source not found., the energy balance for all four DCL processes considered here was estimated.

Table 4. Net calorific values of materials. [40].

\begin{tabular}{|c|l|c|}
\hline$\#$ & \multicolumn{1}{|c|}{ Component } & Net calorific value (MJ/kg) \\
\hline 1 & Diesel & 42.35 \\
\hline 2 & Coal & 27 \\
\hline 3 & Gasoline & 43.65 \\
\hline 4 & Liquefied petroleum gas & 48.5 \\
\hline 5 & Electricity & $3.6 \mathrm{MJ} / \mathrm{kWh}$ \\
\hline 6 & Oil residue & 40.75 \\
\hline 7 & Kerosene & $43.69[41]$ \\
\hline
\end{tabular}




\begin{tabular}{|c|l|c|}
\hline 8 & Naphthalene & 44.5 \\
\hline 9 & Benzene & 40 \\
\hline 10 & Xylene & 43.38 \\
\hline 11 & Phenol & 32.46 \\
\hline 12 & Pyrolytic gas & 8 \\
\hline 13 & Char & 28.13 \\
\hline 14 & Hydrogen & 130 \\
\hline 15 & Natural gas & 47 \\
\hline 16 & Ammonia & 22.5 \\
\hline 17 & Sulfur & 9.2 \\
\hline 18 & Gas oil/light oil/Anthracene & 40.73 \\
\hline
\end{tabular}

The RC process is based on technology scheme developed by Axens and Headwaters Technology Innovation (HTI, Inc), known as the low-severity DCL process. The process occurs in absence of the catalyst with no continuous demand of solvent. A proprietary solvent gets introduced to the process during initial plant start-up and gets recycled during the plant's steady state operation (Figure 4). The mass and energy balance of RC process includes the steam methane reforming section along with DCL and refining sections as shown in Figure 5. The steam methane reforming unit produces $\mathrm{H}_{2}$ from methane via two reactions (i.e., endothermic steam methane reforming and water-gas shift). Natural gas is provided to the steam methane reforming endothermic reaction as a heating energy input in addition to material input. As illustrated in Figure 5, only $14 \%$ of the total natural gas fed to the steam methane reforming unit is used as heating energy input while the rest is used for material conversion to $\mathrm{H}_{2}$. The generated $\mathrm{H}_{2}$ is then fed to the RC process unit along with pulverized coal to generate valuable products such as distillate, isotropic pitch, char, and pyrolytic gas.

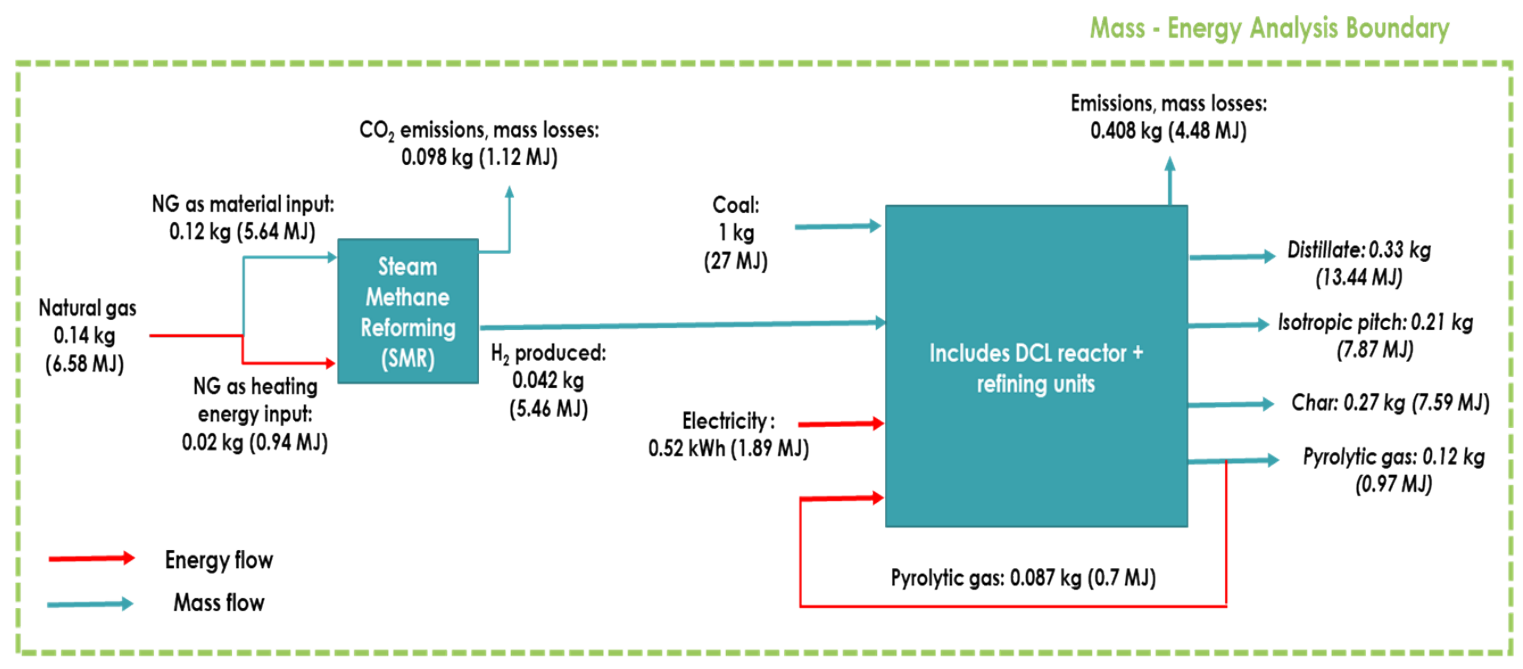

Figure 5. Mass and energy balances of the RC DCL process [39].

The energy requirement of the RC process was low with the only external electrical energy source use without any thermal energy requirement. The RC process thermal energy demand was reported to be adequate by using recycled pyrolytic gas as a combustive energy source. The mass yield of pyrolytic gas from coal was $20 \%$ (dry coal basis) and was similar to a reported value of $8 \%-14 \%$ based on the mass of lignite coal that comprised nearly $37 \%-39 \%$ of the total moisture [42]. The overall process product yield was $\sim 56 \%$ of the total input mass in terms of valuable outputs such as distillate, isotropic pitch, char, and 
pyrolytic gas resulting from the low liquefaction process inefficiency and emissions. The reactor outputs are distilled and separated in a distillation column to obtain final products as distillate, isotropic pitch, etc.

The Shenhua, China DCL technology is currently used for manufacturing hydrocarbon liquids such as gasoline and diesel at the estimated breakeven costs for this facility of $\$ 35-\$ 40$ per barrel of oil (Figure 6). [43]. Bituminous coal containing ash and moisture at 3.34 and $6.7 \mathrm{wt} \%$, respectively, from the Shengfu coal mine was procured and used in this analysis [44]. The facility produced its own on-site electricity through combustion of coal. Hydrogen gas consumption was $6.5 \mathrm{wt} \%$ of ash-free coal [45].

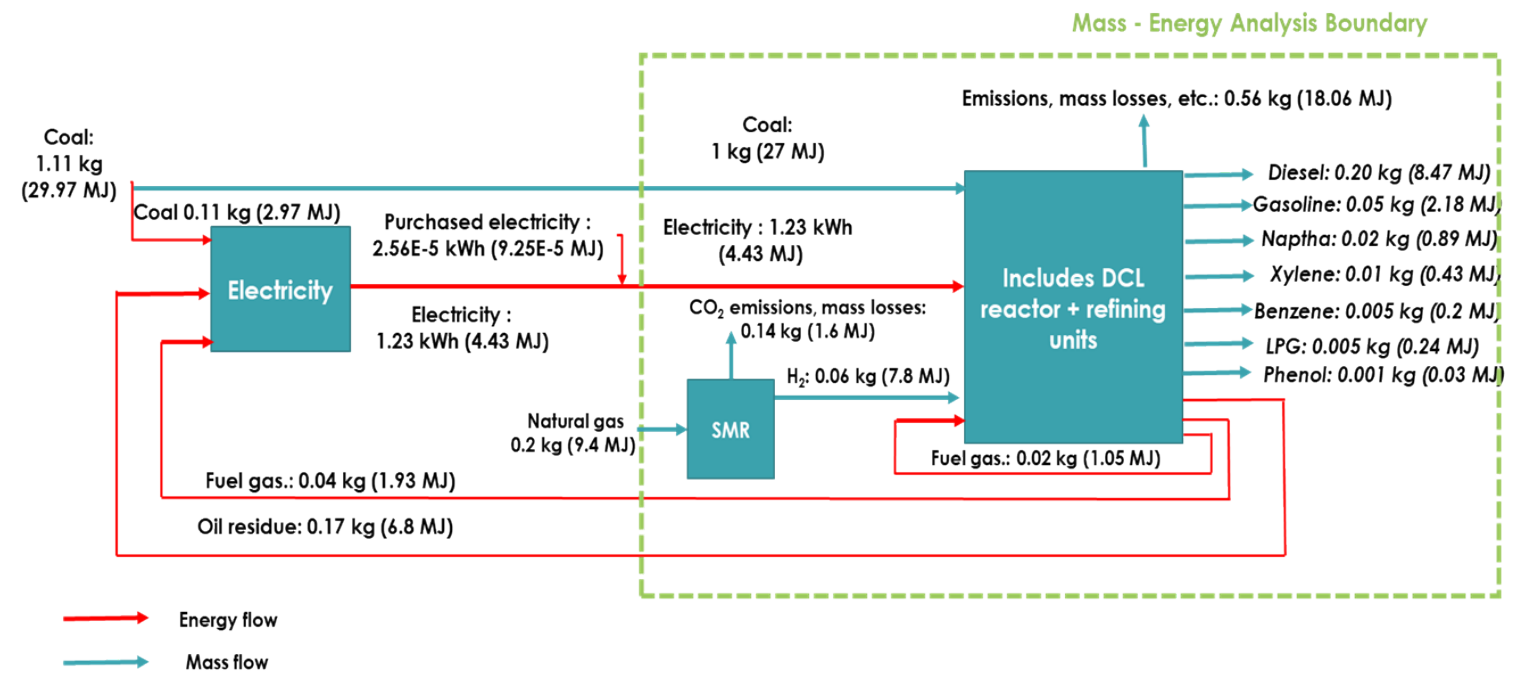

Figure 6. Mass energy balance of Shenhua, China DCL plant.[2].

The technology used in the Shenhua plant was developed by Hydrocarbon Technologies in 1997. The process used two back-mixed reactor stages with a proprietary iron catalyst, operated at 170 bar and $400^{\circ} \mathrm{C}-460^{\circ} \mathrm{C}$ [45].The Shenhua process plant differs from the RC process in that it mainly focuses on producing hydrocarbon liquids while the latter process mainly generates pitch. Therefore, the distillation in refining units of Shenhua plant separate different hydrocarbon liquids (e.g., gasoline, diesel, etc.) whereas the distillation columns of the RC process mainly separate isotropic pitch and distillate.

The NETL-DOE process comprised a technology developed by Headwaters CTL in 2010 and comprised a two-stage hydro liquefaction reactor with a dispersed iron catalyst. The main objective of the process was to produce transportation fuels from bituminous coal [3]. The process uses a hydrocracking technology based on the ebullated-bed reactor system that fluidizes the catalyst bed by the rising $\mathrm{H}_{2}$, feed oil, and recycled reactor liquid. Similar to the Shenhua process described earlier, the NETL-DOE process also uses a two-stage reactor system and mainly produces hydrocarbon liquids as opposed to pitch produced by RC. The hydrocarbon yields (C3 and higher) were $66 \mathrm{wt} \%$ from coal (moist, ash-free basis). The two-stage hydro-liquefaction unit was operated at $460{ }^{\circ} \mathrm{C}$ and $180 \mathrm{bar}$.

Figure 7 shows the NETL-DOE process flow based on the mass and energy (net calorific value basis) balances for the liquefaction unit (DCL unit) and refining section. Coal conversion process to main distillate products, such as liquefied petroleum gas, gasoline, and diesel, is illustrated in Figure 7. Of all the distillate products, most of the inputted energy resided in gasoline followed by kerosene, diesel, gas oil, and liquefied petroleum gas (in descending order). Owing to similar net calorific values $(\mathrm{MJ} / \mathrm{kg}$, Error! Reference source not found.), the mass content of inputted raw materials within distillate products also showed a similar trend as its energy content, with the largest mass output in gasoline followed by kerosene, diesel, gas oil, and liquefied petroleum gas (in descending order). 


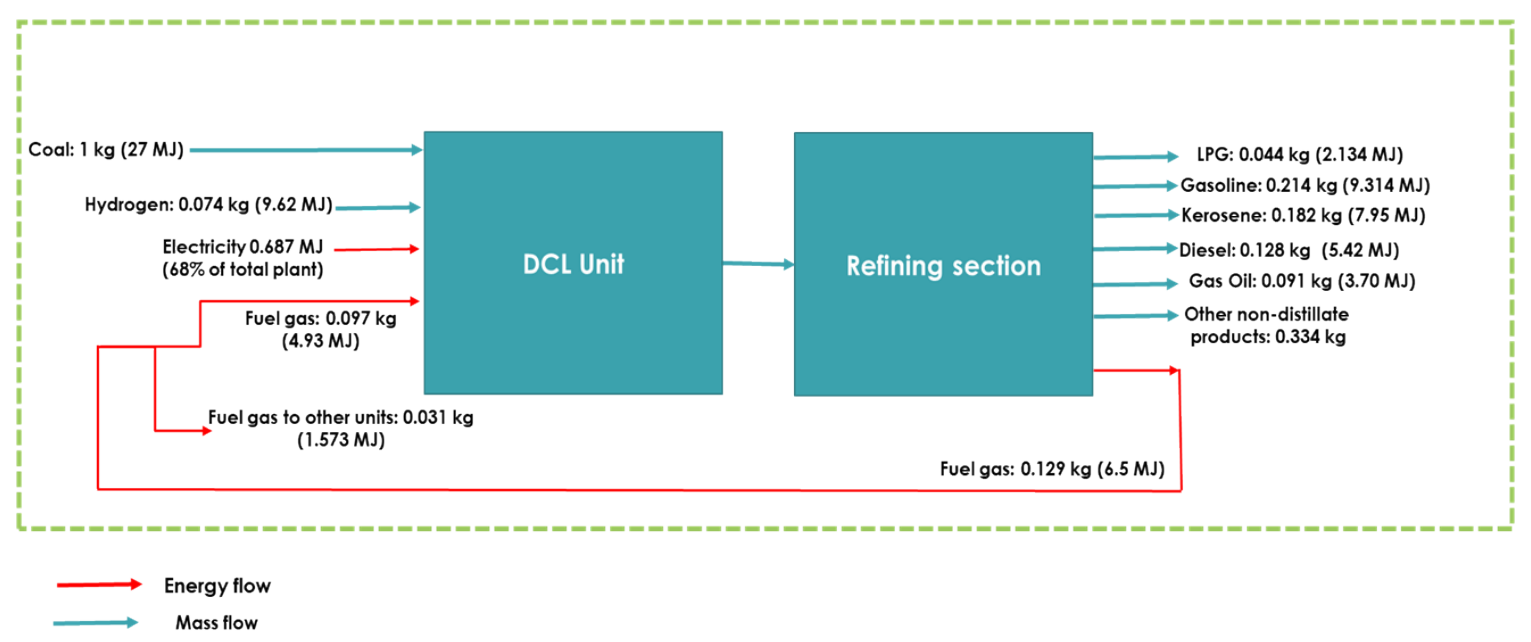

Figure 7. Mass-energy balances of NETL-DOE DCL process [3].

An alternative solvent extraction process for the DCL being developed at the University of Kentucky based on the earlier work [46] differs from the three aforementioned DCL processes in its main output being tar pitch from raw coal in lieu of hydrocarbon liquids such as gasoline, kerosene, etc.

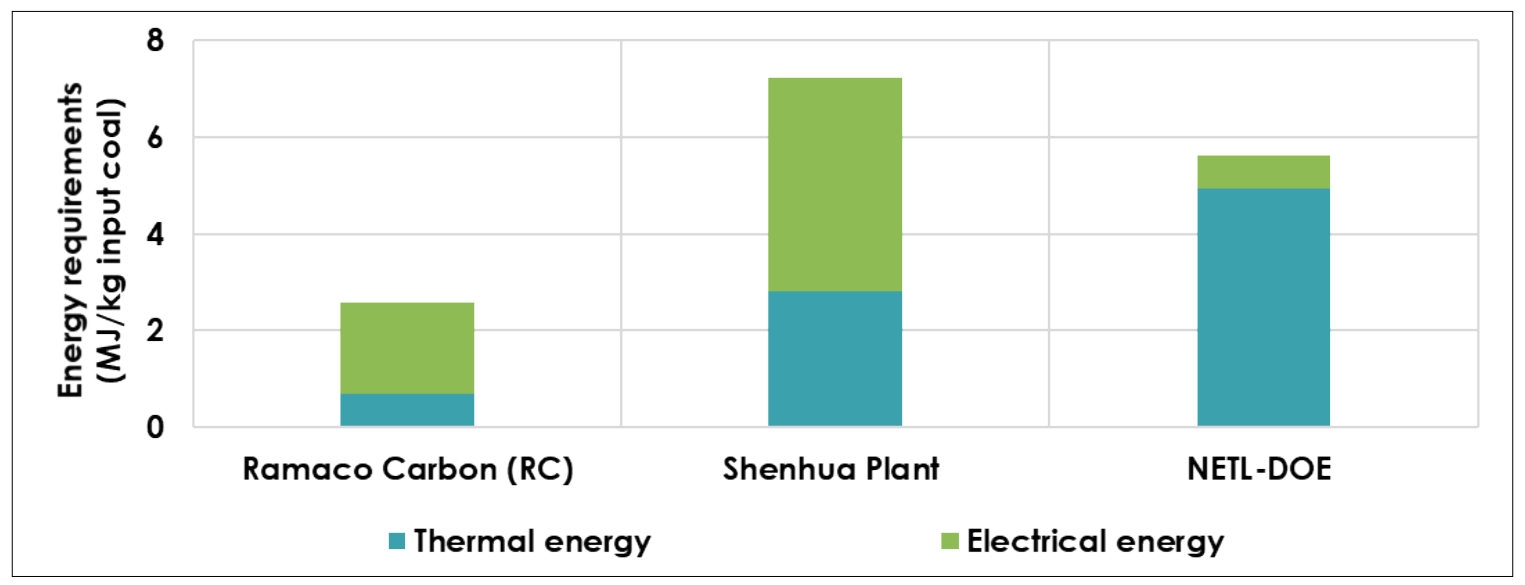

Figure 8. Energy demand (MJ) of different DCL processes per unit mass of input coal (kg).

Mass and energy balances were also estimated for DCL processes available in the literature. Figure 6 and Figure 7 depict the mass energy balances for Shenhua and NETL-DOE processes, respectively. The mass and energy efficiencies of these DCL processes were compared with RC process to determine RC process performance. Following are the main differences between RC process and other DCL processes:

1. The RC process's main output was isotropic pitch. However, the Shenhua plant and NETL-DOE processes produced hydrocarbon liquids such as gasoline and diesel in lieu of isotropic pitch.

2. None of the DCL processes necessitated the use of an external thermal energy source for the liquefaction unit. The thermal energy requirement was completely met through combustion of recycled product gas such as pyrolytic gas (for the RC process) or fuel gas (for the NETL-DOE process).

3. The energy efficiency comparison of the RC process with other DCL processes was estimated by using the energy recovered in commercially valuable products (e.g., pitch, gasoline, diesel) as a share 
of input raw materials (coal and $\mathrm{H}_{2}$ ) based on their mass balance estimates as shown in Figure 5,6 and 7 as follows:

Output Mass Efficiency (\%)

$$
\begin{aligned}
& =\left(\frac{\text { Mass of all inputs }- \text { Mass of emissions, losses exiting the analysis boundary }}{\text { Mass of all inputs entering the process }}\right. \\
& ) \times 100
\end{aligned}
$$

\section{Output Energy Ef ficiency (\%)}

$$
=\left(\frac{\text { Energy of all inputs }- \text { Energy of emissions, losses exiting the process }}{\text { Energy of all inputs entering the process }}\right) \times 100
$$

The mass and energy efficiency comparison of three DCL processes (as shown in Table 5) indicates differing mass efficiencies (in terms of moisture, ash-free coal (maf)). The mass efficiencies of RC and the Shenhua plant processes were similar around 53\%, but for NETL-DOE process, the efficiency was higher at $66 \%$ owing to higher mass conversion attainable in the process. The mass conversion efficiency to distillate products ( $\mathrm{C} 3$ products and higher) was higher in the case of the NETL-DOE process because of the use of a more advanced and recent liquefaction technology - the ebullated-bed reactor system. This system overcomes issues with fixed bed catalyst reactor system (used in the Shenhua process) and increases the conversion yield through higher catalyst activity. This system, owing to its fluidized system, has steady catalyst activity and reaction selectivities insensitive to temperature changes as was observed in the case of a fixed bed reactor system used in the Shenhua process that resulted in in declining catalyst activity and conversion [47]. Despite its higher mass efficiency, the energy efficiency of NETL-DOE process was lower than the RC process but relatively higher than the Shenhua plant process as shown in Table 5.

Table 5. Mass and energy efficiency of direct coal conversion of valuable commercial products.

\begin{tabular}{|c|l|c|c|}
\hline $\begin{array}{c}\text { Sr. } \\
\text { no. }\end{array}$ & \multicolumn{1}{|c|}{ Process } & $\begin{array}{c}\text { Output mass efficiency } \\
\text { (\%) }\end{array}$ & $\begin{array}{c}\text { Output energy efficiency } \\
\text { (\%) }\end{array}$ \\
\hline 1 & RC (includes DCL + refining units) & $55.6 \%$ & $87.4 \%$ \\
\hline 2 & $\begin{array}{l}\text { Shenhua (includes DCL + refining units)- } \\
\text { only distillate products (C3 and above) }\end{array}$ & $50.1 \%$ & $67.4 \%$ \\
\hline 3 & $\begin{array}{l}\text { NETL-DOE (includes DCL + refining } \\
\text { units)_only distillate products (C3 and } \\
\text { above) }\end{array}$ & $65.9 \%$ & $76.4 \%$ \\
\hline
\end{tabular}

The output energy efficiency of the DCL-based RC process is the highest among the three DCL processes. The pitch-based manufacturing process (i.e., RC) appears to be more energy efficient compared with the remaining two transportation fuel output-based processes but possesses mass efficiency that lies between the other two transportation fuel-based DCL processes. Because transportation fuels possess a lower $\mathrm{C} / \mathrm{H}$ ratio than pitch, the energy process efficiencies decrease with the additional lower mass $\mathrm{H}_{2}$ to coal. Furthermore, the differences seem significantly larger for energy efficiency compared with mass efficiency.

The energy demand (thermal and electrical) normalized on a per unit mass of input raw coal basis was estimated for the three direct coal conversion technologies as shown in Figure 8 based on assumptions in cases of unavailable data. The thermal energy demand data for Shenhua process were assumed to be 
average values of the two other DCL processes (RC and NETL-DOE). Owing to differences in manufacturing technology, the energy demands were different for the DCL processes. The energy demand of Shenhua plant was observed to be the highest at $7.24 \mathrm{MJ} / \mathrm{kg}$ input coal because of higher electrical demand than any other DCL processes. The thermal energy demand of all three DCL processes was met internally through the combustion of recycled product gas such as fuel gas or pyrolytic gas. The pitch-based process (i.e., RC) seemed to be more energy efficient, and the largest share of its energy footprint was due to electricity use. On the other hand, the two hydrocarbon fuels-based processes are relatively energy-intensive. The Shenhua plant total energy demand was the highest and more than $61 \%$ of the total demand was met by electricity. From an energy standpoint, the RC process appears to be the most efficient among the three DCL processes considered here.

\subsection{PITCH MANUFACTURING EMBODIED ENERGY}

The embodied energy estimates of two pitch manufacturing processes, $\mathrm{RC}$ and conventional coke manufacturing, were made using the on-site processing estimates (as discussed) in addition to energy associated with the bill of materials used in the manufacturing process. Embodied energy can be defined as the entire energy associated with the manufacturing of a product that comprises energy consumed in each stage of a product lifecycle beginning from raw material acquisition, processing, manufacturing, transportation, and distribution. Embodied energy is one of the widely used for the life cycle energy and environmental impact analysis.

The embodied energy estimates per unit mass of desired product pitch manufacturing for two different production processes were made based on the following information and shown in Figure 9.

1. Embodied energy (MJ) contributions of individual raw material inputs were estimated based on the respective input materials' embodied energy $(\mathrm{MJ} / \mathrm{kg})$ and the material consumption value $(\mathrm{kg})$. The embodied energy contributions of all input raw materials were aggregated to determine the net total embodied energy of raw materials.

2. The net input embodied energy was allocated to each final product based on each product's respective net heating value. In prior literature studies, the allotment of embodied energy of a product was done based on the product of mass and its commercial [48] or net heating value [49].

3. Based on mass and embodied energy of products, the mass specific embodied energy $(\mathrm{MJ} / \mathrm{kg}) \mathrm{was}$ computed for each product.

Calculate net input embodied energy estimated based on

respective materials' mass $(\mathrm{kg})$ and embodied energy values (MJ/kg).
Allocate net input embodied energy (MJ) to each product based on respective component's net heating values.
Compute mass specific

embodied energy (MJ/kg) of each product.

Figure 9. Pitch carbon fiber manufacturing embodied energy calculation methodology. 


\subsection{CONVENTIONAL METALLURGICAL COKE MANUFACTURING PROCESS}

Most commercial coal tar pitch is produced today as a by-product of the coke manufacturing process. Therefore, this process was chosen as the baseline reference for a comparison with the ongoing development of the RC process. The material and energy balance of the coke-making process was estimated based on literature studies that produced $1 \mathrm{~kg}$ of isotropic pitch [49], [50]. The pitch production process is conventionally conducted via two major steps. Coal tar gets produced in the first step and gets subsequently distilled in the second step to produce isotropic pitch. The material and embodied energy input distribution of both these process steps is shown in Table 6 and Table 7 respectively. In case of coke manufacturing process, nearly all the input embodied energy was observed to be sourced from coal whereas on-site processing energy (i.e., electricity, steam) contributed less than $1 \%$ of the total input embodied energy. A high share of coal energy to the coke manufacturing indicates a strong dependence of the coal type and its energy content. Similar to the coke manufacturing process, most of the input embodied energy in coal tar distillation process was observed to be sourced from coal tar as the on-site processing energy (i.e., natural gas) requirement was revealed to be minimal.

Table 6. Embodied energy of traditional coke manufacturing process.

\begin{tabular}{|c|l|l|c|c|}
\hline $\begin{array}{c}\text { Sr. } \\
\text { no. }\end{array}$ & \multicolumn{1}{|c|}{ Input component } & \multicolumn{1}{|c|}{ Amount } & $\begin{array}{c}\text { Unit embodied } \\
\text { energy }\end{array}$ & Net embodied energy (MJ) \\
\hline 1 & Coal & $57.14 \mathrm{~kg}$ & $32 \mathrm{MJ} / \mathrm{kg}$ & $1,828.48$ \\
\hline 2 & Electricity & $1.48 \mathrm{kWh}$ & $9 \mathrm{MJ} / \mathrm{kWh}$ & 13.32 \\
\hline 3 & Steam & $10.85 \mathrm{~kg}$ & $3.3 \mathrm{MJ} / \mathrm{kg}$ & 0.89 \\
\hline \multicolumn{4}{|l}{} & $\mathbf{1 8 4 2 . 6 9}$ \\
\hline
\end{tabular}

Table 7 Embodied energy of inputs of coal tar distillation process.

\begin{tabular}{|c|l|l|c|c|}
\hline $\begin{array}{c}\text { Sr. } \\
\text { no. }\end{array}$ & \multicolumn{1}{|c|}{ Input component } & \multicolumn{1}{|c|}{ Amount } & $\begin{array}{c}\text { Unit embodied } \\
\text { energy }\end{array}$ & Net embodied energy (MJ) \\
\hline 1 & Coal tar & $2 \mathrm{~kg}$ & $38.37 \mathrm{MJ} / \mathrm{kg}$ & 76.75 \\
\hline 2 & $\begin{array}{l}\text { Natural gas (coal tar } \\
\text { distillation) }\end{array}$ & $0.025 \mathrm{~kg}[51]$ & $57.34 \mathrm{MJ} / \mathrm{kg}$ & 1.43 \\
\hline \multicolumn{2}{|l|}{ Total } & $\mathbf{7 8 . 1 8}$ \\
\hline
\end{tabular}

Because the main objective of the process is coke manufacturing used in the integrated steel making, coke contributed to $\sim 80 \%$ of the total output mass, while the share was only $3.51 \%$ for the by-product coal tar of interest as shown in Table 8. Total embodied energy distribution among four major outputs was determined based on each component's unit net heating value $(\mathrm{MJ} / \mathrm{kg})$. The distribution showed a strong dependence on the product mass as the products possessed nearly similar mass specific embodied energy values $(\mathrm{MJ} / \mathrm{kg}$ ) (Table 8 ). For instance, owing to high mass production of coke, nearly $72 \%$ of the input embodied energy was apportioned to it while low shares were attributed to other products because of their lower output mass. Owing to their relatively lower mass production values, the shares of net input embodied energy attributed to other by-products such as coke oven gas, coal tar, and benzene were observed to be low at $22 \%, 4.16 \%, 1.27 \%$, respectively.

Table 8. Mass and embodied energy breakdown of traditional coke manufacturing outputs.

\begin{tabular}{|c|c|c|c|c|c|c|c|c|}
\hline $\begin{array}{l}\text { Sr. } \\
\text { no. }\end{array}$ & $\begin{array}{c}\text { Output } \\
\text { component }\end{array}$ & $\begin{array}{c}\text { Amount } \\
(\mathbf{k g})\end{array}$ & $\begin{array}{c}\text { Mass } \\
(\%)\end{array}$ & $\begin{array}{c}\text { Component } \\
\text { specific }\end{array}$ & $\begin{array}{c}\text { Net } \\
\text { heating }\end{array}$ & $\begin{array}{c}\text { Allocation } \\
\text { factor } \\
\text { based on }\end{array}$ & $\begin{array}{c}\text { Input } \\
\text { embodied } \\
\text { energy }\end{array}$ & $\begin{array}{c}\text { Embodied } \\
\text { energy per }\end{array}$ \\
\hline
\end{tabular}




\begin{tabular}{|c|l|l|l|l|l|l|l|l|}
\hline & & & $\begin{array}{c}\text { heating value } \\
\text { (MJ/kg) }\end{array}$ & $\begin{array}{c}\text { value } \\
\text { (MJ) }\end{array}$ & $\begin{array}{c}\text { net heating } \\
\text { value (\%) }\end{array}$ & $\begin{array}{c}\text { allocation } \\
\text { (MJ) }\end{array}$ & $\begin{array}{c}\text { unit mass } \\
\text { (MJ/kg) }\end{array}$ \\
\hline 1 & $\begin{array}{l}\text { Metallurgical } \\
\text { coke }\end{array}$ & 45.71 & 80 & $28.43[52]$ & $1,299.53$ & 72.43 & $1,334.66$ & 29.15 \\
\hline 2 & Coke oven gas & 8.85 & 15.5 & $44.95[52]$ & 397.80 & 22.12 & 407.91 & 46.09 \\
\hline 3 & Coal tar & 2 & 3.51 & 37 & 74 & 4.18 & 76.75 & 38.37 \\
\hline 4 & Benzene & 0.57 & 0.99 & $40[40]$ & 22.8 & 1.27 & 23.37 & 41.01 \\
\hline \multicolumn{2}{|l|}{ Total } & $\mathbf{5 7 . 1 3}$ & $\mathbf{1 0 0}$ & - & $\mathbf{1 , 7 9 4 . 1 3}$ & $\mathbf{1 0 0}$ & $\mathbf{1 , 8 4 2 . 6 9}$ & - \\
\hline
\end{tabular}

Despite the large differences in the allocated values of the input embodied energy (MJ) for each product, the mass specific embodied energy value $(\mathrm{MJ} / \mathrm{kg})$ of each product was similar to the respective product's specific net heating value $(\mathrm{MJ} / \mathrm{kg})$. For instance, coke's mass specific embodied energy value at $29.15 \mathrm{MJ} / \mathrm{kg}$ was similar to its net heating value at $28.43 \mathrm{MJ} / \mathrm{kg}$ as shown in Table 8 . This is because the total input embodied energy value $(1,844.43 \mathrm{MJ})$ was similar to the total net heating value of all products $(1,798.29 \mathrm{MJ})$. The calculation methodology (Figure 9) eventually assigns the mass specific embodied energy to each product based on a common proportionality ratio (sum of embodied energy/sum of net heating values) and the respective net product heating value. The larger the proportionality ratio, the larger the observed difference was between the product net heating value and its respective embodied energy. Since the proportionality constant was almost unity in the case of coke manufacturing, the mass specific embodied energy values were similar to their respective net calorific values of product species. The embodied energy of coke obtained in this work at $29 \mathrm{MJ} / \mathrm{kg}$ was similar to the literature value of 31$35 \mathrm{MJ} / \mathrm{kg}$ [53].

The mass and embodied energy breakdown of the outputs of coal tar distillation process is illustrated in Table 9. Nearly half of the coal tar tar's input embodied energy was apportioned to isotropic pitch owing to its relatively higher mass yield than other products. The pitch mass specific embodied energy for the coal tar distillation process was estimated to be $37.88 \mathrm{MJ} / \mathrm{kg}$.

Table 9 Mass and embodied energy breakdown of coal tar distillation outputs.

\begin{tabular}{|l|l|l|l|l|l|l|l|l|}
\hline $\begin{array}{l}\text { Sr. } \\
\text { No. }\end{array}$ & $\begin{array}{l}\text { Output } \\
\text { component }\end{array}$ & $\begin{array}{l}\text { Amount } \\
(\mathrm{kg})\end{array}$ & $\begin{array}{l}\text { Mass } \\
(\%)\end{array}$ & $\begin{array}{l}\text { Component } \\
\text { specific } \\
\text { heating } \\
\text { value } \\
(\mathrm{MJ} / \mathrm{kg})\end{array}$ & $\begin{array}{l}\text { Net } \\
\text { heating } \\
\text { value } \\
(\mathrm{MJ})\end{array}$ & $\begin{array}{l}\text { Allocation } \\
\text { factor } \\
\text { based on } \\
\text { net } \\
\text { heating } \\
\text { value }(\%)\end{array}$ \\
$\begin{array}{l}1 . \\
\text { Isotropic Pitch }\end{array}$ & 1.0 & 50.50 & $\begin{array}{l}\text { Input } \\
\text { embodied } \\
\text { energy } \\
\text { allocation } \\
(\mathrm{MJ})\end{array}$ & $\begin{array}{l}\text { Embodied } \\
\text { energy } \\
\text { per unit } \\
\text { mass } \\
(\mathrm{MJ} / \mathrm{kg})\end{array}$ \\
\hline 2. & Coal Tar Oil & 0.74 & 37.37 & $40.75[40]$ & 37.5 & 48.46 & 37.88 & 37.88 \\
\hline 3. & Naphthalene & 0.2 & 10.10 & $40.48[40]$ & 8.09 & 10.45 & 7.82 & 39.1 \\
\hline 4. & $\begin{array}{l}\text { Benzene- } \\
\text { toluene-xylene }\end{array}$ & 0.04 & 2.03 & $40.75[40]$ & 1.63 & 2.12 & 2.01 & 50.25 \\
\hline Total & & & & & 77.37 & 100 & 78.18 & - \\
\hline
\end{tabular}




\subsection{EMBODIED ENERGY OF RC COAL PITCH TAR MANUFACTURING}

The material and energy balances of the previously discussed RC process were used for an embodied energy balance estimation per kilogram of isotropic pitch manufacturing. Based on the input material and its embodied energy content, the total input embodied energy distribution of 212.4 MJ was conducted for the $\mathrm{RC}$ catalytic hydrogenation reactor process as shown in Table 10. The embodied energy distribution of input raw materials revealed that nearly $90 \%$ of the total input embodied energy share was attributed to input materials (i.e., coal and natural gas), while the remaining $10 \%$ of the energy demand (i.e., natural gas input to $\mathrm{H}_{2}$ production and electricity) was due to meet process energy requirements Within materials, most of the embodied energy contribution (nearly $80 \%$ ) was attributed to coal owing to its relatively high material amount usage over other input material, i.e. Natural gas. Consequently, the contribution of natural gas to total input embodied energy was relatively low owing to low material contribution despite possessing nearly twice the component unit embodied energy $(\mathrm{MJ} / \mathrm{kg})$ as that of coal. A similar observation was also made in the case of on-site energy contributions to input embodied energy; the high share was due to electricity despite its lower component unit embodied energy, 22.23 MJ with a lower energy content of $9 \mathrm{MJ} / \mathrm{kWh}$. Similarly, natural gas' contribution to net input embodied energy was only $5.44 \mathrm{MJ}$, due to higher component unit embodied energy of $57.34 \mathrm{MJ} / \mathrm{kg}$ but at a input consumption amount $(0.095 \mathrm{~kg})$, as illustrated in Table 10.

Table 10. Coal pitch tar input embodied energy distribution of the $\mathrm{RC}$ process (includes reactor and refining units).

\begin{tabular}{|c|l|c|c|c|}
\hline $\begin{array}{c}\text { Sr. } \\
\text { no. }\end{array}$ & \multicolumn{1}{|c|}{ Input component } & Amount & $\begin{array}{c}\text { Component unit } \\
\text { embodied energy }\end{array}$ & $\begin{array}{c}\text { Net embodied energy } \\
\text { (MJ) }\end{array}$ \\
\hline 1 & Coal & $4.76 \mathrm{~kg}$ & $32 \mathrm{MJ} / \mathrm{kg}$ & 152.32 \\
\hline 2 & Electricity & $2.47 \mathrm{kWh}$ & $9 \mathrm{MJ} / \mathrm{kWh}$ & 22.23 \\
\hline 3 & $\begin{array}{l}\text { Natural gas (as material input to } \\
\text { produce } \mathrm{H}_{2} \text { ) }\end{array}$ & $0.564 \mathrm{~kg}$ & $57.34 \mathrm{MJ} / \mathrm{kg}$ & 32.34 \\
\hline 4 & $\begin{array}{l}\text { Natural gas (as energy input to } \\
\text { produce } \mathrm{H}_{2} \text { ) }\end{array}$ & $0.095 \mathrm{~kg}$ & $57.34 \mathrm{MJ} / \mathrm{kg}$ & 5.44 \\
\hline \multicolumn{2}{|l|}{ Total } & $\mathbf{2 1 2 . 4}$ \\
\hline
\end{tabular}

The mass distribution of the RC process output stream is illustrated in Table 11 along with embodied energy and net heating values [54]. It should be noted that the products stated in Table 9 are the final products emanating from the process that includes reactor and refining (distillation) units as illustrated in Figure 5. The reactor products get subsequently distilled to produce isotropic pitch. Net heating values have been used for the allocation basis of total input embodied energy among various products. The embodied energy allocation among major reactor products includes distillate, isotropic pitch, pyrolytic gas, and char. In comparison with the total energy input between the two pitch fiber manufacturing pathways ( $1 \mathrm{~kg}$ pitch basis), the RC pathway is $\sim 13$ times and $\sim 9$ times less intensive in terms of input total net heating value and input embodied energy, respectively, than the conventional coke manufacturing as depicted in Tables 7 and 9. The total amount of products obtained in the former pathway is thereby also smaller with higher specific product heating values than in the latter pathway. Estimated RC unit product embodied energies were mostly in the range of 40-60 MJ/kg compared with the coke manufacturing value of $40 \mathrm{MJ} / \mathrm{kg}$. However, there are only two major amounts of net heating value products: metallurgical coke and coke oven gas with a combined share $\sim 94 \%$ of the total in the latter case. In terms of net heating value, only three out of four major final products in the RC process possess most of the share of embodied value of products. Overall, the resulting unit pitch embodied energy of RC manufacturing is estimated to be $\sim 56 \mathrm{MJ} / \mathrm{kg}$ compared with $\sim 39 \mathrm{MJ} / \mathrm{kg}$ by coke manufacturing. 
Table 11. Embodied energy distribution of the process products of RC process (includes reactor and refining units)

\begin{tabular}{|l|l|c|c|c|c|c|c|c|}
\hline $\begin{array}{c}\text { Sr. } \\
\text { no. }\end{array}$ & $\begin{array}{c}\text { Output } \\
\text { component }\end{array}$ & $\begin{array}{c}\text { Amount } \\
\mathbf{( k g )}\end{array}$ & $\begin{array}{c}\text { Mass } \\
\mathbf{( \% )}\end{array}$ & $\begin{array}{c}\text { Unit } \\
\text { component } \\
\text { heating } \\
\text { value } \\
\mathbf{M J J} / \mathbf{k g})\end{array}$ & $\begin{array}{c}\text { Total } \\
\text { component } \\
\text { net heating } \\
\text { value (MJ) }\end{array}$ & $\begin{array}{c}\text { Total energy } \\
\text { allocation } \\
\text { factor based } \\
\text { on net heating } \\
\text { value (\%) }\end{array}$ & $\begin{array}{c}\text { Allocation } \\
\text { of input } \\
\text { embodied } \\
\text { energy } \\
\text { (MJ) }\end{array}$ & $\begin{array}{c}\text { Embodied } \\
\text { energy } \\
\text { (MJ/kg) }\end{array}$ \\
\hline 1 & Isotropic Pitch & 1 & 15.72 & $37.5[50]$ & 37.5 & 26.26 & 55.79 & 55.79 \\
\hline 2 & Distillate & 1.57 & 24.68 & $41.24[55]$ & 64.74 & 45.33 & 96.27 & 61.31 \\
\hline 3 & Pyrolytic gas & 0.57 & 8.96 & $8[56]$ & 4.56 & 3.19 & 6.77 & 11.87 \\
\hline 4 & Char & 1.28 & 20.12 & $28.13[57]$ & 36 & 25.21 & 53.56 & 41.84 \\
\hline 5 & $\begin{array}{l}\text { Mass losses, } \\
\text { emissions }\end{array}$ & 1.94 & 30.50 & - & - & - & - & - \\
\hline Total & & $\mathbf{6 . 3 6}$ & $\mathbf{1 0 0}$ & - & $\mathbf{1 4 2 . 8}$ & $\mathbf{1 0 0}$ & $\mathbf{2 1 2 . 4}$ & - \\
\hline
\end{tabular}

\subsection{COMPARISON OF PITCH EMBODIED ENERGY MANUFACTURING}

Prior to allocating embodied energy between products, the highest input embodied energy to produce $1 \mathrm{~kg}$ of pitch was revealed in the case of coke manufacturing at $1,844.43 \mathrm{MJ} / \mathrm{kg}$ and was nearly 9 times that of RC process (Figure 10). The embodied energy of coke manufacturing was high because of a low coal mass conversion yield of $2 \%$. The lower the conversion yield, the higher the demand of raw materials was to produce pitch, thereby contributing to high raw material input embodied energy. The embodied energy values depicted in Figure 10 is if all the embodied energy of raw materials are allocated to only $1 \mathrm{~kg}$ of pitch.

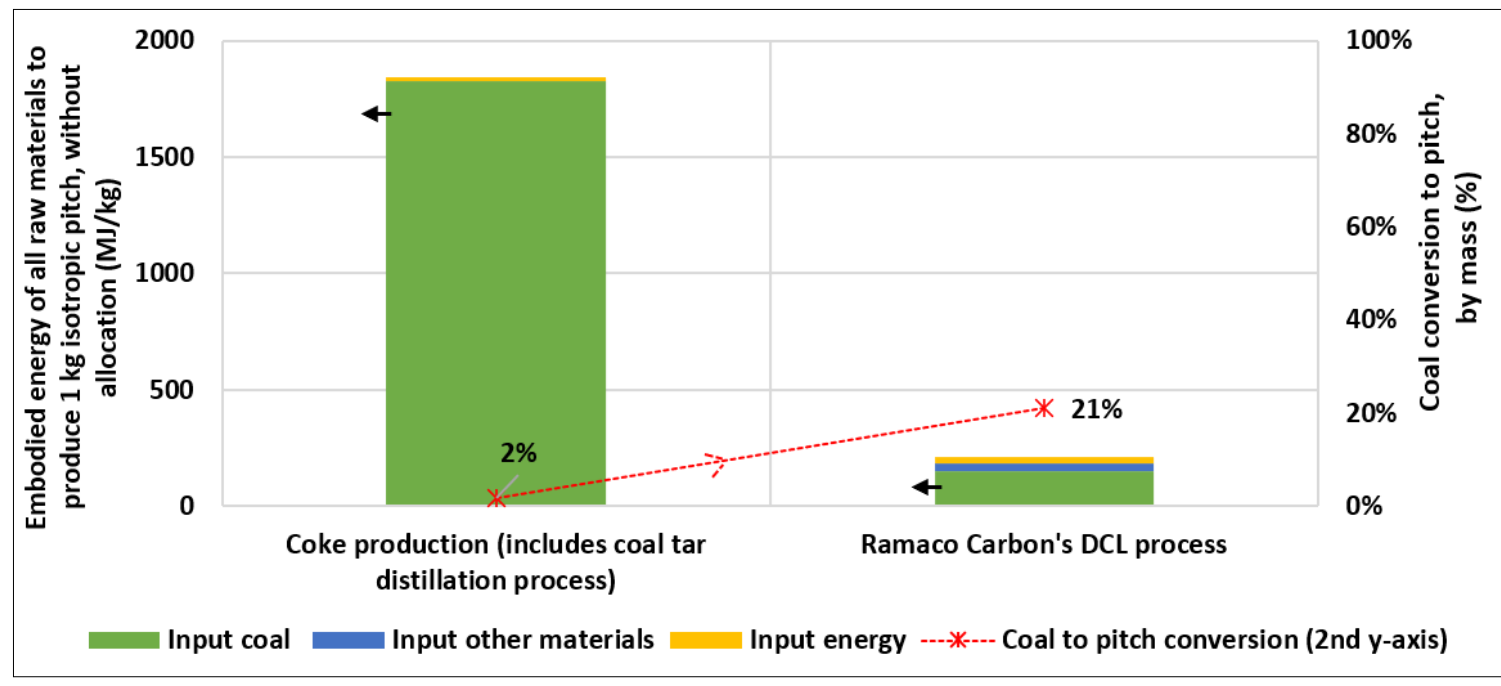

Figure 10. Comparison of net input embodied energy per $1 \mathrm{~kg}$ of pitch via two different processes (without allocation of embodied energy between products).

After allocating the input embodied energy between products, the embodied energy of producing $1 \mathrm{~kg}$ of pitch varied widely with respect to manufacturing process as illustrated in Figure 11. Despite the highest input embodied energy of coke manufacturing process at nearly 1,844.43 MJ (Figure 10), $1 \mathrm{~kg}$ of pitch 
produced from it possessed the lowest embodied energy at 39 MJ (Figure 11). Pitch produced from coke manufacturing process possessed lowest embodied energy as the input contributions from other materials and on-site energy were negligible owing to their low usage. However, these contributions existed in the case of the RC process and were nearly $16 \%$ of the pitch embodied energy.

In the two processes, the maximum embodied energy contribution to pitch resulted from coal with a similar value of $38 \mathrm{MJ} / \mathrm{kg}$ of pitch as observed in Figure 11. This suggests that the coal contribution to the embodied pitch energy is insensitive to the manufacturing process. Therefore, regardless of the coal conversion yield, coal will contribute to $\sim 38 \mathrm{MJ} / \mathrm{kg}$ of the pitch embodied energy. For both pitch production processes, the contributions of material and energy were found to be different owing to the difference in mass and energy demands. For instance, the contribution of on-site energy (thermal and electrical) was negligible for the coke manufacturing process (Figure 11). However, for the RC process, the share of on-site energy contribution to the embodied pitch energy was relatively high at $13 \%$. The contributions were high for the RC process because of its relatively high energy demand to produce $1 \mathrm{~kg}$ of pitch as depicted in Figure 8.

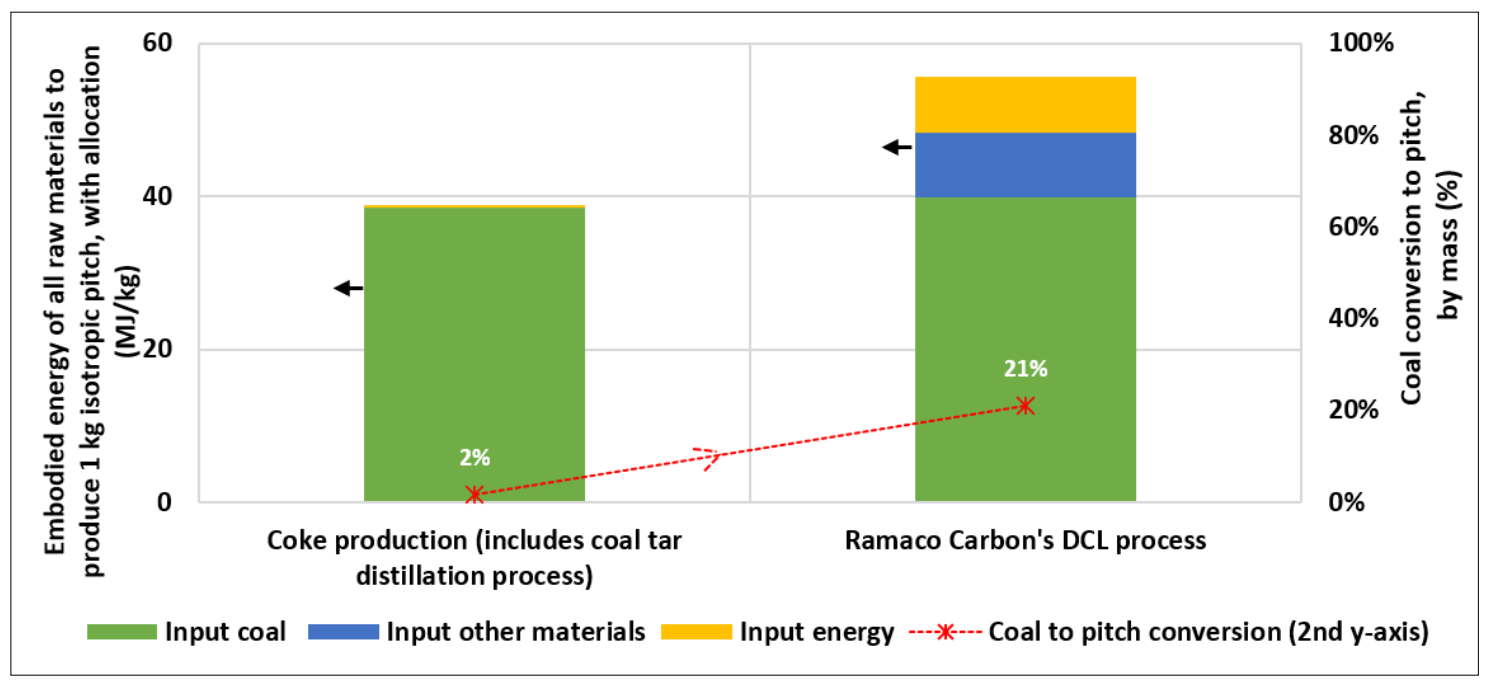

Figure 11. Comparison of unit pitch embodied energy and input material and energy distribution of two pitch manufacturing processes.

\subsection{PITCH CARBON FIBER EMBODIED MANUFACTURING ENERGY}

Cradle-to-gate embodied energy of coal pitch fiber manufacturing was estimated using the materials and on-site energy (bill of materials [BOM]) at three major process steps, starting with the initial conversion of raw coal to mesophase pitch via the RC DCL technology, followed by melt spinning to the mesophase pitch fiber precursor, and finally the multi-step continuous fiber conversion process. Table 12 shows the BOM at three major stages of pitch carbon fiber manufacturing, where the latter two manufacturing stage estimates (i.e., the mesophase pitch precursor and the final pitch fiber conversion) are based on the cost modeling results discussed earlier. Using the BOM embodied energy estimates from the commercial life cycle inventory databases in SimaPro life cycle analysis commercial software, embodied energy by each major process stage was estimated.

Table 12. BOM at three major stages of RC cradle-to-gate coal pitch fiber manufacturing.

\begin{tabular}{|c|c|c|}
\hline Input parameter & Amount & Output embodied energy (MJ/kg) \\
\hline
\end{tabular}




\begin{tabular}{|c|c|c|}
\hline & (per kg of output) & \\
\hline \multicolumn{3}{|c|}{ RC liquefaction output } \\
\hline Bituminous coal & $4.76 \mathrm{~kg}$ & \multirow{3}{*}{230} \\
\hline Natural gas & $37.8 \mathrm{MJ}$ & \\
\hline Electricity & $2.47 \mathrm{kWh}$ & \\
\hline \multicolumn{3}{|c|}{ Mesophase pitch fiber precursor } \\
\hline $\mathrm{RC}$ liquefaction output & $0.35 \mathrm{~kg}$ & \multirow{2}{*}{111} \\
\hline Electricity & $2.79 \mathrm{kWh}$ & \\
\hline \multicolumn{3}{|c|}{ Coal pitch carbon fiber } \\
\hline Mesophase pitch precursor & $1.36 \mathrm{~kg}$ & \multirow{8}{*}{487} \\
\hline Ammonium bicarbonate & $0.01 \mathrm{~kg}$ & \\
\hline Epoxy resin & $0.05 \mathrm{~kg}$ & \\
\hline Nitrogen (Liquid) & $10.2 \mathrm{~kg}$ & \\
\hline Compressed air & $0.103 \mathrm{ft}^{3}$ & \\
\hline Steam & $0.88 \mathrm{~kg}$ & \\
\hline Natural gas & $11.3 \mathrm{ft}^{3}$ & \\
\hline Electricity & $19.5 \mathrm{kWh}$ & \\
\hline
\end{tabular}

Assuming $21 \mathrm{wt} \%$ isotropic yield from the RC DCL liquefaction output followed by $60 \mathrm{wt} \%$ yield of its conversion to the mesophase pitch and melt-spinning into the mesophase pitch precursor for the final pitch carbon fiber manufacturing - results in a $0.13 \mathrm{~kg}$ of raw coal requirement per kilogram of the mesophase pitch for the precursor melt-spinning fiber precursor. An additional energy of $2.24 \mathrm{kWh} / \mathrm{kg}$ of precursor has been estimated for this step from the melt spinning cost modeling as discussed earlier. Similarly, assuming chemical and mechanical yields at the final carbon fiber conversion step of $83 \%$ and $89 \%$, respectively, $1.36 \mathrm{~kg}$ of precursor per kilogram of pitch carbon fiber is necessary. Embodied energy of pitch carbon fiber is estimated to be $487 \mathrm{MJ} / \mathrm{kg}$, significantly increased higher than $80 \mathrm{MJ} / \mathrm{kg}$ due to necessary large amount of precursor and the additional $19.5 \mathrm{kWh} / \mathrm{kg}$ on-site electricity use for the fiber conversion.

Figure 12 shows the comparison of embodied energy estimates for three major carbon fiber manufacturing pathways (i.e., conventional PAN, coke by-product coal pitch, and RC liquefaction coal pitch) at three major levels of processing steps in terms of per kilogram of final carbon fiber. The conventional PAN pathway for carbon fiber pathway energy breakdown of $1,188 \mathrm{MJ} / \mathrm{kg}$ is based on the latest Oak Ridge National Laboratory life cycle analysis using the detailed BOM data as shown in Table 12 for the coal pitch carbon fiber. The contribution of energy at each stage of fiber increases with the use of additional BOM and the process efficiency, and the largest increase occurs at the last fiber conversion stage (i.e., precursor to fiber). A small initial energy difference between the two-pitch fiber raw precursors - $39 \mathrm{MJ} / \mathrm{kg}$ for coke by-product vs. $56 \mathrm{MJ} / \mathrm{kg}$ for the RC liquefaction (as estimated earlier) while maintaining the similar processing in the follow-on two processing steps-results in a slightly higher RC liquefaction final energy of $487 \mathrm{MJ} / \mathrm{kg}$ compared with $472 \mathrm{MJ} / \mathrm{kg}$. A significantly higher $74 \%$ pitch fiber conversion yield results in 2.4 to 2.5 times lower than the conventional $45 \%$ yield PAN fiber energy of 1,188 MJ/kg as shown in Figure 12. 


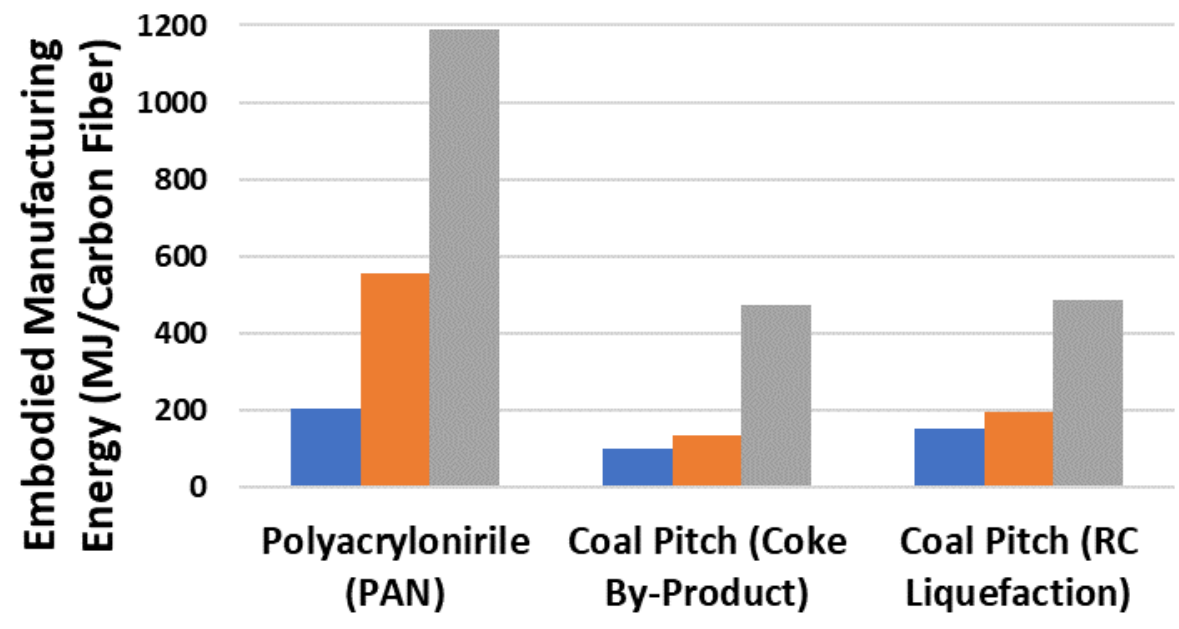

Raw Precursor Final Precursor Carbon Fiber

Figure 12. Comparative conventional and coal pitch carbon embodied energy (MJ/kg of carbon fiber).

\subsection{PITCH CARBON FIBER MANUFACTURING EMISSIONS}

The coal tar pitch manufacturing emissions analysis was considered only for the RC DCL plant by using the facility permissible pollutants emissions information data submitted for its air permit submission to the local government authority in 2019 by Domestic Synthetic Fuels I for a DCL coal to liquids facility [58]. The capacity of the facility was 2,500 US tons of coal per day and primarily produced gasoline, diesel fuel, naphtha, and liquefied petroleum gas. The air permit application of the facility revealed 17 pollutant emissions by the facility. These pollutant values represent the maximum values that can be emitted by the facility manufacturing equipment as estimated by respective manufacturers. This facility was chosen to represent the RC process that produces $1 \mathrm{~kg}$ of pitch per $4.76 \mathrm{~kg}$ of coal with a $21 \%$ conversion yield as shown in Figure 5.

To estimate emissions, the analysis boundary was chosen to include four sections: coal handling, $\mathrm{H}_{2}$ production, H-coal, and utilities as depicted in Figure 13. The H-coal section comprises a technology that liquefies coal to produce pitch that is commercialized by Headwaters Technology Innovation (HTI) Inc. The H-section comprises a two-stage reactor system that liquefies coal to produce transportation liquids and comprises an isothermal ebulliated bed reactor system that facilitates contact among catalyst particles, pulverized coal, and the $\mathrm{H}_{2}$ donor solvent. The catalyst is recirculated with the assistance of a pump. 


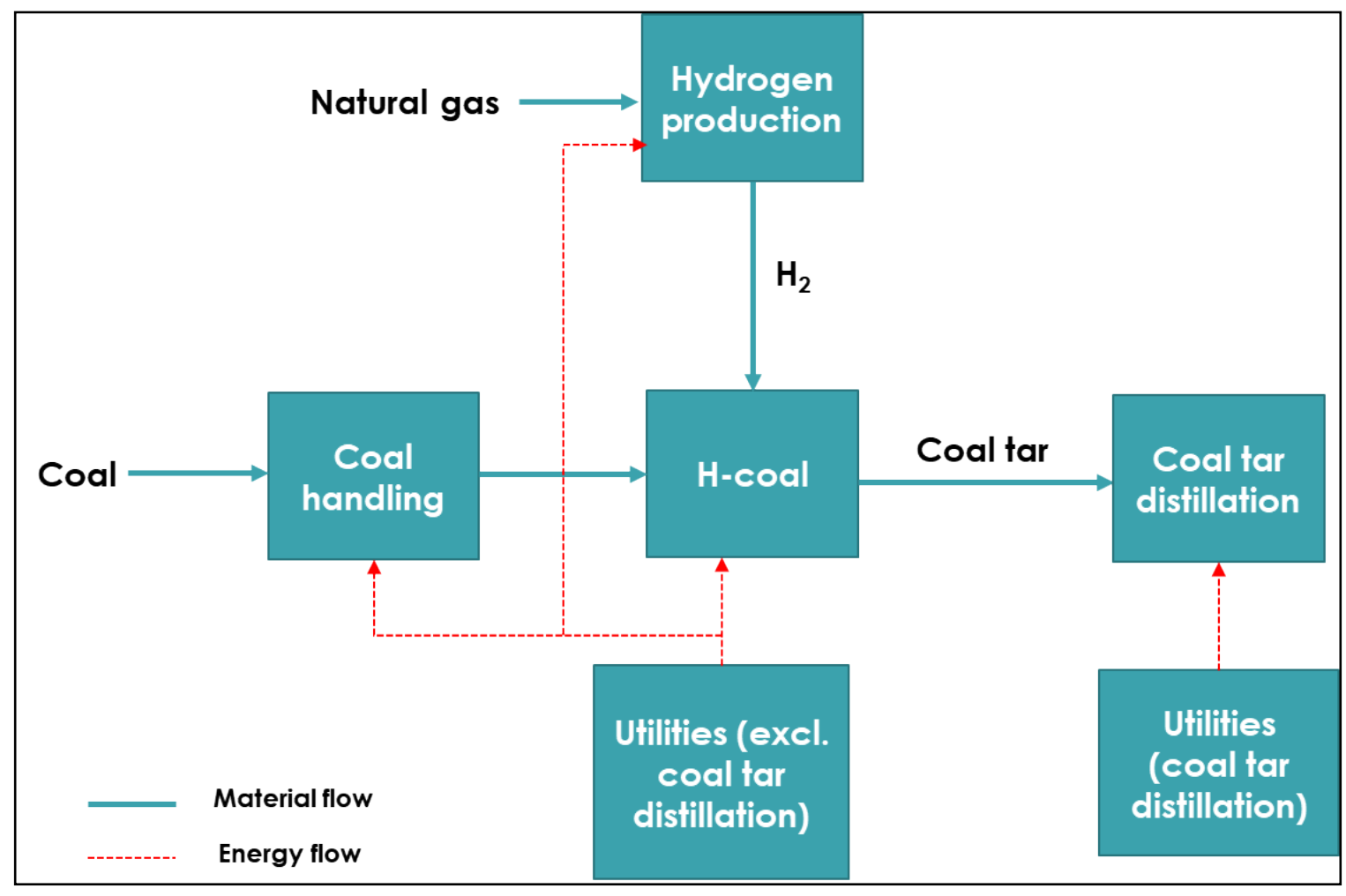

Figure 13. Simplified process flow diagram of DCL facility in West Virginia, USA.

The emissions analysis boundary excluded the facility's product upgrading section that comprises a liquid refining section as the focus of the analysis to estimate emissions for $\mathrm{RC}$ process that produced $1 \mathrm{~kg}$ of pitch in place of liquid fuels. However, since the facility excluded the coal tar distillation unit, the emissions information regarding the coal tar distillation unit was secured from the air permit application submitted by Coopers Creek Chemical Corporation in 2020 [59]. The facility possessed an annual capacity to distill 31,797 metric tonnes of crude coal tar along with crude petroleum tar of 4,279 metric tonnes and decant oil of 12,421 metric tonnes. The facility products include coal tar, coal tar pitch, coal tar pitch cutbacks, distillate oils, and creosote. The air permit application of the coal tar distillation facility revealed maximum values of only six pollutants emitted by the facility, namely SOx, $\mathrm{PM}_{\text {Total }}$ (Particulate matter), volatile organic compounds, TotalHAPs (hazardous air pollutants), NOx, and individual HAPs. The information regarding other pollutant categories was excluded from the analyses because of data unavailability. Typically, NOx and SOx are main pollutants of concern with regard to coal processing facilities, and these pollutants were considered in this analysis.

The four major sections of RC process emissions breakdown by major pollutants per $1 \mathrm{~kg}$ of pitch of the RC process are illustrated in Figure 14. Of all the pollutants, $\mathrm{PM}_{\text {Total }}$ was emitted in the largest quantity. The amount of $\mathrm{PM}_{\text {Total }}$ was revealed to be nearly $2 \mathrm{~g} / \mathrm{kg}$ of pitch with the largest contribution made by coal tar distillation section within the plant at $82 \%$, followed by sections of utilities $(7 \%), \mathrm{H}_{2}$ production $(5 \%)$, coal handling (4\%), and H-coal section (2\%). Despite the reactor (H-coal section) lying at the core of the process plant, its share in the total plant's $\mathrm{PM}_{\text {Total }}$ emissions was observed to be the lowest whereas the coal tar distillation unit's share was revealed to be the highest. This indicates that from a PM Total $_{1}$ standpoint, the coal tar distillation unit was the largest emitter among all units. In the case of pollutant categories such as NOx, volatile organic compounds, and TotalHAPs, the coal tar distillation unit was the largest source of emissions among all plant sections. The pollutant contribution of other plant sections such as $\mathrm{H}$-coal, $\mathrm{H}_{2}$ production, coal handling, and utilities were considerably lower relative to the coal tar distillation unit. This was expected because the coal tar distillation is typically carried out near to $100{ }^{\circ} \mathrm{C}-$ 
$300{ }^{\circ} \mathrm{C}$ with the exact temperature depending on the desired final product distribution. Owing to such a high temperature, the volatile constituents within coal's aromatic structure get emitted. It should be noted that the end product from the coal tar distillation unit is isotropic pitch and therefore emissions from isotropic pitch to mesophase pitch conversion process were not captured in this work due to data unavailability.

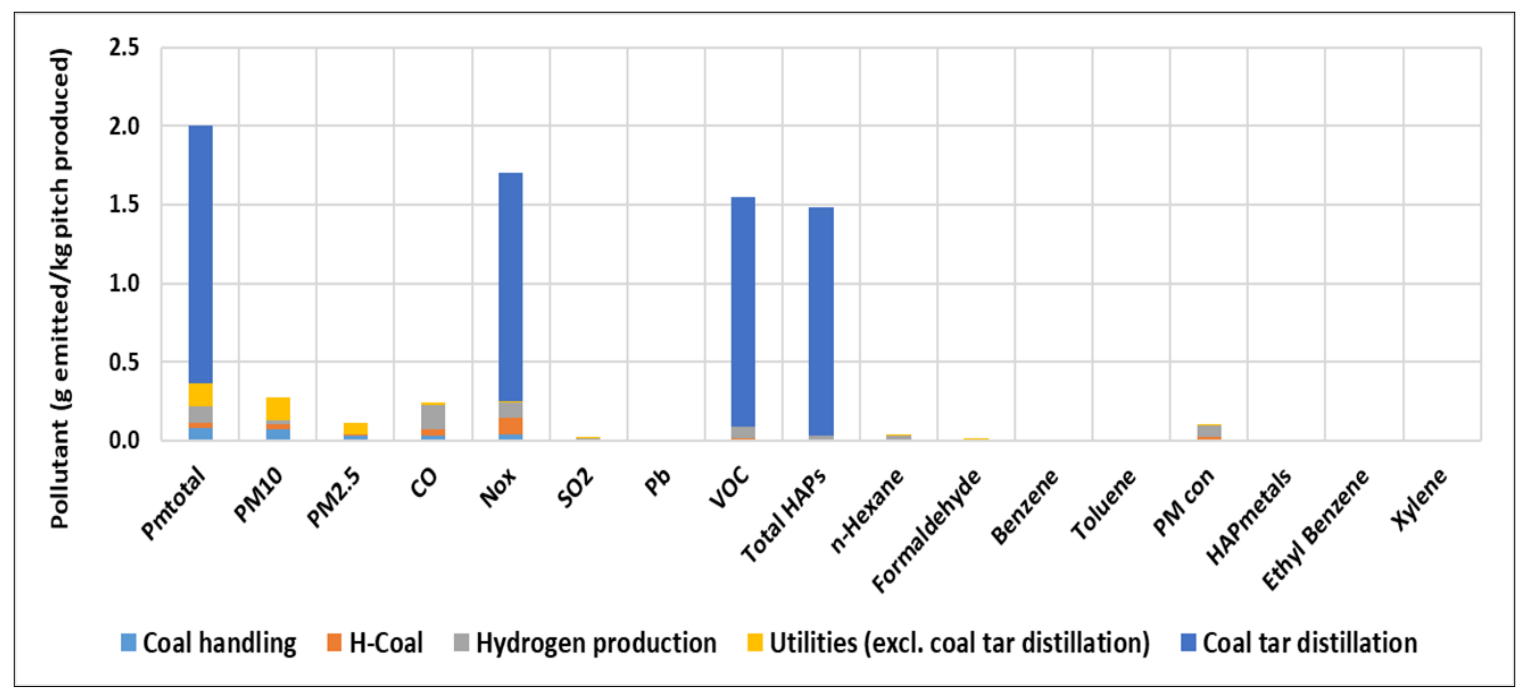

Figure 14. Section-wise breakdown of emissions by RC DCL manufacturing process by major pollutant types.

The hydrocarbons such as n-Hexane, benzene, toluene, ethyl benzene, and xylene were also observed to be present in minor quantities as illustrated in Figure 14. However, these aromatic hydrocarbons were primarily produced by the $\mathrm{H}_{2}$ production and utilities sections ( $71 \%$ of total plant's share) while the remaining plant sections that processed coal were relatively minor emitters. It should be noted that emissions of aromatic hydrocarbon were not considered for coal tar distillation unit due to data unavailability.

\subsection{PAH CONTENT AND EMISSIONS IN COAL PITCH MANUFACTURING}

Coal is a complex heterogenous mixture composed of organic and inorganic materials along with presence of trace elements such as arsenic, selenium, and mercury. One of the major emissions concerns during coal combustion, coking, and pyrolysis is PAHs as mentioned with $\mathrm{PM}_{\text {Total }}$, NOx, and volatile organic compounds. They are toxic in nature and can adversely affect human health. Typically, coal comprises of over one hundred different types of PAHs. Of these, EPA has identified 16 toxic and hazardous to human life PAHs (EPA-PAHs) as priority pollutants: naphthalene, acenaphthylene, acenaphthene, fluorene, phenanthrene, anthracene, fluoranthene, pyrene, chrysene, benzo[a]anthracene, benzo[b]fluoranthene, benzo[k]fluoranthene, benzo[a]pyrene, indeno(1,2,3-c,d)pyrene, benzo(g,h,i)perylene, and dibenzo(a,h)anthracene [60].

The total PAH and EPA-PAH concentrations within coal can vary widely depending on the its rank determined by its vitrinite reflectance (\%) and source location. Vitrinite reflectance is defined as the proportion of incident light reflected from vitrinite maceral of the coal under high magnification in oil immersion. Total PAH concentration variation with vitrinite reflectance shows a bell-shaped trend, which increases with vitrinite reflectance for peat and brown coal types, whereas for hard and anthracite coal types, its concentration decreases with vitrinite reflectance values greater than $1.0 \%$ [61] [62] [52]. The variation of EPA-PAH concentration with vitrinite reflectance shows a similar trend, but its corresponding values are lower than total $\mathrm{PAH}$, as expected. 
Total PAH and EPA-PAH concentrations for different types of US coal are depicted in Table 13. As stated previously, a correlation is absent between PAH concentration and coal rank. However, for similar coal origins and types, certain resemblances may exist. For instance, the total PAH and EPA-PAH concentrations of lignite were similar around mean values of 7.5 and $1.1 \mathrm{mg} / \mathrm{kg}$ respectively due to common origin source (Northern Great Plains). A similar observation can also be seen in the case of subbituminous coals as their total PAH concentrations were around $11 \mathrm{mg} / \mathrm{kg}$ because of their common origin source. From only the standpoint of EPA-PAH concentration, anthracite coals appear to possess the lowest total concentration among all coal ranks (Table 13) at values lower than $0.1 \mathrm{mg} / \mathrm{kg}$ of coal and the most suitable rank of coal for pitch production. However, in the case of bituminous coals, the concentration can vary significantly between 0.1 to $8.2 \mathrm{mg} / \mathrm{kg}$ of coal depending on location as depicted in Table 13. Along with anthracite coals, bituminous coals with low EPA-PAH concentrations at 0.1 $\mathrm{mg} / \mathrm{kg}$ of coal can be also considered as coals for pitch production.

Table 13. Total PAH and EPA-PAH concentrations in different US raw coal types [52].

\begin{tabular}{|c|c|c|c|}
\hline $\begin{array}{l}\text { Sr } \\
\text { no. }\end{array}$ & Coal name & $\begin{array}{l}\text { Total PAHs } \\
(\mathrm{mg} / \mathrm{kg} \text { coal })\end{array}$ & $\begin{array}{l}\text { EPA-PAHs } \\
\text { (mg/kg coal) }\end{array}$ \\
\hline 1 & Lignite A, Northern Great Plains, Beulah, USA & 8.5 & 1.2 \\
\hline 2 & Lignite A, Northern Great Plains, Pust, USA & 6.5 & 1 \\
\hline 3 & Sub-bituminous coal C, Northern Great Plains, Smith-Roland, USA & 12 & 0.1 \\
\hline 4 & Sub-bituminous coal C, Gulf Coast, Bottom, USA & 14 & 1.6 \\
\hline 5 & Sub-bituminous coal B, Northern Great Plains, Dietz, USA & 14 & 0.8 \\
\hline 6 & Sub-bituminous coal B, Northern Great Plains, Wyodak, USA & 5.4 & 0.3 \\
\hline 7 & Sub-bituminous coal A, Rocky Mountains, Deadman, USA & 12 & 1.5 \\
\hline 8 & Highly volatile bituminous coal C, Rocky Mountains, Blue, USA & 77 & 5.3 \\
\hline 9 & Highly volatile bituminous coal B, Eastern Coal, Ohio \#4A, USA & 60 & 8.2 \\
\hline 10 & $\begin{array}{l}\text { Highly volatile bituminous coal A, Rocky Mountains, Blind } \\
\text { Canyon, USA }\end{array}$ & 78 & 4.4 \\
\hline 11 & Highly volatile bituminous coal A, Eastern Coal, Pittsburgh, USA & 76 & 11 \\
\hline 12 & $\begin{array}{l}\text { Medium-volatility bituminous coal, Rocky Mountains, Coal Basin } \\
\text { M, USA }\end{array}$ & 29 & 1.8 \\
\hline 13 & Low volatile bituminous coal, Eastern Coal, Pocahontas \#3, USA & 20 & 3.8 \\
\hline 14 & Semianthracite, Eastern Coal, PA Semi-Anth. C, USA & 5.9 & 2.1 \\
\hline 15 & Anthracite, Eastern Coal, Lykens Valley \#2, USA & 0.2 & $<0.1$ \\
\hline 16 & Highly volatile bituminous coal, Blind Canyon, USA & 78.3 & - \\
\hline 17 & Highly volatile bituminous coal C-1, USA & 7.5 & 0.5 \\
\hline 18 & Highly volatile bituminous coal C-2, USA & 3.4 & 0.4 \\
\hline 19 & Highly volatile bituminous coal C-3, USA & 2.4 & 0.3 \\
\hline 20 & Highly volatile bituminous coal B-1, USA & 1.6 & 0.3 \\
\hline 21 & Highly volatile bituminous coal B-2, USA & 12.7 & 2.4 \\
\hline 22 & Highly volatile bituminous coal A-1, USA & 13.7 & 5.4 \\
\hline 23 & Highly volatile bituminous coal A-2, USA & 27.6 & 6.4 \\
\hline 24 & Low-volatility bituminous coal, USA & 1.2 & 0.3 \\
\hline
\end{tabular}

Afanasov et al. conducted a quantitative analysis through gas chromatography-mass spectrometry techniques and determined the EPA-PAH concentration in three types of coal tar pitch [63]. The pitch 
source varied as pitch type 1 was procured from JSC Mittal Steel Temirtau whereas pitch types 2 and 3 were procured from OAO Altai-Koks. Both the facilities primarily generated coke while pitch was only a by-product. The properties of these three types of coal tar pitch are depicted in Table 14. The PAH emissions were obtained using the solvent extraction and ultrasound extraction methods. Chemical properties of the three pitch types were very similar because of their similar coal rank (bituminous), with a slight variation in the case of pitch type 3 .

Table 14. Properties of three different types of coal tar pitch [62].

\begin{tabular}{|c|l|c|c|c|}
\hline Sr. no. & \multicolumn{1}{|c|}{ Pitch property } & Pitch 1 & Pitch 2 & Pitch 3 \\
\hline 1 & Origin coal rank & $\begin{array}{c}\text { Metallurgical } \\
\text { (bituminous) }\end{array}$ & Bituminous & Bituminous \\
\hline 2 & Softening point $\left({ }^{\circ} \mathrm{C}\right)$ & 90 & 90 & 63 \\
\hline 3 & Insoluble weight fraction in toluene (\%) & 31 & 33 & 19 \\
\hline 4 & Insoluble weight fraction in quinoline (\%) & 6 & 8 & 5 \\
\hline 5 & Ash weight fraction (\%) & 0.1 & 0.1 & 0.1 \\
\hline 6 & Coke residue weight fraction (\%) & 57 & 58 & 57 \\
\hline 7 & Volatiles weight fraction (\%) & 57 & 55 & 65 \\
\hline
\end{tabular}

The concentrations of EPA-PAHs in the three types of coal tar pitches are depicted in Figure 15. The PAH concentration differed among pitches with respect to PAH molecular weights with notable similarities observed in pitch types 2 and 3. For instance, the concentration of high-molecular weight PAHs (chrysene, benzo[b]fluoran-thene, benzo[k]fluoranthene, benzo[a]pyrene, indeno[1,2,3-c,d]pyrene, dibenzo[a,h]anthracene, andbenzo[g,h,i]perylene) were similar to pitch types 2 and 3 despite their dissimilar origins and pitch properties. However, the concentration of low-molecular weight PAHs (naphthalene, acenaphthene, phenanthrene, fluorene, and anthracene) differed considerably with respect to pitch types as was revealed in Figure 15. Furthermore, the total concentration of intermediate PAHs (flouranthene, pyrene, benzo[a]anthracene) were observed to be typically higher than low- and highmolecular weight PAHs in all three pitch types.

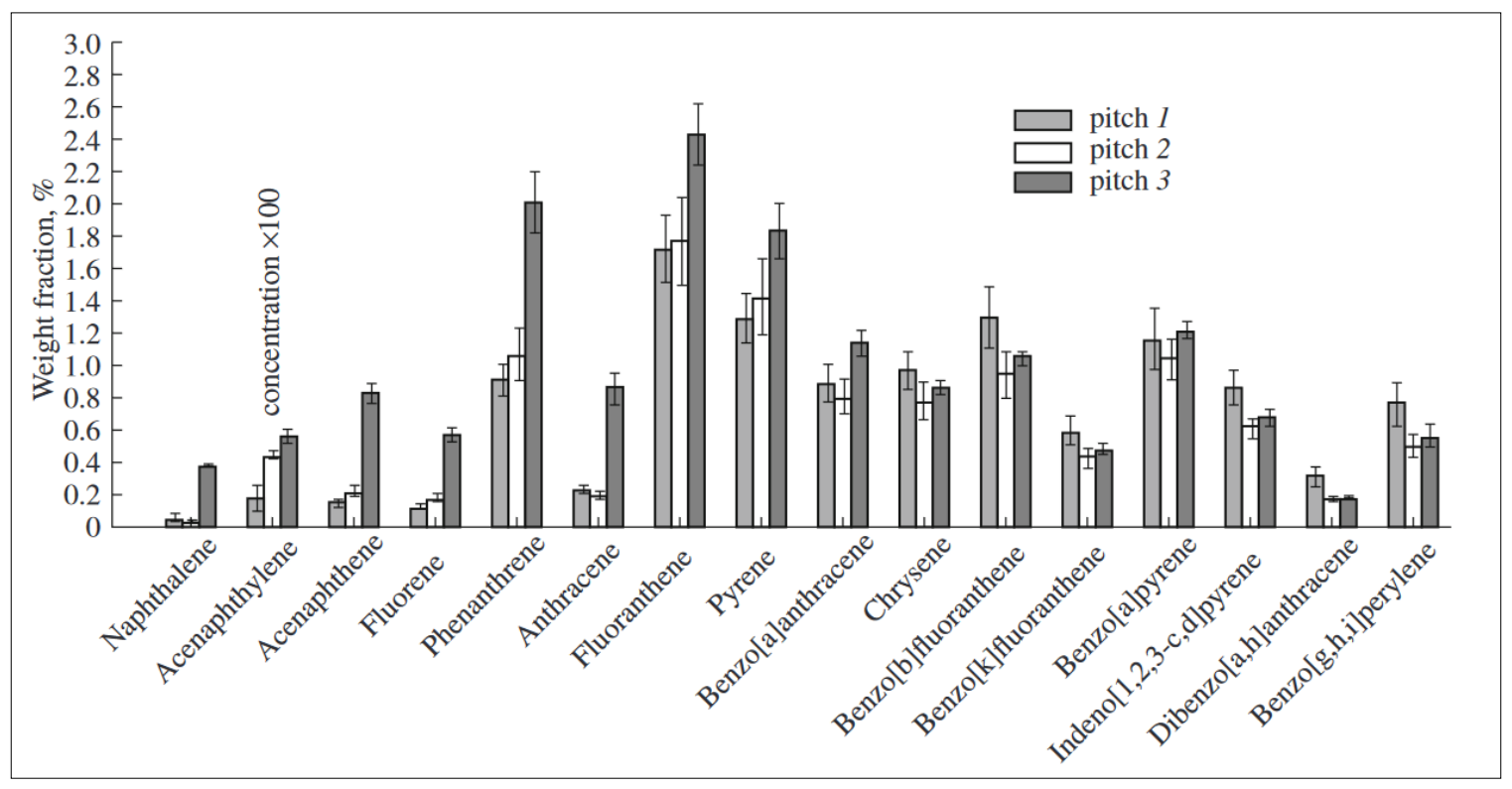

Figure 15 Concentration of EPA-PAHs in three coal tar pitch samples [63]. 
Toxic equivalency factor is a commonly used metric to assess the occupational and environmental health risks of pollutants, and these values for EPA-PAHs are illustrated in Table 15. The toxicity level of highmolecular weight PAHs (i.e., benzo(a)pyrene and dibenz(a,h)anthracene) was deemed to be highest followed by low-molecular weight PAHs such as benz(a)anthracene and pyrene.

Table 15. Toxic equivalency factors of EPA-PAHs [64].

\begin{tabular}{|c|c|c|}
\hline Sr. no. & EPA-PAH & Toxic equivalency factor value \\
\hline 1 & Napthalene & $1 \times 10^{-3}$ \\
\hline 2 & Acenaphthene & $1 \times 10^{-3}$ \\
\hline 3 & Acenaphthylene & $1 \times 10^{-3}$ \\
\hline 4 & Fluorene & $1 \times 10^{-3}$ \\
\hline 5 & Phenanthrene & $1 \times 10^{-2}$ \\
\hline 6 & Anthracene & $1 \times 10^{-3}$ \\
\hline 7 & Fluoranthene & $1 \times 10^{-3}$ \\
\hline 8 & Pyrene & $1 \times 10^{-1}$ \\
\hline 9 & Benz(a)anthracene & $1 \times 10^{-2}$ \\
\hline 10 & Chrysene & $1 \times 10^{-1}$ \\
\hline 11 & Benzo(b)fluoranthene & $1 \times 10^{-1}$ \\
\hline 12 & Benzo(k)fluoranthene & 1 \\
\hline 13 & Benzo(a)pyrene & $1 \times 10^{-1}$ \\
\hline 14 & Ideno(1,2,3-cd)pyrene & 1 \\
\hline 15 & Dibenz(a,h)anthracene & $1 \times 10^{-2}$ \\
\hline 16 & Benzo(g,h,i)perylene & \\
\hline
\end{tabular}

US government agencies such as the Occupational Safety and Health Administration (OSHA) and EPA have established certain workplace air and water emission standards for PAHs as depicted in Table 16. The US government agencies specify standards for total PAH emissions but do not provide information regarding the breakdown of species-specific emission limits for air as observed in the case of water contaminants. The total PAHs concentration in workplace air was observed to lie between 0.1 and 0.2 $\mathrm{mg} / \mathrm{m}^{3}$ while the maximum level of contaminants in water typically lies between $1 \times 10^{-4} \mathrm{mg} / \mathrm{L}$ and $3 \times 10^{-4}$ $\mathrm{mg} / \mathrm{L}$, depending on specific PAH species as shown in Table 16.

Table 16. Standards and regulations for PAH exposure. [65].

\begin{tabular}{|c|l|l|l|l|}
\hline Sr. no. & \multicolumn{1}{|c|}{ Parameter } & \multicolumn{1}{c|}{ Agency } & \multicolumn{1}{c|}{ Area focus } & \multicolumn{1}{c|}{ Standards value } \\
\hline 1 & $\begin{array}{l}\text { Threshold limit } \\
\text { value of } \\
\text { concentration }\end{array}$ & $\begin{array}{l}\text { American } \\
\text { Conference of } \\
\text { Governmental } \\
\text { Industrial Hygienists }\end{array}$ & Workplace air & $\begin{array}{l}0.2 \mathrm{mg} / \mathrm{m}^{3} \text { for benzene-soluble coal } \\
\text { tar pitch fraction }\end{array}$ \\
\hline 2 & $\begin{array}{l}\text { Recommended } \\
\text { airborne exposure } \\
\text { limit }\end{array}$ & $\begin{array}{l}\text { National Institute for } \\
\text { Occupational Safety } \\
\text { and Health }\end{array}$ & Workplace air & $\begin{array}{l}0.1 \mathrm{mg} / \mathrm{m}^{3} \text { for coal tar pitch volatile } \\
\text { agents }\end{array}$ \\
\hline
\end{tabular}




\begin{tabular}{|c|c|c|c|c|}
\hline 3 & $\begin{array}{l}\text { Legal airborne } \\
\text { permissible } \\
\text { exposure limit }\end{array}$ & $\begin{array}{l}\text { Occupational Safety } \\
\text { and Health } \\
\text { Administration }\end{array}$ & Workplace air & $\begin{array}{l}0.2 \mathrm{mg} / \mathrm{m}^{3} \text { for benzene-soluble coal } \\
\text { tar pitch fraction }\end{array}$ \\
\hline 4 & $\begin{array}{l}\text { Maximum } \\
\text { contaminant level }\end{array}$ & EPA & $\begin{array}{l}\text { Water } \\
\text { contamination }\end{array}$ & $\begin{array}{l}1 \times 10^{-4} \mathrm{mg} / \mathrm{L} \text { for benz(a)anthracene; } \\
2 \times 10^{-4} \mathrm{mg} / \mathrm{L} \text { for benzo(a)pyrene, } \\
\text { benzo(b)fluoranthene, } \\
\text { benzo(k)fluoranthene, and chrysene; } \\
3 \times 10^{-4} \mathrm{mg} / \mathrm{L} \text { for } \\
\text { dibenz }(\mathrm{a}, \mathrm{h}) \text { anthracene; and } \\
3 \times 10^{-4} \mathrm{mg} / \mathrm{L} \text { for indenol }(1,2,3- \\
\mathrm{c}, \mathrm{d}) \text { pyrene }\end{array}$ \\
\hline
\end{tabular}

\subsection{OTHER TOXIC POLLUTANTS OCCURRING IN COAL}

Aside from major coal constituent elements (carbon, $\mathrm{H}_{2}$, oxygen, and sulfur), minor elements and trace elements also form an integral part of the coal structure. The minor elements typically constitute nearly $0.1-1 \mathrm{wt} \%$ of coal while the concentration of trace elements occur in 100 parts per million or less [66]. As illustrated in Figure 16, the common minor elements present in coal comprise sodium, magnesium, aluminum, etc., whereas trace elements comprise lithium, beryllium, and so on.
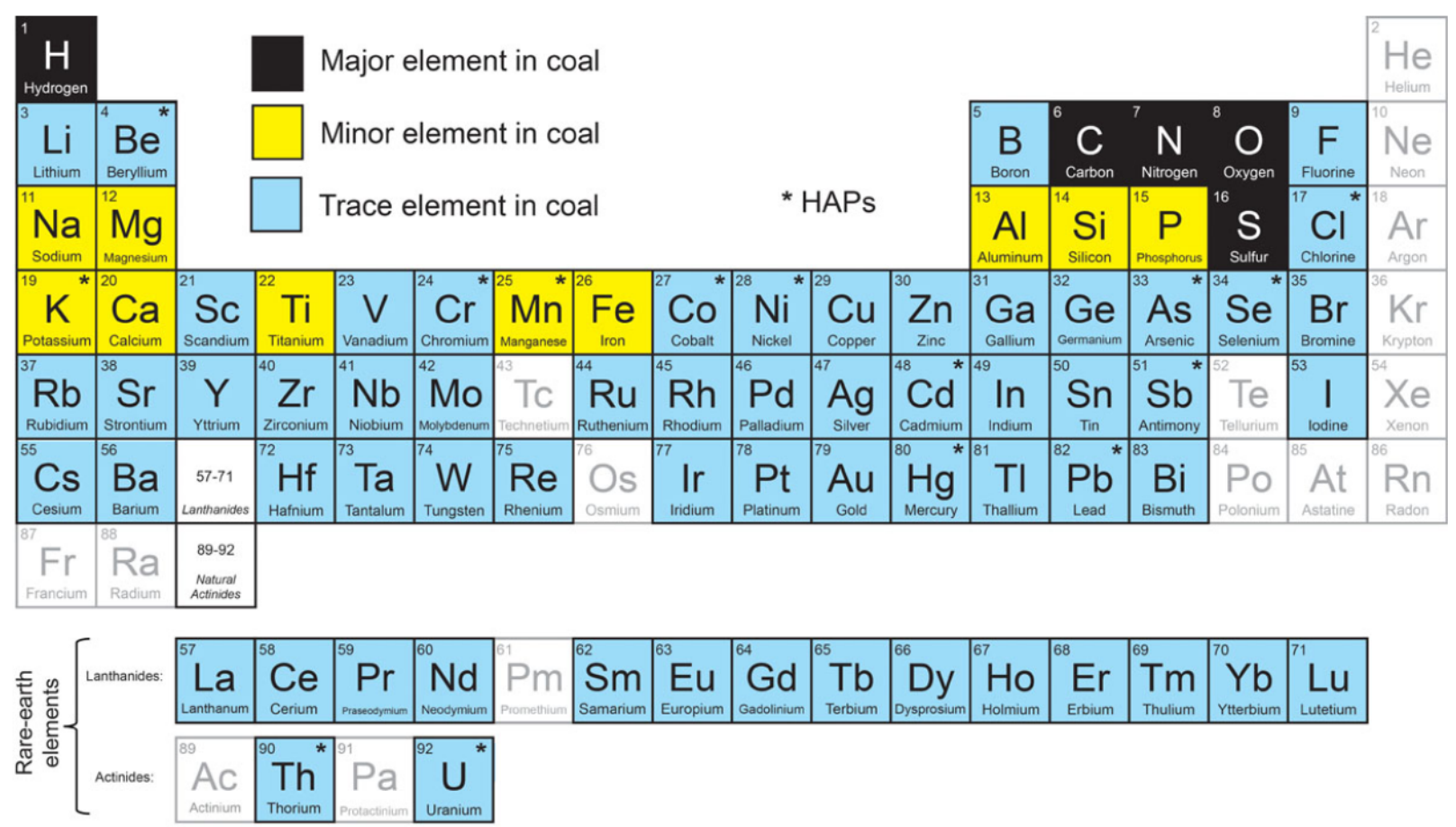

Figure 16. Major, minor, and trace constituent elements of coal [66].

Coal also constitutes 15 trace elements officially designated as hazardous by EPA that are termed as HAPs in Figure 16. Of these 15 HAPs, only mercury emissions from coal-fired power plants have been regulated and monitored by EPA because of their adverse effects on human health. Aside from mercury, exposure, other trace elements such as zinc and chromium can be also be hazardous to human life [67]. 


\subsection{OTHER TOXIC POLLUTANTS OCCURRING IN COAL}

Similar to the comparative embodied carbon fiber manufacturing energy analysis, emission impacts of carbon fiber manufacturing at the level of 12 major impact categories based on the TRACI 2.1 life cycle analysis impact assessment method in SimaPro software. Various types of pollutant emissions at the level of isotropic coal pitch manufacturing were only considered. For two other major carbon fiber manufacturing steps (fiber precursor and final fiber manufacturing), limited similar process emissions for both pitch and PAN carbon fiber were used. Table 15 shows the emissions by major pollutant types per kilogram of isotropic coal pitch (Figure 14) based on the detailed emissions data by four major tar processing units: coal handling, H-coal, hydrogen production, and non-coal and tar distillation. The presence of aggregated HAPs estimated in the air application permit [58] was further disaggregated by specific chemical species to reflect differences among their human health impacts. The isotropic pitch manufacturing shares (by weight percentage of HAPs in Figure 14) were disaggregated by 11 major HAP chemical species similar to the available emission shares of a coal-powered electricity generation plant based on the life cycle emissions inventory database of GaBi software [68]. All pollutant emissions but hydrogen cyanide emissions (highlighted in Table 17) are considered in the TRACI 2.1 emission impact assessment method.

Table 17. Major pollutant emissions of isotropic coal pitch manufacturing [58] [68].

\begin{tabular}{|l|l|}
\hline Pollutant type & Emissions (g/kg of pitch) \\
\hline $\mathrm{PM}_{\mathrm{T} \text { otal }}$ & $2.00 \mathrm{E}+00$ \\
\hline $\mathrm{PM}_{10}$ & $2.70 \mathrm{E}-01$ \\
\hline $\mathrm{PM}_{2.5}$ & $1.08 \mathrm{E}-01$ \\
\hline $\mathrm{CO}$ & $2.40 \mathrm{E}-01$ \\
\hline $\mathrm{NOx}$ & $1.71 \mathrm{E}+00$ \\
\hline $\mathrm{SO}_{2}$ & $1.09 \mathrm{E}-02$ \\
\hline $\mathrm{Pb}$ & $3.65 \mathrm{E}-04$ \\
\hline Volatile organic compound & $1.55 \mathrm{E}+00$ \\
\hline n-Hexane & $2.61 \mathrm{E}-02$ \\
\hline Formaldehyde & $1.46 \mathrm{E}-03$ \\
\hline Benzene & $4.17 \mathrm{E}-04$ \\
\hline Toluene & $4.17 \mathrm{E}-04$ \\
\hline PM con & $9.78 \mathrm{E}-02$ \\
\hline Ethyl benzene & $5.22 \mathrm{E}-05$ \\
\hline Xylene & $5.22 \mathrm{E}-05$ \\
\hline HAP emissions & \\
\hline Mercury & $1.63 \mathrm{E}-07$ \\
\hline Antimony & $5.16 \mathrm{E}-04$ \\
\hline Beryllium & $5.96 \mathrm{E}-05$ \\
\hline Cadmium & $3.19 \mathrm{E}-04$ \\
\hline Chromium & $5.46 \mathrm{E}-04$ \\
\hline Lead & $5.01 \mathrm{E}-05$ \\
\hline Nickel & $3.79 \mathrm{E}-04$ \\
\hline Selenium & $2.25 \mathrm{E}-04$ \\
\hline Hydrogen chloride & $1.45 \mathrm{E}+00$ \\
\hline Hydrogen fluoride & $2.98 \mathrm{E}-02$ \\
\hline & \\
\hline
\end{tabular}


Because of unavailability of species-specific PAH emissions data in the air application permit [58], the life cycle emissions inventory of coal-powered electricity generation plants [68] was used to generate the $\mathrm{PAH}$ emissions profile of the pitch production process. The individual amounts of major PAH species were calculated based on the amounts of coal used in the pitch production process $(4.76 \mathrm{~kg})$ and are displayed in Table 18 and assuming that the PAH emissions profile of the coal liquefaction process was equal to that of the coal powered electricity generation plants. Even though more than $100 \mathrm{PAH}$ species may be emitted in coal-powered plants, only the major species (illustrated in Table 18) of PAHs designated as hazardous by EPA [69] were assumed to be emitted in the case of pitch production. Table 18 also shows the toxicity of each PAH chemical species normalized on the basis of benzo $\{$ a $\}$ pyrene of toxicity factor 1 (Table 15). All but 5 out of 13 PAH pollutant emissions (highlighted in Table 18) are considered in the TRACI2.1 emission impact assessment method. Relative toxicity factors of all chemical species (shown in the last column of Table 18) in terms of relative benzo \{a\} pyrene toxicity factor and emissions amount show low environmental impacts of these five chemical species not considered in the impact assessment.

Table 18. Major PAH pollutant emissions of isotropic coal pitch manufacturing [68] [64].

\begin{tabular}{|l|c|c|c|}
\hline Pollutant name & $\begin{array}{l}\text { Emission } \\
\text { (g/kg of pitch) }\end{array}$ & $\begin{array}{l}\text { Toxicity } \\
\text { equivalency } \\
\text { factor }\end{array}$ & $\begin{array}{l}\text { Toxicity } \\
\text { equivalency factor } \\
\text { (benzo\{a\}pyrene) }\end{array}$ \\
\hline Acenaphthene & $6.07 \mathrm{E}-02$ & $1.00 \mathrm{E}-03$ & $4.19 \mathrm{E}+03$ \\
\hline Anthracene & $1.33 \mathrm{E}-09$ & $1.00 \mathrm{E}-02$ & $9.20 \mathrm{E}-04$ \\
\hline Benzofluoranthene & $1.20 \mathrm{E}-09$ & $1.00 \mathrm{E}-01$ & $8.30 \mathrm{E}-03$ \\
\hline Benzo $\{\mathrm{a}\}$ anthracene & $6.78 \mathrm{E}-10$ & $1.00 \mathrm{E}-01$ & $4.68 \mathrm{E}-03$ \\
\hline Benzo $\{\mathrm{a}\}$ pyrene & $1.45 \mathrm{E}-08$ & $1.00 \mathrm{E}+00$ & $1.00 \mathrm{E}+00$ \\
\hline Benzo $\{$ ghi\}perylene & $6.02 \mathrm{E}-10$ & $1.00 \mathrm{E}-02$ & $4.16 \mathrm{E}-04$ \\
\hline Chrysene & $1.66 \mathrm{E}-09$ & $1.00 \mathrm{E}-02$ & $1.14 \mathrm{E}-03$ \\
\hline Dibenz(a)anthracene & $3.75 \mathrm{E}-10$ & NA & NA \\
\hline Fluoranthene & $4.36 \mathrm{E}-09$ & $1.00 \mathrm{E}-03$ & $3.01 \mathrm{E}-04$ \\
\hline Fluorene & $1.39 \mathrm{E}-08$ & $1.00 \mathrm{E}-03$ & $9.57 \mathrm{E}-04$ \\
\hline Indeno[1,2,3-cd]pyrene & $4.48 \mathrm{E}-10$ & $1.00 \mathrm{E}-01$ & $3.10 \mathrm{E}-03$ \\
\hline Phenanthrene & $4.42 \mathrm{E}-08$ & $1.00 \mathrm{E}-03$ & $3.05 \mathrm{E}-03$ \\
\hline Acenaphthylene & $9.93 \mathrm{E}-09$ & $1.00 \mathrm{E}-03$ & $6.86 \mathrm{E}-04$ \\
\hline
\end{tabular}

Figure 17 shows the emission impacts of coal pitch carbon fiber relative to conventional PAN carbon fiber under 10 impact categories considered in the TRACI2.1 life cycle analysis impact assessment method. Similar to the comparative carbon fiber embodied energy estimates discussed earlier, higher carbon fiber conversion yield for coal pitch carbon fiber results in a $16 \%$ to $76 \%$ range of reduction in their emission impacts among all impact categories considered. Most of the emission reduction impacts of coal pitch carbon fiber (i.e., more than $80 \%$ ) were observed under two impact categories (i.e., ozone and fossil depletion) because of a lower amount of pitch precursor use from a higher pitch fiber conversion yield. The emission reduction impacts of coal pitch fiber were the least under the four impact categories (i.e., eutrophication, carcinogenic, non-carcinogenic, and respiratory effects) in the range of $24 \%$ to $40 \%$ lower than PAN fiber. For the same reason of a higher pitch carbon conversion yield, these impacts were lower for the detrimental environmental coal fuels industry. Although 5 out of 12 major EPA-PAHs are 
not included in the TRACI2.1 impact assessment method, however all of these PAH chemicals do not impose a higher toxicity than the baseline benzo $\{a\}$ pyrene PAH chemical as discussed earlier and shown highlighted in Table 16. Not only the PAH controlled equipment use is limited today due to a lack of EPA regulation enforcement, but difficulties in the conversion of actual LCA mass emissions per unit of manufactured mass output to total EPA-PAH limit in terms of $\mathrm{mg} / \mathrm{m}^{3}$ fail to assess accurately its overall environmental impacts. Additional environmental impact analysis of coal pitch carbon fiber manufacturing is needed to consider the on-site manufacturing process emissions including PAH emissions for the comparative environmental viability of new fiber manufacturing technologies.

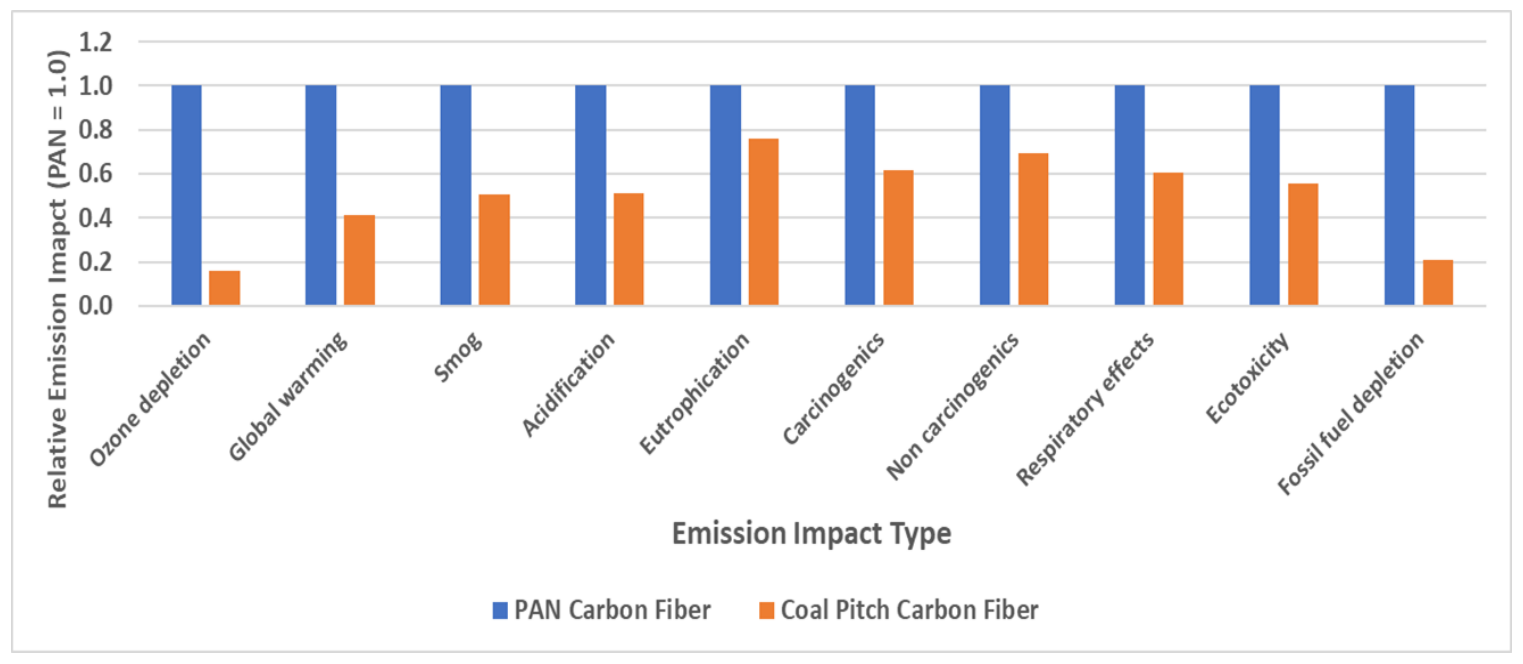

Figure 17. Comparative environmental emissions impacts of conventional PAN vs. coal pitch carbon fiber manufacturing.

\section{PITCH CARBON FIBER MANUFACTURING}

Pitch-based high-performance fibers from commercially available pitches are technically harder. They were first prepared from mesophase pitches derived from petroleum-based naphtha-cracking pitches. Coal tar pitch, a by-product of metallurgical coke manufacturing for the iron/steel industry, is a potential source of pitch carbon fiber manufacturing. The beehive process and the by-product process are the two proven processes for manufacturing metallurgical coke. The primary method, the by-product method, accounts for more than $98 \%$ of US coke production. In the traditional by-product method of coke wet quenching, air is excluded from the coking chambers, and the necessary heat for coking distillation is supplied from external combustion of some of the gas recovered from the coking process. In traditional coke wet quenching, the quench car carries the coke to the quench tower, where the coke is deluged with water to prevent it from burning after exposure to air (thereby mitigating airborne toxic pollutants); therefore, no superheated steam for further use is available, unlike in the alternative coke dry quenching method. Treated wastewater in the quenching stage and losses from burning off can be reused in this case. With this method, in addition to $87 \mathrm{wt} \%$ of the major product, coke, coke oven gas ( $8 \mathrm{wt} \%)$, coal tar pitch (4 wt \%), sulfur (1 wt \%), and crude benzene (1.2 $\mathrm{wt} \%)$ are produced as valuable by-products [54]. About $40 \%$ of the coke oven gas $(59 \mathrm{lb})$ is estimated to be used as a fuel for underfiring the coke oven. 1.41 tonnes of US hard mix coal (predominantly bituminous coal) are assumed to be used to produce 1 tonne of metallurgical coke. Currently, coal tar obtained from 5.5 million tons of coal is used to produce 1,000 tons/year of carbon fiber - in addition to needle coke, pitch coke, lithium batteries, and alumina fiber - by the Sakaide plant of Mitsubishi Chemical Corporation in Japan. [32]

Isotropic coal tar pitch, valued at $\$ 700 /$ ton, is obtained from the by-product recovered coal tar in metallurgical coke manufacturing. Initially, $\sim 5 \%$ coal tar is produced. The coal tar is used to produce two 
major types of co-products (oils and pitch) after distillation. Oil by-products include naphthalene, creosote (wood treating), and carbon black feedstock and coal tar pitch with a 50\% yield. The by-product pitch is currently used predominantly in aluminum smelter electrodes and in graphite electrodes, specialty carbon products, pavement coatings, and refractories. Figure 18 shows a schematic process representation of the conversion of isotopic pitch to the fiber precursor manufacturing. Isotropic by-product pitch is upgraded to mesophase pitch necessary for pitch carbon fiber precursor production, by heating in a nitrogen blanket of $180 \mathrm{~L} / \mathrm{h}\left((\sim 2700 \mathrm{~kg} / \mathrm{h})\right.$ at $400^{\circ} \mathrm{C}$ for $8 \mathrm{~h}$, with an $\sim 50 \%$ yield of mesophase pitch [70]. The mesophase pitch is then converted into a fiber precursor by melt spinning, a rapid cooling and solidification process. The pitch is heated until it melts in a closed system and is then pressed through a spinneret to form continuous long fibers that are collected as fiber tapes (or non-woven mat) using the classic melt spinning technology. During this process, the fiber is drawn and stretched to maintain a certain tension to ensure molecular alignment along the fiber axis and a smaller diameter. A lower melting point facilitates spinning at a higher speed, resulting in a lower precursor cost.

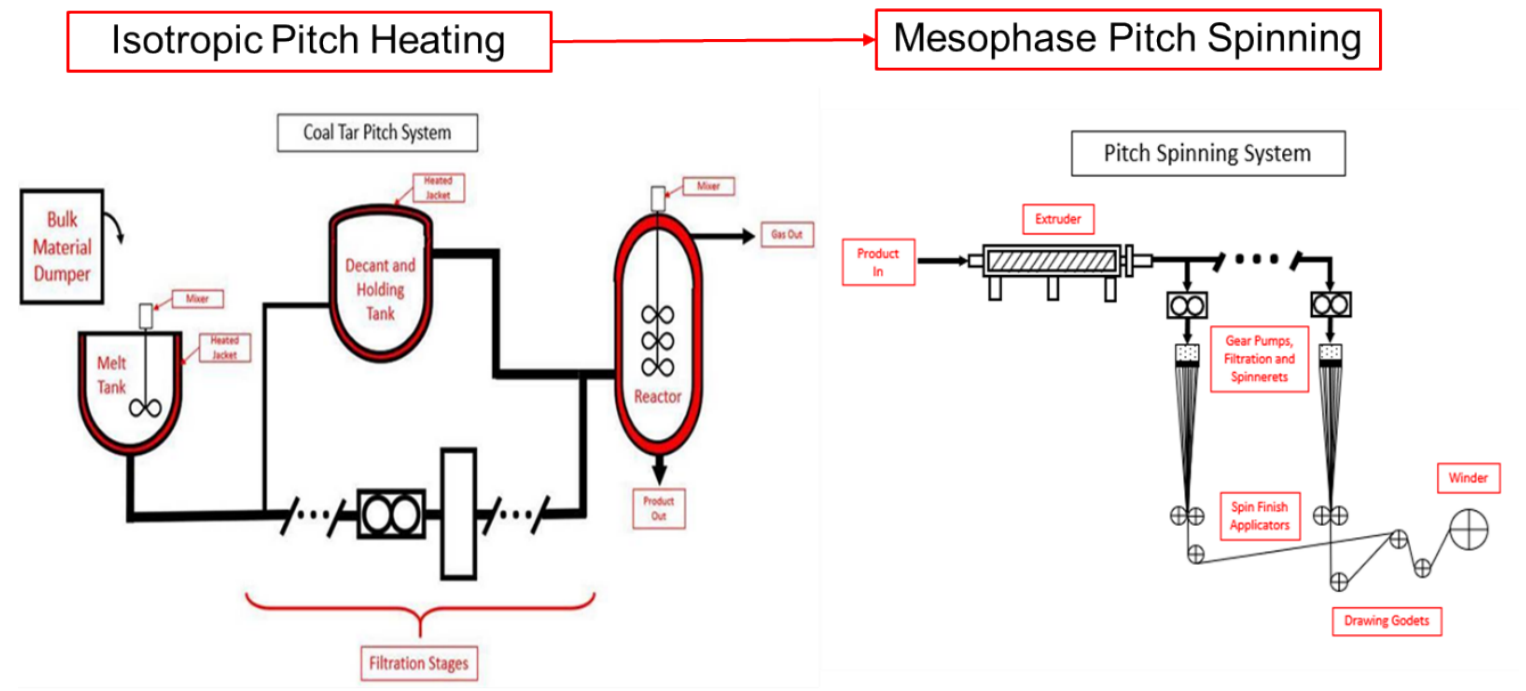

Figure 18. A schematic process flow mesophase coal tar pitch precursor manufacturing.

The spun fibers (green fiber) are then thermally treated in a continuous process similar to the conventional PAN fiber manufacturing process. Green fibers are first dried to remove solvents for fugitive sizing without any formal pretreatment and stretching necessary for conventional PAN fibers. Similar to conventional PAN fibers manufacturing, continuous heating occurs starting with oxidation, carbonization, and finally graphitization for an improved fiber modulus, if necessary. During carbonization in an inert atmosphere, all non-carbon elements are removed from the fiber; it undergoes further cross-linking, and the resulting fiber becomes a carbon fiber. Graphitization is simply carbonization at a high temperature to improve the alignment and orientation of the crystalline regions along the fiber direction, resulting in an increase in the carbon fiber overall modulus. The final step to improve the fiber surface properties, mainly adhesion, is done by passing it through air, $\mathrm{CO}_{2}$, ozone, nitric acid, or sodium hypochlorite.

\subsection{MESOPHASE COAL PITCH PRECURSOR MANUFACTURING COST}

A carbon fiber cost model, based on a process cost modeling approach, was developed for cost estimation at two specific stages of the final carbon fiber manufacturing process: mesophase coal pitch precursor and final pitch carbon fiber. The cost estimates were made at the level of major sequential steps of a fiber manufacturing process. The focus was on the cost instead of the alternative indicator price because the latter depends on changing market supply/demand dynamics and provides no further details regarding the major cost drivers that affect the competitiveness of a specific manufacturing technology. Cost is 
estimated at each major process step as determined by the major economic and technical processing input parameters. The cost is further disaggregated into four major cost categories: materials, capital, labor, and energy. Cost estimation at each process level by major cost categories helps to identify major cost drivers at the specific process level and how each process cost by major category contributes to the final fiber cost.

The 50,000 tow mesophase coal pitch precursor manufacturing cost was estimated at the level of two major manufacturing steps: conversion of isotropic coal tar pitch to mesophase coal tar pitch, followed by melt spinning of mesophase pitch to coal pitch precursor at an annual production volume manufacturing capacity of 7,500 tonnes (Table 19). The raw material, isotropic coal tar pitch $(\$ 0.70 / \mathrm{kg})$, is converted to mesophase pitch fiber and then melt-spun. Heating of isotopic pitch was assumed to be in a conventional 15,000 gal capacity asphalt heater tank with an estimated capital cost of $\$ 0.5$ million [71]. The $24 \mathrm{~h}$ heatup duty using natural gas is estimated to be $1.6 \mathrm{MBtu} / \mathrm{h}$ for the conversion of isotropic pitch to mesophase pitch at $400{ }^{\circ} \mathrm{C}$ for $8 \mathrm{~h}$ in a $\mathrm{N}_{2}$ atmosphere.

Table 19. Parameter assumptions to estimate carbon fiber manufacturing cost.

\begin{tabular}{|l|l|}
\hline \multicolumn{1}{|c|}{ Parameter } & \multicolumn{1}{c|}{ Value } \\
\hline Annual precursor production volume & 7,500 tonnes/year \\
\hline Isotropic pitch heating & \\
\hline Technology & Asphalt tar heating tank \\
\hline Heating temperature & $400{ }^{\circ} \mathrm{C}$ for $8 \mathrm{~h}$ in $\mathrm{N}_{2}$ \\
\hline Heat-up duty & $1.6 \mathrm{MBtu} / \mathrm{h}$ for $24 \mathrm{~h}$ \\
\hline Capital investment & $\sim \$ 0.5 \mathrm{M}$ \\
\hline Spinning & \\
\hline Technology & Mono Component Spin Beam:UOY/POY \\
\hline Drawn denier & $1.5 \mathrm{~g} /$ filament/9,000 m \\
\hline Holes per spinneret/position $(\#):$ & 4,000 \\
\hline Six-position beam extruders $(\#):$ & 20 \\
\hline Total position/spinneret $(\#)$ & 120 \\
\hline Windup speed & $230 \mathrm{~m} / \mathrm{min}$ \\
\hline Capital investment & $\sim \$ 43 \mathrm{million}$ \\
\hline Labor $(\#$ full-time employees) & 10 \\
\hline Energy $(\mathrm{kWh} / \mathrm{kg})$ & 2.6 \\
\hline Facility $\left(\mathrm{ft}{ }^{2}\right)$ & 21,690 \\
\hline
\end{tabular}

The mesophase pitch is melt-spun into a fiber precursor by using the similar mono component UOY/POY technology depending on the fiber elongation requirements and take-up type, and the proprietary spin beam design developed by Hills, Inc. [72]. The precursor fiber of linear density of $1.5 \mathrm{~g} /$ filament $/ 9,000 \mathrm{~m}$ is melt-spun at a fairly low speed of $230 \mathrm{~m} / \mathrm{min}$ in a 4,000-filament spinneret/position but significantly higher than the conventional PAN conversion line, which may be challenging to generally matched to the oxidation line speed because of the fragile nature of the relatively small organic molecule precursor fibers. It is assumed that a significantly higher spinneret precursor throughput will be spooled for the final significantly lower speed fiber conversion line. A fairly low precursor output of $9.2 \mathrm{~kg} / \mathrm{h} /$ position is estimated because of the low spinning speed and a fewer number of holes per position. The total capital cost is estimated to be $\$ 43$ million for 20 beams with 6 positions per beam for a total 120 positions necessary for an annual precursor output of 7,500 tonnes. Assuming each spinneret power rating to be 20 
$\mathrm{kW}$ and total annual operating hours of $\sim 7,000 \mathrm{~h}$, energy consumption is estimated to be $2.8 \mathrm{kWh} / \mathrm{kg}$ position.

The total coal pitch precursor cost is estimated to be $\$ 4.52 / \mathrm{kg}$; Figure 19 shows the total precursor cost breakdown by major cost categories. Materials and capital have the largest cost shares of 53\% and 31\%, respectively, of the total precursor cost. The high share of the former cost category is because of the assumed current $\$ 0.70 / \mathrm{kg}$ cost of the available unprocessed isotropic pitch and a significantly lower $50 \%$ conversion efficiency of isotropic to mesophase pitch. Of the two major manufacturing steps, the melt spinning step contributes to $56 \%$ of the total precursor cost (as shown in Figure 20), which results in the higher contribution of capital costs to the total precursor cost.

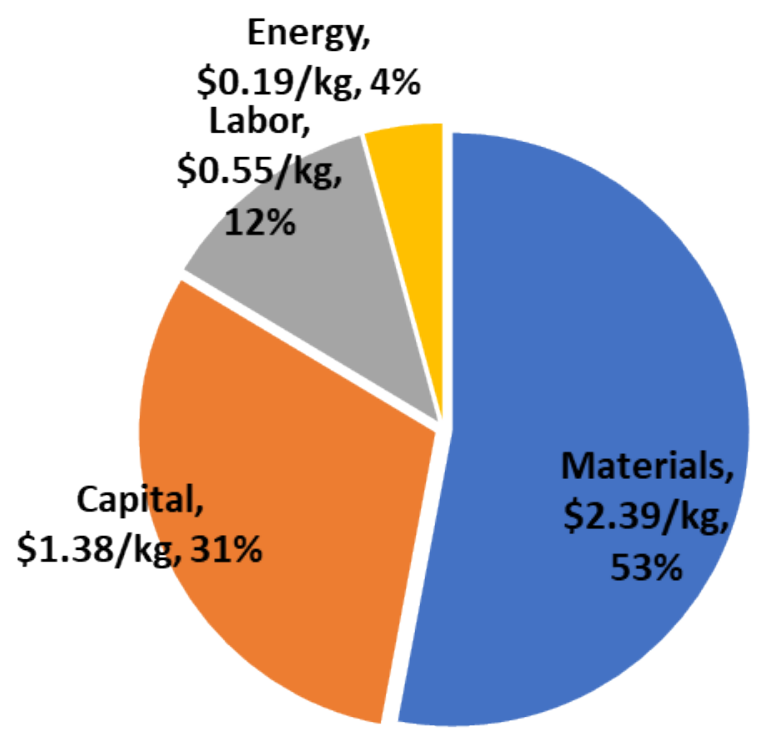

Figure 19. Total coal tar pitch fiber precursor cost distribution by major cost categories.

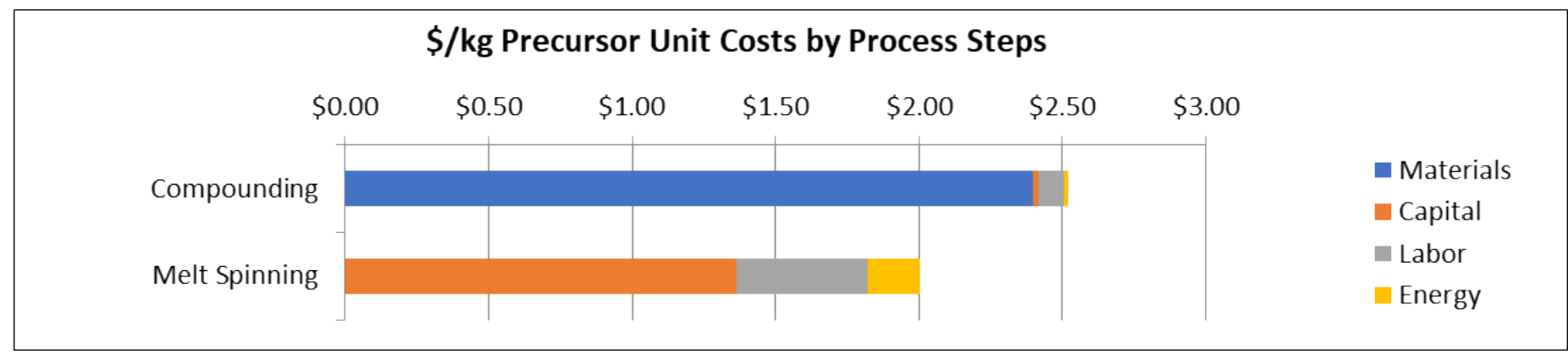

Figure 20. Total coal tar pitch fiber precursor cost distribution by major processing steps.

The estimated total mesophase pitch precursor cost of $\$ 4.52 / \mathrm{kg}$ is higher than the projected cost of $\$ 3.30 / \mathrm{kg}$ for the ACP20 mesophase pitch developed by Advanced Carbon Products. The latter uses isotropic pitch ACP10 based on a low-cost refinery oil continuous process [73]. The isotropic yield obtained with this process was $>85 \%$, and the assumed final mesophase pitch yield of $50 \%$ was considerably lower in this analysis. The key to driving down costs is to manufacture the isotropic and mesophase pitch in continuous, non-batch, short-residence-time processes. Alternative cheaper sources of raw material pitch could also significantly affect the final coal pitch precursor cost. Unlike petroleum pitch, coal pitch has the advantage of being an abundant domestic resource with minimal market price fluctuations. The petroleum-based chemical acrylonitrile widely used currently for commercial-grade 
carbon fibers had wide price fluctuations in the range of $\$ 748 /$ tonne to $\$ 2,436 /$ tonne in 2017 and 2018 [74]. Its price has declined since the peak achieved in 2011, as world oil prices decline because of the market oversupply.

\subsection{COAL PITCH CARBON FIBER MANUFACTURING COST}

Coal pitch carbon fiber manufacturing of large 50,000 tow similar to the conventional PAN fiber but significantly lower small tow pitch carbon fiber in the market today, starting with the fiber precursor material involves 9 sequential manufacturing steps as shown in Figure 21. As discussed earlier, the coal pitch and the commodity-grade PAN fiber manufacturing processes are similar, except the initial fiber pretreatment is replaced with an additional graphitization step at the end of precursor heating process for stiffness and the associated small increase in the strength of the coal pitch carbon fiber. An absence of fiber tension requirement due to a significantly lower fiber shrinkage during its conversion process allows to process a significantly larger amount of laid fibers instead in the form of tow bands with a required minimum spacing in non-compartmentalized belt-type ovens. Additionally, a single combined lowtemperature and high-temperature carbonization furnace is considered. Table 20 lists the assumptions of major processing parameters based on the communication with experts involved in the 2001 construction of Conoco's $\$ 125$ million 1,800 tonnes/year new technology of the low-value refinery product streams based pitch carbon fibers production facility in Ponca City, Oklahoma, USA [75]. However, that petroleum pitch carbon fiber facility plan for the material was scrapped in 2002 when the market turned out to be weaker than expected.

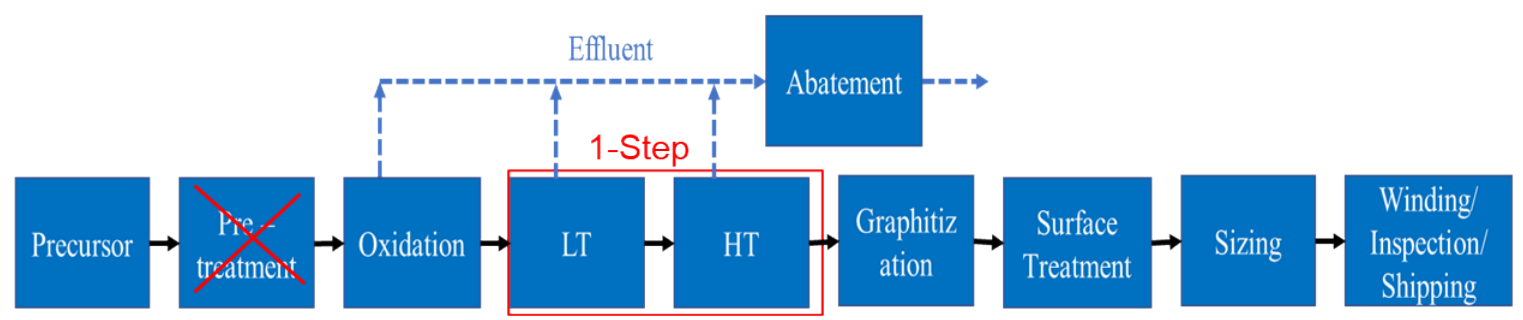

Figure 21. Major sequential processing steps of pitch carbon fiber manufacturing. $\mathrm{LT}=$ low-temperature; $\mathrm{HT}=$ high-temperature.

Table 20. Baseline major input parameters of 3,750 tonnes/year 50,000 tow pitch carbon fiber manufacturing.

\begin{tabular}{|c|c|}
\hline Parameter & Value \\
\hline Annual fiber production volume & 50,000 tow fiber at 3,750 tonnes/year \\
\hline Tow linear density & $1.79 \mathrm{~g} / 10,000 \mathrm{~m} /$ filament or $8.9 \mathrm{~g} / \mathrm{m}$ \\
\hline Tow spacing & $20 \mathrm{~mm}$ \\
\hline Precursor cost & $\$ 3.56 / \mathrm{kg}$ \\
\hline Line speed & $7.6 \mathrm{~m} / \mathrm{min}$ \\
\hline Total energy & $30 \mathrm{kWh} / \mathrm{kg}$ \\
\hline Yield & Chemical: 0.83 ; Mechanical: 0.89; Total: 0.74 \\
\hline Furnace temperature and time & $\begin{array}{l}\text { Oxidation: } 400{ }^{\circ} \mathrm{C} \text { for } 30 \mathrm{~min} \text {; low-temperature carbonization } \\
\text { temperature*: } 700^{\circ} \mathrm{C} \text { for } 0.5 \mathrm{~min} \text {; high-temperature carbonization } \\
\text { temperature*: } 1,400^{\circ} \mathrm{C} \text { for } 1.0 \mathrm{~min} \text {; graphitization temperature*: } 2200 \\
{ }^{\circ} \mathrm{C} \text { for } 0.5 \mathrm{~min} \\
{ }^{*} \text { In an inert atmosphere }\end{array}$ \\
\hline Total labor & 9 full-time employees/shift \\
\hline Total capital equipment investment & $\$ 54$ million (installed) \\
\hline
\end{tabular}


The manufacturing process yields (both mechanical and chemical) were estimated at each sequential process step as the product of the yields of the follow-on step and the user-input specific process step itself, starting with the final desired annual production volume output at the final process step. A significantly higher mechanical process yield at the large-scale commercial production scale of $89 \%$ was assumed despite the fragile nature of pitch fibers. A resulting total combined yield of $74 \%$ was significantly higher than PAN fibers, resulting from a higher chemical yield of $\sim 83 \%$ achievable for pitch carbon fibers. A significantly higher chemical yield of $74 \%$ mainly contributed to a lower 1.35 units of pitch precursor at an estimated cost of $\$ 3.56 / \mathrm{kg}$ per unit of final pitch carbon fiber, compared with 2.2 units of precursor for commodity-grade carbon fiber. Both tow spacing of $20 \mathrm{~mm}$ and fiber line speed of $7.6 \mathrm{~m} / \mathrm{min}$ were assumed to be similar to that of PAN fibers. A significantly higher linear tow density of $8.9 \mathrm{~g} / \mathrm{m}$ resulted in a significantly annual output of 3,750 tonnes/year for a similar 1,500 tonnes/year capacity PAN fiber line.

The initial precursor processing began at the limiting overall output rate of $7.9 \mathrm{~m} / \mathrm{min}$ in an oxidation oven at $400{ }^{\circ} \mathrm{C}$ for the longest processing time of $30 \mathrm{~min}$. Two subsequent precursor heating cycles occurred in a single combined low-temperature and high-temperature furnace at $700{ }^{\circ} \mathrm{C}$ for $0.5 \mathrm{~min}$ and $1,400{ }^{\circ} \mathrm{C}$ for $1 \mathrm{~min}$, respectively, in an inert nitrogen atmosphere. A three-zone graphitization furnace of $1.5 \mathrm{~m}$ muffle width ( $3 \mathrm{~m}$ effective line width with laid fibers in several vertical layers) with an installed power rating of $293 \mathrm{~kW}$ each (i.e., total $880 \mathrm{~kW}$ for a three-zone furnace), at an estimated furnace installed cost of $\sim \$ 5$ million, was assumed for the additional graphitization heating step. This final heating step occurred at $2,200{ }^{\circ} \mathrm{C}$ for $0.5 \mathrm{~min}$ in an inert nitrogen/argon atmosphere [76]. The total installed capital investment was estimated to be $\$ 54$ million, of which the oxidation and graphitization heating furnaces had $\sim 10 \%$ share each. For a highly automated continuous capital-intensive carbon fiber manufacturing operation, the total labor force was estimated to be only 9.5 full-time employees/shift. Total electricity consumption was estimated to be $19.5 \mathrm{kWh} / \mathrm{kg}$, of which the oxidation process step share is the largest at $\sim 60 \%$.

The baseline 50,000 tow pitch carbon fiber cost for an annual production volume of 3,750 tonnes/year was estimated to be $\$ 10.29 / \mathrm{kg}$. This is lower than the cost of the commodity-grade PAN currently available because of a significantly lower amount of precursor material is required for pitch carbon fiber. The estimated pitch carbon fiber cost is $\sim 2 \mathrm{X}$ max. lower than the current PAN market price $(\$ 18 / \mathrm{kg}-$ $\$ 22 / \mathrm{kg}$ ), but several orders of magnitude lower than the limited supply of pitch carbon fiber at $\$ 88 / \mathrm{kg}-$ $\$ 100 / \mathrm{kg}$ used for niche applications today. A significantly lower materials cost share of the pitch fiber mainly driven by the higher manufacturing yield has the significant cost reduction opportunity in this case over the PAN fiber. A poor economies of scale in limited supply of pitch fiber besides the consideration of selling, general, and administrative expenses and profit margin, which are influenced by the market supply/demand dynamics, causes its market price to be several folds higher than the estimated cost in this analysis. A premium price of pitch carbon fiber today is due to the monopoly market, limited to a few manufacturers satisfying the limited demand for niche applications.

Figure 22 shows the baseline carbon fiber cost distribution by major cost categories and processing steps. Materials dominates the total fiber cost share of $61 \%$, followed by the capital cost share of $25 \%$, similar to the commodity-grade PAN carbon fiber manufacturing. A higher and larger diameter pitch fiber linear density of $8.9 \mathrm{~g} / \mathrm{m}$ laid instead of spaced tow bands in non-compartmentalized heat zone batch type belt ovens results in a higher annual output of 3,750 tonnes and therefore, their resulting impacts of economies of scale on the fiber capital and energy cost shares. The energy cost share is similar to the labor, and the final fiber cost is sensitive to fluctuations in electricity price, as well as to whether the manufacturing facility is in a location with access to inexpensive electricity. The high sensitivity of fiber cost to electricity price has driven carbon fiber manufacturers to states with low electricity costs, such as 
Washington, Wyoming, South Carolina, Alabama, Texas, and Tennessee. A potential viable location for a coal pitch carbon fiber manufacturing facility could be in U.S. Northwestern and Southeastern States since it would have access not only to an abundant, affordable coal supply but also to low-cost electricity. It is also important to consider the raw material coal pitch supply locations by source (i.e., steel-making vs. coal liquefaction), which would dictate the fiber manufacturing economics.
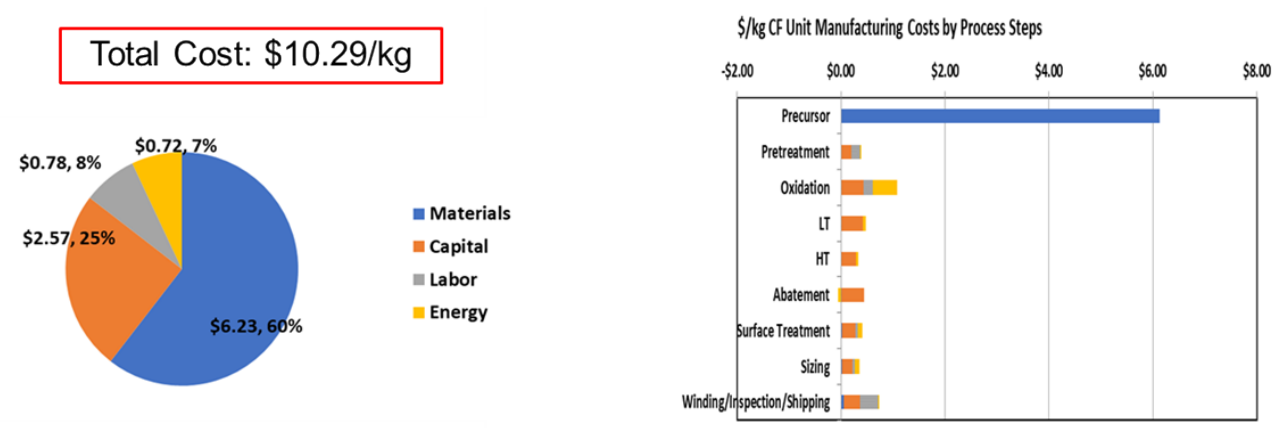

Figure 22. Total coal tar pitch carbon fiber cost distribution by major cost categories and processing steps.

Precursor cost contributes $\sim 61 \%$ of the total carbon fiber cost as shown in Figure 22. Among the major processing steps, oxidation is the most expensive, contributing to $\sim 11 \%$ of the total fiber cost. As indicated earlier, oxidation is the final output-limiting conversion step because it requires the most processing time; therefore, it is also the most capital- and energy-intensive step. The additional processing step of graphitization, should higher final fiber stiffness be required, is estimated to contribute an additional $\$ 0.34 / \mathrm{kg}$ to the final estimated pitch carbon fiber cost of $\$ 10.29 / \mathrm{kg}$. The impact of this step on the fiber economics requires further evaluation using the updated capital cost estimates of the necessary expensive energy-intensive heating furnaces, and the associated high maintenance cost of frequent breakdowns. An earlier study [77] estimated the final pitch carbon cost at $\$ 9.63 / \mathrm{kg}$, assuming a fiber conversion cost of $\$ 5.50 / \mathrm{kg}$, based on a pitch precursor cost of $\$ 3.30 / \mathrm{kg}$ vs. the $\$ 4.52 / \mathrm{kg}$ assumed in this analysis. The reported estimate is too optimistic for an assumed fiber conversion cost of $\$ 3.10 / \mathrm{kg}$, even if the additional graphitization processing cost is not included in that estimate.

\section{REFERENCES}

[1 S. Mazumdar, D. Pichler, M. Benevento, W. Seneviratine and L. Ray, "2020 State of the Industry

] Report," Composites Manufacturing, pp. 17-26, January/February 2020.

[2 Z. Kong, X. Dong, B. Xu, R. Li, Q. Yin and C. Song, "EROI analysis for direct coal liquefaction

] without and with CCS: The case of the Shenhua DCL Project in China," Energies, vol. 8, no. 2, pp. 786-807, 2015.

[3 L. Lee and R. Chang, "Production and optimization of direct coal liquefaction derived low carbon-

] footprint transportation fuels," Headwaters, CTL, Inc.-NETL (US DOE), 2010.

[4 U. E. I. Administration, "Coal Explained," 9 October 2020. [Online]. Available:

] https://www.eia.gov/energyexplained/coal/how-much-coal-is-left.php. [Accessed 28 December 2020].

[5 W. V. U. a. t. U. o. Tennessee, "An Economic Analysis of the Appalachian Coal Industry Ecosystem:

] Summary Report," Appalachian Regional Commission, 2018.

[6 United States Geological Survey (USGS), "USGS Coalfields of the Conterminous United States,"

] [Online]. Available: https://www.usgs.gov/media/images/usgs-coalfields-conterminous-united-states. [Accessed December 2020]. 
[7 U. E. I. Administration, "Annual Coal Report: Table 1.Coal Production and Number of Mines by State ] and Mine Type," 5 October 2020. [Online]. Available: https://www.eia.gov/coal/annual/. [Accessed 28 December 2020].

[8 R. Carbon, "Ramaco Carbon," 2020. [Online]. Available: https://ramacocarbon.com/. [Accessed 30

] December 2020].

[9 U. E. I. Administration, "U.S. Coal Reserves: Table 14. Recoverable Coal Reserves at Producing

] Mines by State," 5 October 2020. [Online]. Available: https://www.eia.gov/coal/reserves/. [Accessed 28 December 2020].

[1 R. Group, "The Year in Coal," 4 January 2018. [Online]. Available: https://rhg.com/research/the-year0] in-coal/. [Accessed 30 December 2020].

[1 U. E. I. Adminstration, "Annual Energy Outlook 2018," 2019. [Online]. Available:

1] https:/www.eia.gov/outlooks/aeo/data/browser/\#/?id=95-AEO2018\&region=0$0 \&$ cases $=$ ref2018\&start $=2016 \&$ end $=2050 \& \mathrm{f}=$ A\&linechart $=\sim$ ref20. [Accessed 15 January 2019].

[1 U. E. I. Administration, "Annual Coal Report," 5 October 2020. [Online]. Available:

2] https://www.eia.gov/coal/annual/\#: :text=U.S.\%20coal\%20consumption\%20decreased\%2014.8,decre ase $\% 20$ from $\% 20$ the $\% 202018 \% 20$ level.. [Accessed 8 January 2021].

[1 U. E. I. Administration, "Coal Data Browser," 2018. [Online]. Available:

3] https://www.eia.gov/coal/data.php. [Accessed December 2018].

[1 IEA, "World Energy Outlook 2018," November 2018. [Online]. Available:

4] https://www.iea.org/reports/world-energy-outlook-2018. [Accessed 20 December 2019].

[1 EveryCRSReport.com, "The U.S. Coal Industry: Historical Trends and Recent Developments," 18

5] August 2017. [Online]. Available: https://www.everycrsreport.com/reports/R44922.html. [Accessed December 2020].

[1 I. Reid, "Non-Energy Uses of Coal: Executive Summary, No. 91," International Energy Agency, 2018. 6]

[1 J. Ji, D. Wang, Z. Suo and Y. Xu, "Study on direct coal liquefaction residue influence on mechanical 7] properties of flexible pavement.," International Journal of Pavement Research and Technology, vol. 11, no. 4, pp. 355-362, 2017.

[1 D. Journal, "Coal Gasification 2018 Global Market Growth, Opportunities , Industry Applications,

8] Analysis And Forecast To 2023," Wiseguy Reports, 2019. [Online]. Available: http://www.digitaljournal.com/pr/3738687. [Accessed 30 Decemenr 2020].

[1 M. a. Markets, "Methanol Market by Feedstock (Natural Gas and Coal), Derivative (Formaldehyde,

9] MTO/MTP, Gasoline, MTBE, and MMA), Sub-derivative (UF/PF Resins and Olefins), End-Use Industry (Construction, Automotive, and Electronics) and by Region - Global Trends \& Forec," Markets and Markets, 2018.

[2 bccResearch, "Syngas Chemicals: Global Markets to 2022," bccResearch, 2018.

$0]$

[2 M. a. Markets, "Naphthalene Derivatives Market by Form (Powder, Liquid), Derivative (SNF,

1] Phthalic Anhydride, Naphthalene Sulfonic Acid, Alkyl Naphthalene Sulfonates, Naphthols), End-Use Industry (Construction, Agrochemicals), and Region-Global Forecast to 2022," Markets and Markets, 2017.

[2 G. M. Insights, "Rare Earth Metals Market Size By Metal (Cerium, Dysprosium, Erbium, Europium,

2] Gadolinium, Holmium, Lanthanum, Lutetium, Neodymium, Praseodymium, Promethium, Samarium, Scandium, Terbium, Thulium, Ytterbium, Yttrium), By Applications (Magnets, Colorants, Al," June 2020. [Online]. Available: https://www.gminsights.com/industry-analysis/rare-earth-metalsmarket?utm_source=globenewswire.com\&utm_medium=referral\&utm_campaign=Paid_Globnewswir e. [Accessed 30 December 2020].

[2 G. V. Research, "Carbon Fiber Market Size, Share \& Trends Analysis Report By Raw Material (PAN, 3] Pitch), By Tow Size, By Application (Automotive, Aerospace \& Defense, Wind Turbines), By 
Region, And Segment Forecasts, 2018 - 2025," August 2017. [Online]. Available:

https://www.grandviewresearch.com/industry-analysis/carbon-fiber-market-analysis. [Accessed October 2019].

[2 A. M. Research, "Nanomaterials Market by Type - Global Opportunity Analysis and Industry

4] Forecast, 2014-2022," Sept.," Allied Market Research, 2016.

[2 G. M. Insights, "Graphene Market Size By Product (Graphene Oxide, Graphene Nanoplatelets, Mono-

5] layer \& Bi-layer Graphene, Others), By Application (Electronics, Aerospace \& Defense, Energy, Automotive, Healthcare, Others), Industry Analysis Report, Regional Outlook, Applic," November 2019. [Online]. Available: https://www.gminsights.com/industry-analysis/graphene-market. [Accessed 30 December 2020].

[2 M. Publishers, December 2017. [Online]. Available:

6] https://marketpublishers.com/members/variantmarket/info.html?orderby=2\&q=graphite+market\&publ isher $\% 5 \mathrm{~B} \% 5 \mathrm{D}=10362 \&$ price_min $=\&$ price_max $=\&$ date_min $=\&$ date_max $=\&$ pages_min $=\&$ pages_ma $\mathrm{x}=$. [Accessed 30 December 2020].

[2 G. V. Research, "Building Thermal Insulation Market Size, Share \& Trends Analysis Report By

7] Product, (Glass Wool, Mineral Wool, EPS, XPS), By Application (Roof, Wall, Floor), By End-use, By Region, And Segment Forecasts, 2019 - 2025," May 2019. [Online]. Available:

https://www.grandviewresearch.com/industry-analysis/building-thermal-insulation-market. [Accessed 30 December 2020].

[2 NIST, "New NIST Research Center Helps the Auto Industry 'Lighten Up'," NIST, 25 July 2014.

8] [Online]. Available: https://www.nist.gov/featured-stories/new-nist-research-center-helps-autoindustry-

lighten\#: :text=A\%2010\%20percent $\% 20$ reduction $\% 20$ in,the $\% 20$ manufacturability $\% 20$ of $\% 20$ these $\%$ 20materials.. [Accessed 25 January 2021].

[2 W. W. a. V. Mathes, "The Market for Glass Fibre Reinforced Plastics (GRP) in 2019," AVK

9] (Federation of Reinforced Plastics), 2019.

[3 C. Red, "The markets: Automotive (2021)," CompositesWorld, 9 Decemner 2020.

$0]$

[3 M. R. Future, "Pitch Based Carbon Fiber Market," Market Research Future, August 2019. [Online].

1] Available: https://www.marketresearchfuture.com/reports/pitch-based-carbon-fiber-market-8215. [Accessed 27 December 2020].

[3 M. Rainaldi, "Pitch-Based Carbon Fiber for Automotive and Industrial Applications," in 2017

2] Composites World Carbon Fiber, Charleston, South Carolina, 2017.

[3 U. E. I. Administration, "International Coal and Coke," 2020. [Online]. Available:

3] https:/www.eia.gov/international/data/world/coal-and-coke/coal-and-cokeproduction? $\mathrm{pd}=1 \& \mathrm{p}=3 \mathrm{i} 00000000000000000000000000000000000180000000000000 \mathrm{~g} \& \mathrm{u}=0 \& \mathrm{f}=\mathrm{A} \& \mathrm{v}$ $=$ mapbubble $\& \mathrm{a}=-\& \mathrm{i}=$ none $\& \mathrm{vo}=$ value $\& \mathrm{t}=\mathrm{C} \& \mathrm{~g}=$ none $\& \mathrm{l}=249--$

$238 \& s=1325376000000 \& \mathrm{e}=1546300800000 \&$. [Accessed 18 Dec 2020].

[3 S. G. Platts, "Market Insights," 25 Mar 2020. [Online]. Available:

4] https://www.spglobal.com/platts/en/search-results?q=metallurgical\%20coke. [Accessed 18 Dec 2020].

[3 U. E. I. Administration, "Annual Coal Report," 2019. [Online]. Available:

5] https://www.eia.gov/coal/data.php\#prices. [Accessed 18 Dec 2020].

[3 U. E. I. Administration, "Coal Data," 2020. [Online]. Available:

6] https://www.eia.gov/coal/annual/pdf/table34.pdf. [Accessed 18 Dec 2020].

[3 Alibaba, "Price of Coal Tar," 2020. [Online]. Available: https://www.alibaba.com/showroom/price-of-

7] coal-tar.html. [Accessed 2020 Dec 2020].

[3 X. Ren, D. Fang, J. Jin and J. Gao, "New proceed achieved in the direct coal liquefaction," Chem Ind

8] Eng Prog, pp. 29, 198-204, 2010. 
[3 C. Atkins and J. Dietz, Personal communication with Sujit Das and Prashant Nagapurkar, Oak Ridge, 9] TN, 2020.

[4 Eurostat, Energy balance guide, European commission, 2019.

$0]$

[4 Calverton Energy, "Energy and Fuel data sheet," March 2011. [Online]. Available:

1] https://www.claverton-energy.com/wordpress/wpcontent/uploads/2012/08/the_energy_and_fuel_data_sheet1.pdf. [Accessed 20 November 2020].

[4 B. Avid, P. Barnasan, M. Born, J. Dugarjav, D. Yadamsuren and A. Tuvshinjargal, "Pyrolysis and TG

2] Analysis of Shivee Ovoo Coal from Mongolia," Journal of Thermal Analysis and Calorimetry, vol. 68, no. 3, pp. 877-885, 2002.

[4 O. Benjamin, J. Strege, M. Kurz, A. Snyder and M. Jensen, "Feasibility of Direct Coal Liquefaction in 3] the modern economic climate," NETL (US DOE), 2009.

[4 S. Li, X. Chen, A. Liu, L. Wang and G. Yu, "Study on co-pyrolysis characteristics of rice straw and 4] Shenfu bituminous coal blends in a fixed bed reactor," Bioresource Technology 155C:252-257, 2014. [4 A. G. Comolli, T. L. K. Lee, G. A. Popper and P. Zhou, "The Shenhua coal direct liquefaction plant," 5] Fuel Processing Technology, vol. 59, no. 2-3, pp. 207-215, 1999.

[4 University of Kentucky - New Carbon, LLC, "Technical and economic assessment of mild coal 6] extraction," University of Kentucky, 2005.

[4 J. Sánchez, J. Ancheyta and R. Ruiz, "A Review of Process Aspects and Modeling of Ebullated Bed

7] Reactors for Hydrocracking of Heavy Oils," Catalysis Reviews,, pp. 60-105, 2010.

[4 H. Kua, "The Consequences of Substituting Sand with Used Copper Slag in Construction," Journal of 8] Industrial Ecology, vol. 17, no. 6, pp. 869-879, 2013.

[4 "Report for the EU commission- Comments of the Cefic "Coal Chemicals Sector Group"," European 9] Chemical Industry Council, 2012.

[5 J. Rocha, A. R. Coutinho and C. Luengo, "Biopitch produced from eucalyptus wood pyrolysis liquids

0] as a renewable binder for carbon electrode manufacture," Brazilian Journal of Chemical Engineering, vol. 19, no. 2, 2002.

[5 X. Bing, L. Yuxiang, Y. Meigui, L. Chuntao, L. Jingxing and L. Hongjie, "Energy consumption 1] analysis of coal tar distillation process," Coal Conversion journal, vol. 32, no. 2, 2009.

[5 C. Achten and T. Hofmann, "Native polycyclic aromatic hydrocarbons (PAH) in coals-A hardly

2] recognized source of environmental contamination," Science of The Total Environment, vol. 407, no. 8, pp. 2461-2473, 2009.

[5 P. Ball, L. Huatuco, R. J. Howlett and R. Setchi, "Sustainable Design and Manufacturing," Springer, 3] pp. 291-292, 2019.

[5 X. Liu and Z. Yuan, "Life cycle environmental performance of by-product coke production in China," 4] Journal of Cleaner Production, vol. 112, pp. 1292-1301, 2016.

[5 F. Burke, S. Brandes, D. McCoy, R. Winschel, D. Gray and Tomlinson, "Summary report of the DOE

5] direct liquefaction process development campaign of the late twentieth century," National Energy Technology Laboratory (NETL), 2001.

[5 A. Hlavsova, A. Corsaro, H. Raclavská, D. Juchelková, H. Škrobánková and Frydrych, "Syngas

6] Production from Pyrolysis of Nine Composts Obtained from Nonhybrid and Hybrid Perennial Grasses," Bioenergy and its environmental impacts - Scient. World. J, 2014.

[5 University of Tennesse, "Pyrolysis Char Heating values," [Online]. Available:

7] http://biorefinery.utk.edu/technical_reviews/char\%20bio-oil\%20HHV.pdf. [Accessed 20 December 2020].

[5 Domestic synthetic fuels, LLC, "Application for Minor source permit to construct Direct liquefaction 8] coal to liquids facility," 2019. 
[5 Coopers creek chemical corporation, State only operating permit, Commonwealth of Pennysylvania,

9] Department of environmental protection, air quality program.

[6 G. Liu, Z. Niu, D. Van Niekerk, J. Xue and L. Zheng, "Polycyclic Aromatic Hydrocarbons (PAHs)

0] from Coal Combustion: Emissions, Analysis, and Toxicology," Reviews of environmental contamination and toxicology, vol. 192, pp. 1-28, 2008.

[6 S. Stout and S. Emsbo-Mattingly, "Concentration and character of PAHs and other hydrocarbons in

1] coals of varying rank - Implications for environmental studies of soils and sediments containing particulate coal," Organic Geochemistry, vol. 39, no. 7, pp. 801- 819, 2008.

[6 Z.-B. Zhao, K. Liu, W. Xie, W.-p. Pan and J. Riley, "Soluble polycyclic aromatic hydrocarbons in raw 2] coals," Journal of hazardous materials, vol. 73, no. 1, pp. 77-85, 2000.

[6 I. M. Afanasov, A. V. Kepman, V. A. Morozov, A. N. Seleznev and V. V. Avdeev, "Determination of

3] polyaromatic hydrocarbons in coal tar pitch," Journal of Analytical Chemistry, vol. 64, pp. 361-365, 2009.

[6 A. Kumar, N. Kothiyal and K. S, "Determination of some carcinogenic PAHs with toxic equivalency

4] factor along roadside soil within a fast developing northern city of India," J Earth Syst Sci, no. 123, pp. 479-489, 2014.

[6 Center for Disease control CDC, "Polycyclic Aromatic Hydrocarbons (PAHs): What are the Standards

5] and Regulations for PAHs Exposure?," Center for Disease control CDC, [Online]. Available: https://www.atsdr.cdc.gov/csem/csem.asp?csem=13\&po=8. [Accessed November 2020].

[6 University of Kentucky, "Major, Minor, and Trace Elements," December 2019. [Online]. Available:

6] https://www.uky.edu/KGS/coal/coal-major-minor-trace-elements.php. [Accessed 2020].

[6 S. Sala, B. A., C. S., C. E., S.-M. E and S. M, "Indicators and Assessment of the environmental impact

7] of EU consumption. Consumption and Consumer Footprint for assessing and monitoring EU policies with Life Cycle Assessment," Publications Office of the European Union, Luxembourg, 2019.

[6 Gabi Software Inc, Gabi Professional life cycle inventory database Sp36, 2018.

8]

[6 United States Enviromental Protection Agency (EPA), "Polycyclic aromatic hydrocarbons (PAHs),"

9] 2008. [Online]. Available: https://archive.epa.gov/epawaste/hazard/wastemin/web/pdf/pahs.pdf. [Accessed 15 December 2020].

[7 A. Owen, "Coal Tar Pitch Processing Towards Mesophase-Based Carbon Fiber," in Ramaco Research 0] Rodeo Workshop, Sheridan, WY, 2018.

[7 C. Horten, E-mail communication with Sujit Das, Oak Ridge National Laboratory, Oak Ridge, TN,

1] Heatec, Inc. Chattanooga, TN. Oct. 15, 2018.

[7 C. Chiles, E-mail communication with Sujit Das, Oak Ridge National Laboratory, Oak Ridge, TN,

2] Hills, Inc. Melbourne, FL July 23, 2018.

[7 J. Sloan, "Coming to carbon fiber: Low-cost mesophase pitch precursor," CompositesWorld, 9 May

3] 2016. [Online]. Available: https://www.compositesworld.com/news/coming-to-carbon-fiber-low-costmesophase-pitch-precursor.

[7 Intratec Solutions,LLC, Chemicals Pricing Data, San Antonio, TX, 2018.

4]

[7 C. Levan, Personal communication with Sujit Das, Oak Ridge National Laboratory, Oak Ridge, TN,

5] Aug 18, 2020.

[7 K. Defiel, Personal communication with Sujit Das, Oak Ridge National Laboratory, Oak Ridge, TN,

6] Eisenmann Corporation, TS Sales, IL, USA on 11/29, 2018.

[7 C. Boyer, T. Holcombe and D. Malone, "New Process for Making Mesophase Pitch," in Carbon Fiber

7] Conference held on Nov. 11, 2016.

[7 X. Liu and Z. Yuan, "Life cycle environmental performance of by-product coke production in China,"

8] 2015. [Online]. Available: https://doi.org/10.1016/j.jclepro.2014.12.102. 
[7 [Online].

9] 